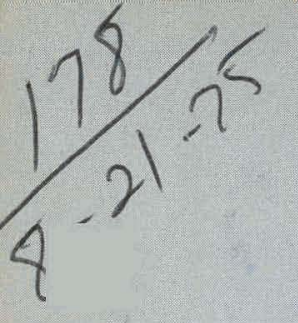

\title{
ANALYSIS OF STRESSES IN FILAMENT-WOUND SPHERICAL PRESSURE VESSELS PRODUCED BY THE DELTA-AXISYMMETRIC PATTERN
}

C. E. Knight, Jr.

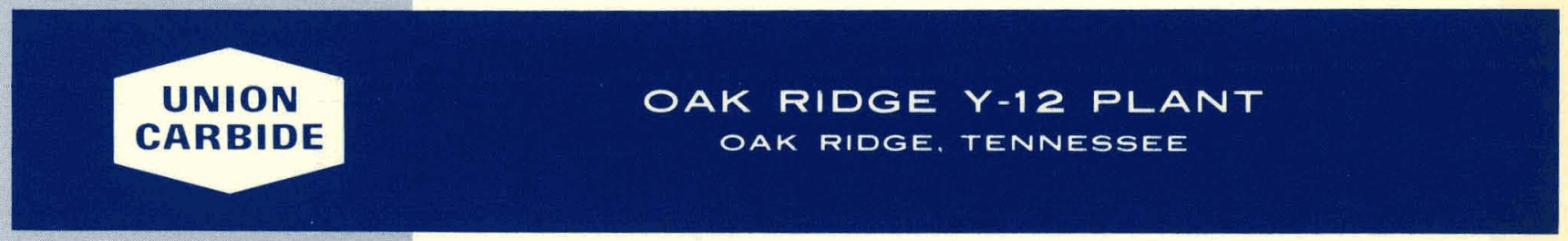

prepared for the U.S. ENERGY RESEARCH AND DEVELOPMENT ADMINISTRATION under U.S. GOVERNMENT Contract $W-7405$ eng 26

\section{MASTER}




\section{DISCLAIMER}

This report was prepared as an account of work sponsored by an agency of the United States Government. Neither the United States Government nor any agency Thereof, nor any of their employees, makes any warranty, express or implied, or assumes any legal liability or responsibility for the accuracy, completeness, or usefulness of any information, apparatus, product, or process disclosed, or represents that its use would not infringe privately owned rights. Reference herein to any specific commercial product, process, or service by trade name, trademark, manufacturer, or otherwise does not necessarily constitute or imply its endorsement, recommendation, or favoring by the United States Government or any agency thereof. The views and opinions of authors expressed herein do not necessarily state or reflect those of the United States Government or any agency thereof. 


\section{DISCLAIMER}

Portions of this document may be illegible in electronic image products. Images are produced from the best available original document. 
Reference to a company or product name does not imply approval or recommendation of the product by Union Carbide Corporation or the U.S. Energy Research and Development Administration to the exclusion of others that may meet specifications.

Printed in the United States of America. Available from Natinnal Ter.hnis.al Informațion Service

U.S. Department of Commerce

5285 Port Royal Road, Springfield, Virginia 22161

Price: Printed Copy \$4.00; Microfiche $\$ 2.25$

This report was prepared as an account of work sponsored by the United States Government. Neither the United States nor the Energy Research and Development Administration, nor any of their employees, nor any of their contractors, subcontractors, or their employees, makes any warranty, express or implied, or assumes any legal liability or responsibility for the accuracy, completeness or usefulness of any information, apparatus, product or process disclosed, or represents that its use would not infringe privately owned rights. 


\title{
ANALYSIS OF STRESSES IN FILAMENT-WOUND SPHERICAL PRESSURE VESSELS PRODUCED BY THE DELTA-AXISYMMETRIC PATTERN.
}

\author{
C. E. Knight, Jr.
}

Fabrication Systems Development Department

Y-12 Development Division

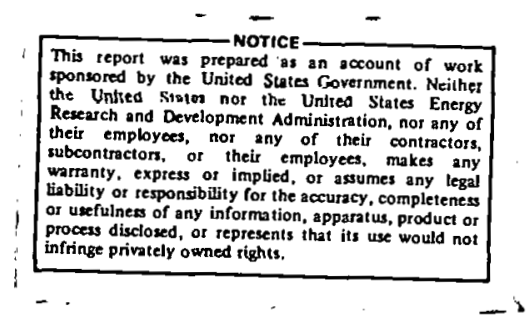

Oak Ridge Y-12 Plant

P. O. Box Y, Oak Ridge, Tennessee 37830

Prepared for the US Energy Research and Development Administration Under US Government Contract W-7405-eng-26 


\begin{abstract}
Spherical pressure vessels may be produced by filament winding the composite material with a delta-axisymmetric pattern. This particular pattern yields a composite with high fiber density and efficient and reproducible structures. The pattern is readily defined mathematically and, thus, eases the analysis problem.
\end{abstract}




\section{CONTENTS}

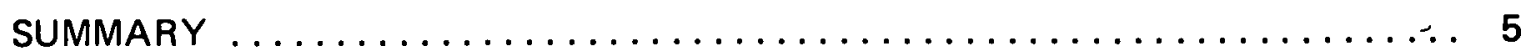

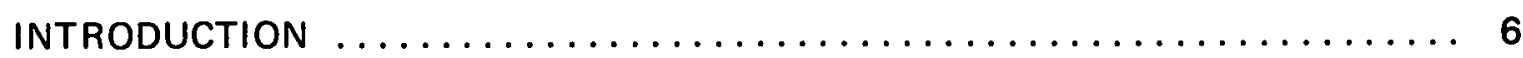

STRESS ANALYSIS IN FILAMENT-WOUND PRESSURE VESSELS $\ldots \ldots \ldots \ldots, 7$

Vessel Design ..................................... 7

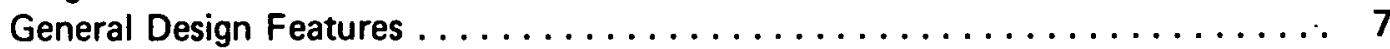

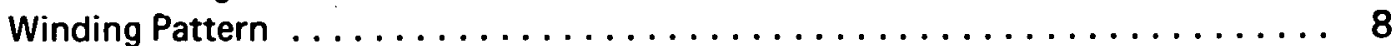

Winding Process $\ldots \ldots \ldots \ldots \ldots \ldots \ldots \ldots \ldots \ldots \ldots \ldots \ldots, \ldots \ldots, 10$

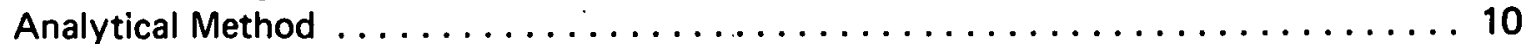

Numerical Approach $\ldots \ldots \ldots \ldots \ldots \ldots \ldots \ldots \ldots \ldots \ldots \ldots, \ldots \ldots \ldots$

Element Formulation $\ldots \ldots \ldots \ldots \ldots \ldots \ldots \ldots \ldots \ldots \ldots \ldots, 10$

Element Assembly ................................ 13

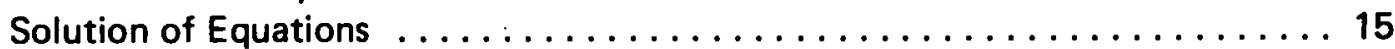

Approximation for Nonlinear Material $\ldots \ldots \ldots \ldots \ldots \ldots \ldots \ldots \ldots \ldots \ldots$

Computer Program Modifications $\ldots \ldots \ldots \ldots \ldots \ldots \ldots \ldots \ldots \ldots \ldots \ldots \ldots \ldots \ldots$

Original Program Description . . . . . . . . . . . . . . . . . . . . . . 16

Program Modification ............................... 17

Description of Input and Output $\mid \ldots \ldots \ldots \ldots \ldots \ldots \ldots \ldots \ldots \ldots \ldots \ldots \ldots \ldots$

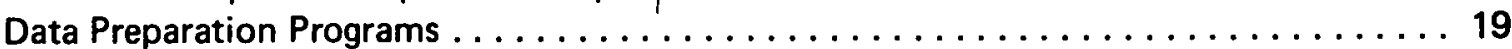

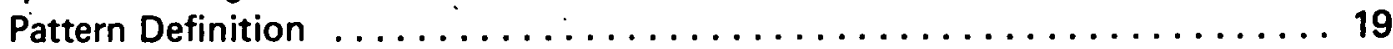

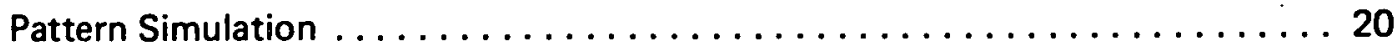

Mesh Generation .................................... 21

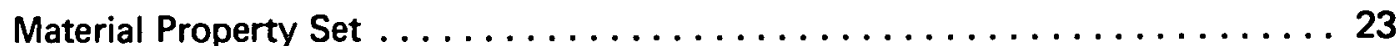

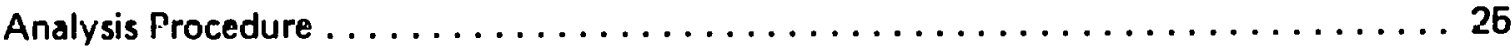

Definition of the Problem ............................ 25

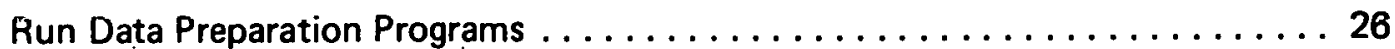

Editing the Assembled Data Set $\ldots \ldots \ldots \ldots \ldots \ldots \ldots \ldots \ldots \ldots \ldots, 28$

Evaluation of the Results ............................ 29

Case Study of an Eight-Inch-Diameter Vessel . . . . . . . . . . . . . . . . . 29

Vessel Description and Input Data ...................... 29

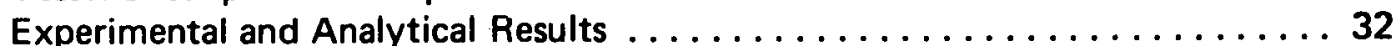

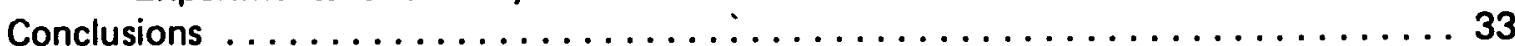

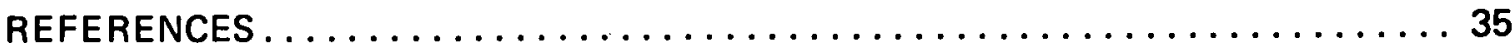

APPENDIX A........................................ 36

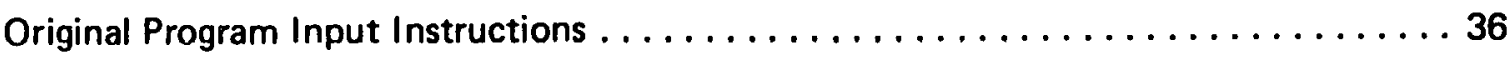

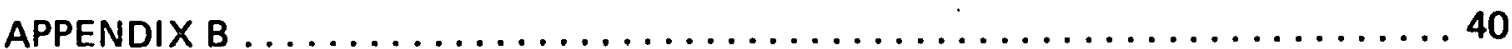

Modified Computer Program Instructions $\ldots \ldots \ldots \ldots \ldots \ldots \ldots \ldots \ldots \ldots \ldots, \ldots$

Modified Program Fortran Listing $\ldots \ldots \ldots \ldots \ldots \ldots \ldots \ldots \ldots \ldots \ldots \ldots \ldots$ 
APPENDIX C ................................. 57

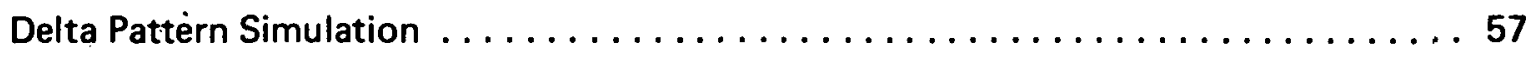

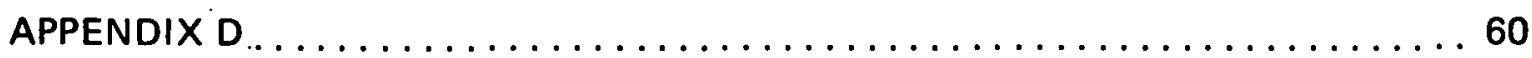

Mesh Generation Program $\ldots \ldots \ldots \ldots \ldots \ldots \ldots \ldots \ldots \ldots \ldots \ldots \ldots \ldots \ldots \ldots \ldots \ldots \ldots$

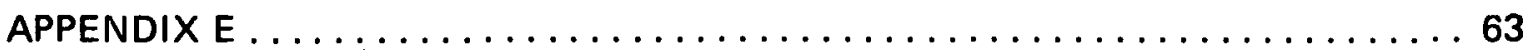

Oriented Filament-Wound Composite Material Properties Set $\ldots \ldots \ldots \ldots \ldots \ldots$

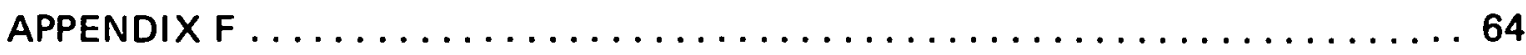

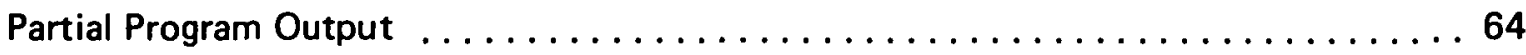




\section{SUMMARY}

Spherical pressure vessels may be produced by filament winding the composite material with a delta-axisymmetric pattern. This particular pattern yields a composite with high fiber density and efficient and reproducible structures. The pattern is readily defined mathematically and, thus, eases the analysis problem.

The finite-element method has been applied to analyze the stresses in the vessels. An existing program has been modified and utilized for the analysis. Modifications involved the program size, orthotropic material properties, and special features associated with the fiber composite material. Several auxiliary data preparation programs provide some if the input data needed to describe the finite-element model.

The stress-analysis capability may be used to evaluate a pattern design or optimize the pattern for a specific application. In this report, analytical and experimental studies for a vessel are described. The vessel was about eight inches in diameter and was constructed of "S" glass with ERL 2258/MPDA epoxy resin. Studies showed good correlation. 


\section{INTRODUCTION}

Filament-wound spherical pressure vessels may be constructed of properly oriented filament-wound patterns for the load-carrying member and a metal liner for leak-tight containment. Small-diameter fibers in an epoxy-resin matrix make up the filament-wound material. The resulting composite has highly directional elastic and strength properties. The fundamental goal is to achieve a pressure, vessel with the best possible strength-to-weight ratio. To aid in this effort, a method for detailed analysis of winding patterns and materials is needed. This method is to be used to evaluate designs and help modify the design to improve efficiency.

A general numerical stress-analysis method of rapidly increasing importance is the finite-element method. This method provides for the analysis of complex problems not generally solved in any other way. The finite-element method was applied to the analysis of axisymmetric filament-wound pressure vessels at the Oak Ridge Y-12 Plant. (a) An available program for the analysis of axisymmetric solids with special-case orthotropic properties was modified for three-dimensional orthotropy; and, more especially, for filament-wound materials. The size of the program was increased considerably in order to approximate the structure adequately.

Several data-preparation programs were written to provide the input necessary to run the finite-element program. These programs were concerned with modeling the filament-wound pattern from a geometrical standpoint and also to specify the material properties to be used in each element. An analysis procedure was established for using the data-preparation programs to set up the finite-element program for a particular case.

(a) Operated by the Union Carbide Corporation's Nuclear Division for the US Energy Research and Development Administration. 


\section{STRESS ANALYSIS IN FILAMENT-WOUND PRESSURE VESSELS}

\section{VESSEL DESIGN}

\section{General Design Features}

Fiber-reinforced composite materials offer the potential of both high performance and low weight in many structural applications. The specific application described here is a spherical pressure vessel. The general design features are indicated in Figure 1.

The structural member of the vessel is a filament-wound shell fabricated from continuous fiber strands and an epoxy-resin matrix. The filament-wound shell is not leaktight to liquids or gases, especially when the shell is pressurized. Therefore, a liner for the vessel is required. This liner serves to contain the charge; the liner material may be polymeric or metal, depending on the application. The fill tube or port provides the inlet and outlet passages for the charge. These tubes are usually relatively small to minimize disturbance in the winding pattern and to keep the axial forces on the fill tube area low. The vessel may have one or two ports on the axis of the winding pattern. If only one port is used, the pattern is adjusted to cover the liner surface at the opposite port location.

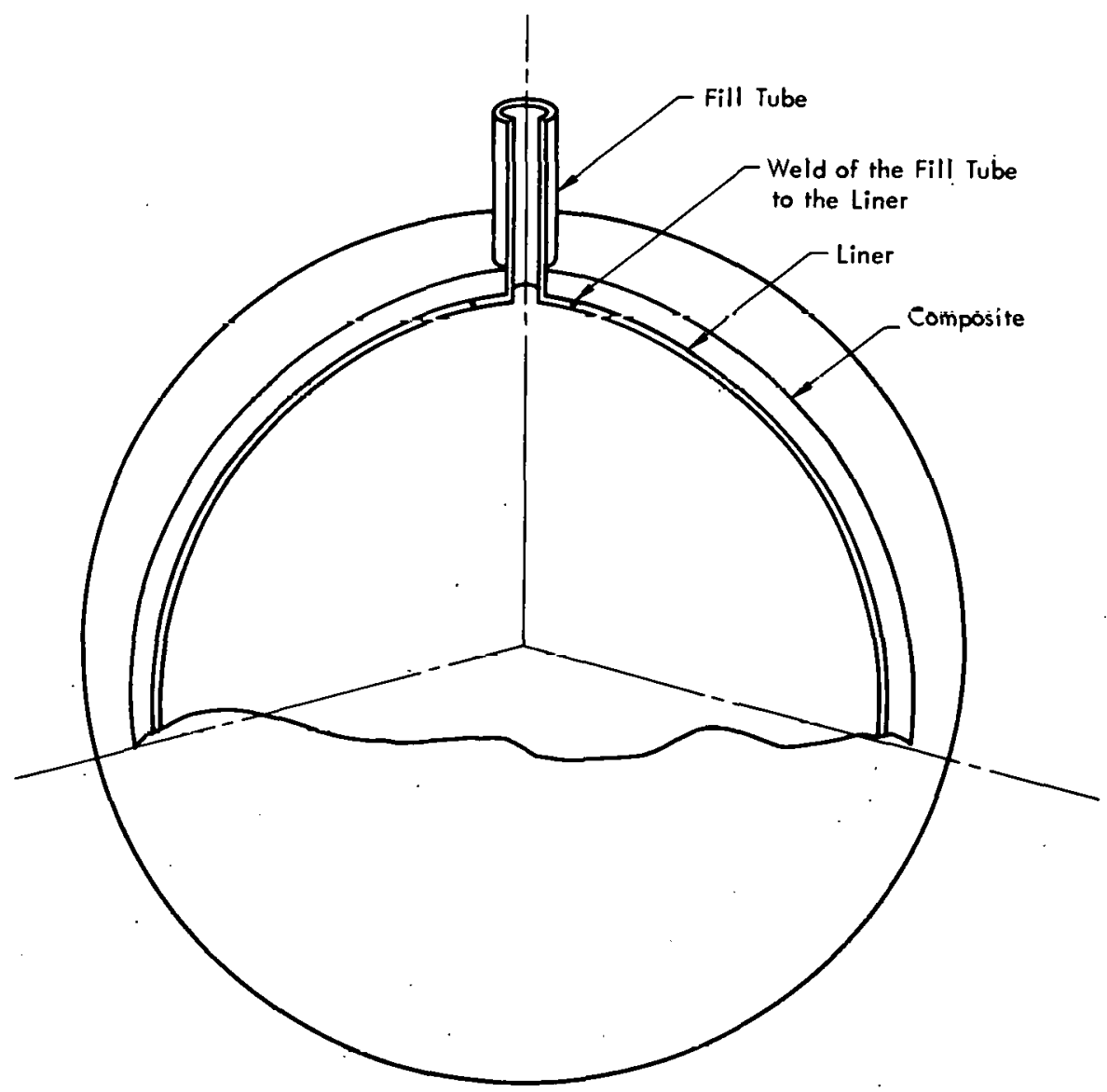

Figure 1. GenERAL DESIGN OF the fILAMENT-WOUND SPHERICAL PRESSURE VESSELS. 


\section{Winding Pattern}

The winding pattern for the sphere results in a uniform distribution of fiber orientations and uniform total thickness over most of the surface. This pattern is named the "delta-axisymmetric" pattern. Sets of bands are applied equally spaced around the winding or symmetry axis, vielding an incrementally symmetric (thus the term "delta-axisymmetric") pattern. The basic pattern may be defined by considering the geometry of a sphere, as illustrated in Figure 2 where the lines in the sketch represent band edges. Coordinates are defined with reference to a polar axis and a reference plane through the axis. The coordinates are noted in Figure 3. The poles of the sphere are located where the polar axis intersects the sphere. Longitudinal (meridional) lines run from pole to pole on the sphere surface and lie in a plane passing through the polar axis. Latitudes are circles on the sphere surface with centers lying on the polar axis. A point on the sphere surface may be located by specifying the polar angle (angle between the polar axis and the radius to the point on the longitude) and a circum.

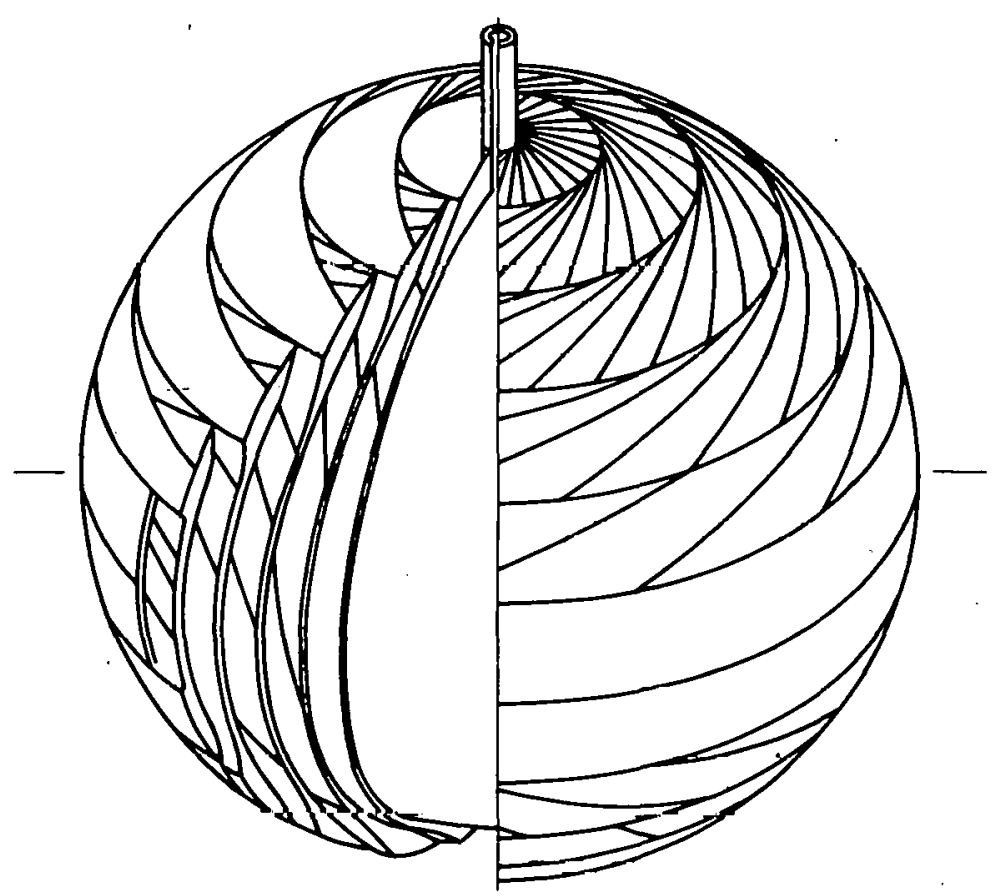

FIgure 2. DELTA-AXISYMMETIC PATTERN ON A SPHERE. ferential angle langle measured in the equatorial plane between a reference plane and the longitudinal plane through the point). As mentioned, sets of bands are applied to the sphere. A band is generated by circumferential winding on a great circle path and parallel paths on both sides of the great circle. The band is actually wound by starting at the specified location of the band edge on one side of the great circle and circumferential winding at the desired lead rate for the fiber being used until the desired band width is established.

The basic pattern is defined by the requirement for total coverage of the sphere surface with the design thickness. The thickness of a single band may be found experimentally for a given fiber, resin system, and set of winding conditions. The design thickness divided by two times the band thickness (each band set gives two layers of coverage) gives the number of band sets required. [For example, if the design thickness is $2.7 \mathrm{~mm}$ and the band thickness is $0.15 \mathrm{~mm}$, the number of band sets is $2.7 /(2 \times 0.15)=9$.] The sets are applied equally spaced along the meridian from the pole to the equator. The bandwidth is equal to the spacing on the surface along the meridian. Equally spaced along the meridian, the bandwidth is $90 / 9=10$ degrees intercept on the surface. The number of bands in each set is calculated to give complete coverage (side-by-side band placement) at the equator. The bands cross the 


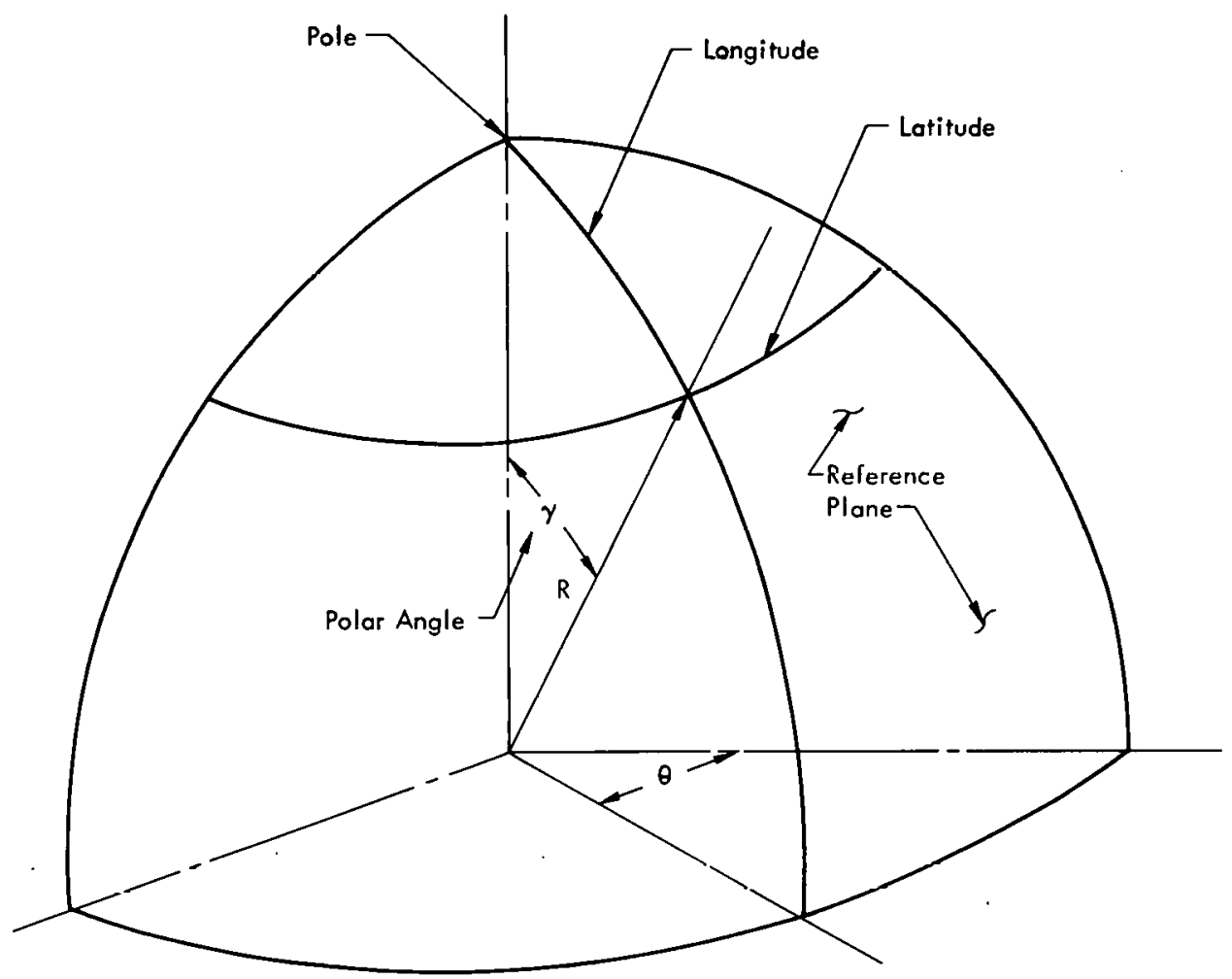

Figure 3. SPHERICAL COORDINATES.

equator at an angle related to their position along the meridian. The first set of bands are placed so that one edge is tangent to the polar axis, then the opposite edge of the band set lies on a latitude circle at a position along the meridian, one bandwidth away. The central plane of the band is on a great circle of the sphere and makes an angle, $\gamma$, with the polar axis equal to one half the bandwidth intercept angle on the sphere surface. The angle between the equator and the central plane is $(\pi / 2-\gamma)$. The length of the equator covered by one band is then equal to the bandwidth divided by $\sin (\pi / 2-\gamma)$. The number of bands in that set is equal to the equator circumference divided by the coverage of one band. In the previous example, $\gamma$ is 5 degrees, the equator coverage is 10 degrees divided by the sin of 85 degrees (10.04 degrees), and the number of bands is 36 since only an integer number of bands may be applied. The second set of bands is applied with one edge tangent to the latitude circle of the first set and the other edge lying on a latitude circle one band width further away. This set required 35 bands. Similarly, the other band sets are applied progressively along the meridian to the equator. The complete basic pattern yields $100 \%$ coverage of the sphere and a uniform total thickness.

The basic pattern is usually altered to meet requirements for a specific design. The most obvious alteration is allowance for the fill-tube opening in the pattern. A fill tube may be applied at one or both poles of the sphere. The pattern is shifted or adjusted to provide the opening. There are many schemes for adjusting the patterns which will be described in a later section. 


\section{Winding Process}

The winding process applies the fiber and resin by the machine according to the pattern design. The sphere is held in the machine with the reference planes aligned for startup. The band is generated by machine motions. When the first band is completed, the sphere is indexed to the next band position. This sequence is followed until all the bands are applied. Finally, the part is removed from the machine and the resin matrix is cured.

\section{ANALYTICAL METHOD}

\section{Numerical Approach}

Two major types of numerical analysis methods currently exist for solving solid mechanics problems: (1) the finite-difference method, and (2) the finite-element method. The finite-difference method approximates the governing differential equations by a set of algebraic-difference equations; the finite-element method approximates the continuum by subdivision of the continuum into small elements and solving the governing equations exactly for an assumed behavior of the element. The finite-element-method has several distinct advantages for the problem being considered here and, consequently, is used for this analysis. The advantages are: (1) ability to handle nonhomogenous and anisotropic materials easily; (2) ease of applying boundary conditions, and (3) ability to vary the mesh size to obtain better accuracy in areas of expected stress concentration. As stated, the finite-element method approximates the continuum by a set of interconnected elements. The element behavior is approximated usually by a polynomial function which must satisfy the governing equations of elasticity. The elements are assembled and a set of simultaneous algebraic equations result. These equations are solved for the unknowns, yielding the desired solution to the problem.

\section{Element Formulation}

The key to successful analysis is the formulation of element bahavior. In most cases, the formulation will be based on displacements within the element. The element will be made up of a set of lines defining the element boundary and connected at points called the element nodes. The simplest case is one of straight boundary lines and nodal points at the corners of the element. The simplest element geometry is a triangle. Both these conditions (straight boundaries and corner nodes) are employed here. However, for axisymmetric bodies, the element is a ring with a triangular cross section, as illustrated in Figure 4 . In order to have a finite number of degrees of freedom (finite number of algebraic equations), it is assumed that the displacements within the element can be expressed in terms of the displacements of the nodal points through some interpolation functions. The displacement vector anywhere in the element is defined as:

$$
\{f\}=\left\{\begin{array}{l}
u \\
v
\end{array}\right\}
$$

where: $u$ represents the $r$ component of displacement and $v$ the $z$ component of displacement. 


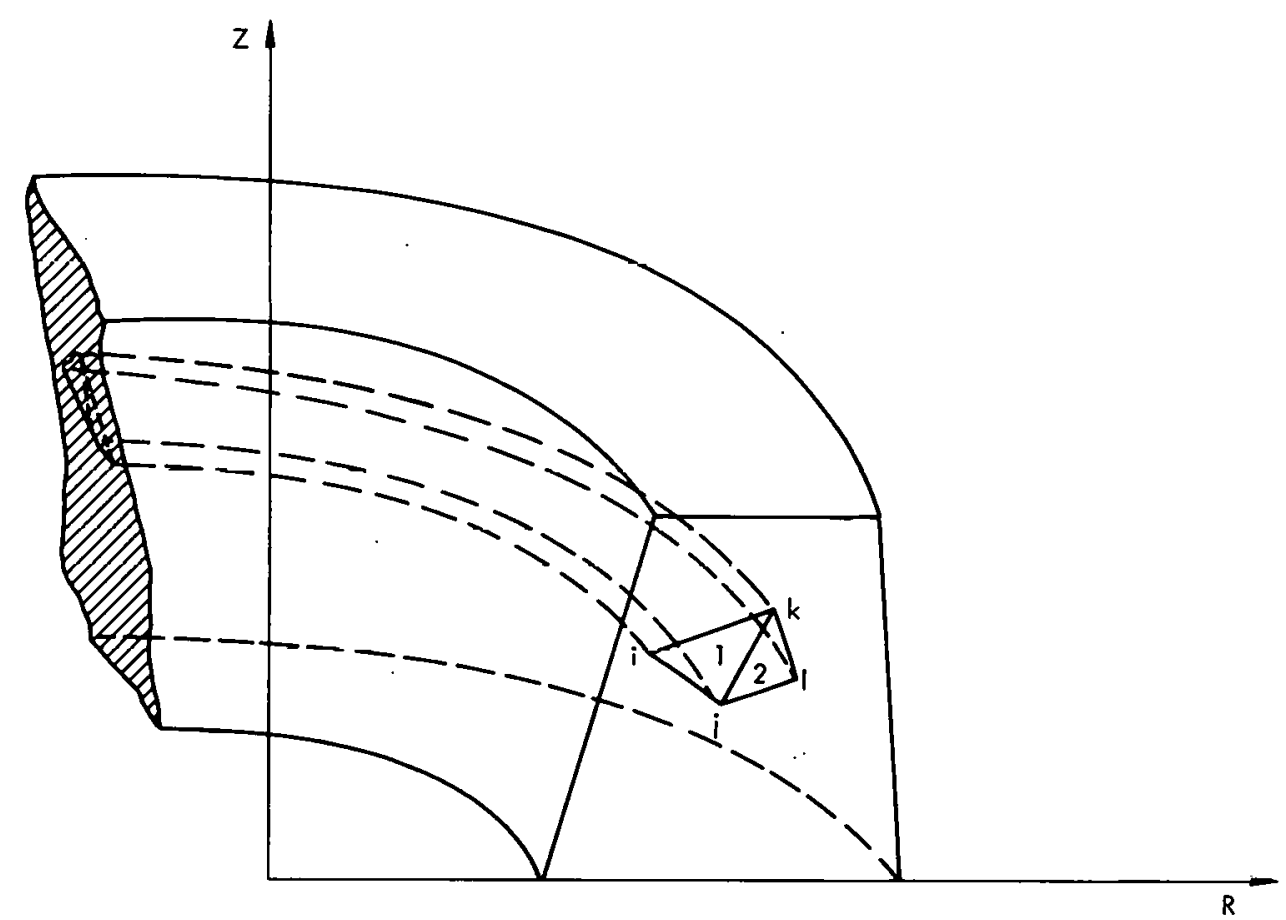

Figure 4. TRIANGULAR-RING FINITE ELEMENTS.

The nodal-point displacement vector, $\delta$, is given by:

$$
\{\delta\}^{e}=\left\{\begin{array}{c}
\delta_{i} \\
\delta_{j} \\
\delta_{k}
\end{array}\right)=\left\{\begin{array}{c}
u_{i} \\
v_{i} \\
u_{j} \\
v_{j} \\
u_{k} \\
v_{k}
\end{array}\right\}^{e}
$$

where: the superscript e refers to a given element, and subscripts $i$, $j$, and $k$. denote three nodal points. Assume the displacement field in the element is defined by a linear polynomial, then:

$$
\begin{gathered}
u=a_{1}+a_{2} r+a_{3} z \\
v=a_{4}+a_{5} r+a_{6} z
\end{gathered}
$$

Since this relation holds anywhere within the element, it must be valid at the nodal points. 
Then:

$$
\{\delta\}^{e}=\left[\begin{array}{cccccc}
1 & r_{i} & z_{i} & 0 & 0 & 0 \\
0 & 0 & 0 & 1 & r_{i} & z_{i} \\
1 & r_{j} & z_{j} & 0 & 0 & 0 \\
0 & 0 & 0 & 1 & r_{j} & z_{j} \\
1 & r_{k} & z_{k} & 0 & 0 & 0 \\
0 & 0 & 0 & 1 & r_{k} & z_{k}
\end{array}\right] \quad\left\{\begin{array}{l}
a_{1} \\
a_{2} \\
a_{3} \\
a_{4} \\
a_{5} \\
a_{6}
\end{array}\right\}=[A]\{a\} \cdot(4)
$$

Solving Equation 4 for $\{a\}$ :

$$
\{a\}=[A]^{-1}\{\delta\}^{e} \text {. }
$$

and, substituting into Equation 3:

$$
\{f\}=[M][A]^{-1}\{\delta\}^{e}=[N]\{\delta\}^{e},
$$

which expresses the element displacement field in terms of the nodal displacements and their coordinates, where:

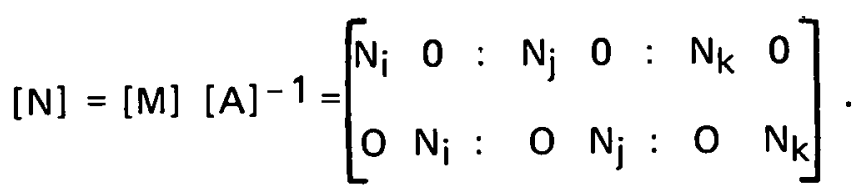

In this expression:

$$
\begin{aligned}
& N_{i}=\left(b_{i}+c_{j} x+d_{i} y\right) / 2 A, \\
& b_{i}=r_{j} z_{k}-r_{k} z_{j}, \\
& c_{i}=z_{j}-z_{k}, \text { and } \\
& d_{i}=r_{k}-r_{j} .
\end{aligned}
$$

A represents the area of the triangle $=1 / 2\left(b_{i}+b_{j}+b_{k}\right)$ with cyclic permutation of subscripts to obtain $N_{j}$ and $N_{k}$.

It can be shown that this formulation automatically satisfies the compatibility condition (ie, neither gaps nor overlaps develop along element boundaries).

The strain-displacement relations are given by:

$$
\{\epsilon\}=\left\{\begin{array}{l}
\epsilon_{r} \\
\epsilon_{\theta} \\
\epsilon_{z} \\
\gamma_{r z}
\end{array}\right\}=\left\{\begin{array}{c}
\frac{\partial u}{\partial r} \\
\frac{u}{r} \\
\frac{\partial v}{\partial z} \\
\frac{\partial u}{\partial z}+\frac{\partial v}{\partial r}
\end{array}\right) .
$$


Using Equation 6:

$$
\{\epsilon\}=[B]\{\delta\} e,
$$

where:

$$
\begin{gathered}
{[B]=\left[\begin{array}{ll}
\left.B_{i} B_{j} B_{k}\right], \text { and } \\
{\left[B_{i}\right]=\frac{1}{2 A}\left[\begin{array}{ll}
0 & d_{i} \\
c_{i} & 0 \\
b_{i} \\
d_{i}
\end{array}+c_{i}+\frac{d_{i z}}{r}\right.} & 0 \\
7 a & c_{i}
\end{array}\right] .}
\end{gathered}
$$

$A, b_{i}, c_{i}$, and $d_{i}$ are defined in Equation $7 a$.

The stress-strain relations are given by Hooke's law as:

$$
\{\sigma\}=\left\{\begin{array}{l}
\sigma_{\mathrm{r}} \\
\sigma_{\theta} \\
\sigma_{\mathrm{z}} \\
\tau_{\mathrm{rz}}
\end{array}\right\}=[\mathrm{D}]\{\epsilon\},
$$

where the elasticity matrix, $[D]$, is given by:

$$
[D]^{-1}=\left[\begin{array}{cccc}
\frac{1}{\mathrm{E}_{\mathrm{r}}} & -\frac{\nu^{\prime} \theta}{\mathrm{E}_{\mathrm{r}}} & -\frac{\nu_{\mathrm{rz}}}{\mathrm{E}_{\mathrm{r}}} & 0 \\
-\frac{\nu \mathrm{r}_{\theta}}{\mathrm{E}_{\mathrm{r}}} & \frac{1}{\mathrm{E} \theta} & \frac{-\nu_{\theta z}}{\mathrm{E} \theta} & 0 \\
-\frac{\nu r_{\mathrm{z}}}{\mathrm{E}_{\mathrm{r}}} & -\frac{\nu_{\theta z}}{\mathrm{E}_{\theta}} & \frac{1}{\mathrm{E}_{\mathrm{z}}} & 0 \\
0 & 0 & 0 & \frac{1}{\mathrm{G}_{\mathrm{rz}}}
\end{array}\right] .
$$

\section{Element Assembly}

The solution is obtained by applying the principle of minimum potential energy. The principle states that: "Among all the possible displacement configurations that are compatible with the geometrical constraints, the configuration that satisfies the equations of equilibrium is the one that minimizes the total potential energy"; so, the total potential energy must be a minimum. 
The potential energy is made up from two sources: (1) internal strain energy, and (2) concentrated forces acting through surface displacement. Here, body forces are neglected and it is assumed that all loads are distributed as point loads at the nodal points. The potential energy, $\mathrm{PE}$, for an element is:

$$
P E^{e}=\iiint_{v} 1 / 2\{\epsilon\}^{\top}\{\sigma\} d v_{e^{-}}\{R\}^{\top}\{\delta\}
$$

where:

$$
\{R\}^{T} \quad \text { represents the nodal-point-load matrix. }
$$

The potential energy for the system is then the sum of all the element potential energies:

$$
P E=\sum_{e=1}^{E} P E^{e}
$$

where:

E represents the total number of elements.

The requirement that the total potential energy be a minimum is satisfied by making its "first variation" equal to zero. Since the problem is formulated in terms of displacements, this requirement can be satisfied by expressing the variation in terms of the partial derivatives with respect to the nodal-point displacements. Mathematically, this expression becomes:

$$
d(P E)=\frac{\partial(P E)}{\partial u_{1}} d u_{1}+\frac{\partial(P E)}{\partial v_{1}} d v_{1}+\frac{\partial(P E)}{\partial u_{2}} d u_{2}+. . \frac{\partial(P E)}{\partial v_{m}} d v_{m}=0
$$

where:

m represents the total number of nodal points.

Since the $u_{1}, v_{1}, u_{2}, v_{2} \ldots u_{m}$, and $v_{m}$ terms are independent variables, each partial derivative must equal zero, thus:

$$
\begin{gathered}
\frac{\partial(P E)}{\partial u_{1}}=0, \\
\frac{\partial(P E)}{\partial v_{1}}=0 \ldots, \text { or } \\
\frac{\partial(P E)}{\partial\{\delta\}}=\{0\}
\end{gathered}
$$


This expression gives the $2 m$ equations necessary to solve for the $2 m$ nodal-point displacement.

\section{Solution of Equations}

Using Equations 9, 11, 13, and 14, along with Equation 16, gives the following result:

$$
\begin{gathered}
\frac{\partial(P E)}{\partial\{\delta\}}=\sum_{e=1}^{E} \frac{\partial}{\partial\{\delta\}}\left(\iiint v_{e} 1 / 2\{\delta\}^{\top}[B]^{\top}[D][B]\{\delta\} d v_{e}\right) \\
\quad \frac{\partial}{\partial\{\delta\}} R^{\top}\{\delta\}=\{0\} .
\end{gathered}
$$

Since the nodal-point displacements are constants with respect to integration with in the element, the displacement matrix can be removed from the integral giving, after taking the partial derivative:

Simplifying:

$$
\frac{\partial(P E)}{\partial\{\delta\}}=\left(\sum_{e=1}^{E} \iiint_{v_{e}}[B]^{T^{\prime}}[D][B] d v_{e}\right)\{\delta\}-\{R\}=\{0\}
$$

$$
\frac{\partial(P E)}{\partial\{\delta\}}=[K]\{\delta\}-\{R\}=\{0\} .
$$

where the stiffness matrix for the structure is:

$$
[K]=\sum_{e=1}^{E} \iiint v_{e}[B]^{T}[D][B] d v_{e}
$$

By applying the boundary conditions, a set of $2 \mathrm{~m}$ equations for the $2 \mathrm{~m}$ nodal-point displacements results. If the nodes are numbered and ordered properly, the $[K]$ matrix will be banded and symmetric, resulting in simplification of the solution method.

\section{Approximation for Nonlinear Material}

During the pressurization of a vessel, the liner must deform plastically since the strain of the composite is generally higher than the yield strain of the metal. In order to account for this deformation, the liner must be allowed to yield plastically in the analysis. The procedure used in the original program, briefly described in the explanation to follow, is applied: The plasticity theory is a total deformation theory and uses the Von Mises yield function. The stress-strain response of the material is described by a bilinear curve, as shown in Figure 5. The input data required are: the initial modulus, the yield stress, and the ratio of the 


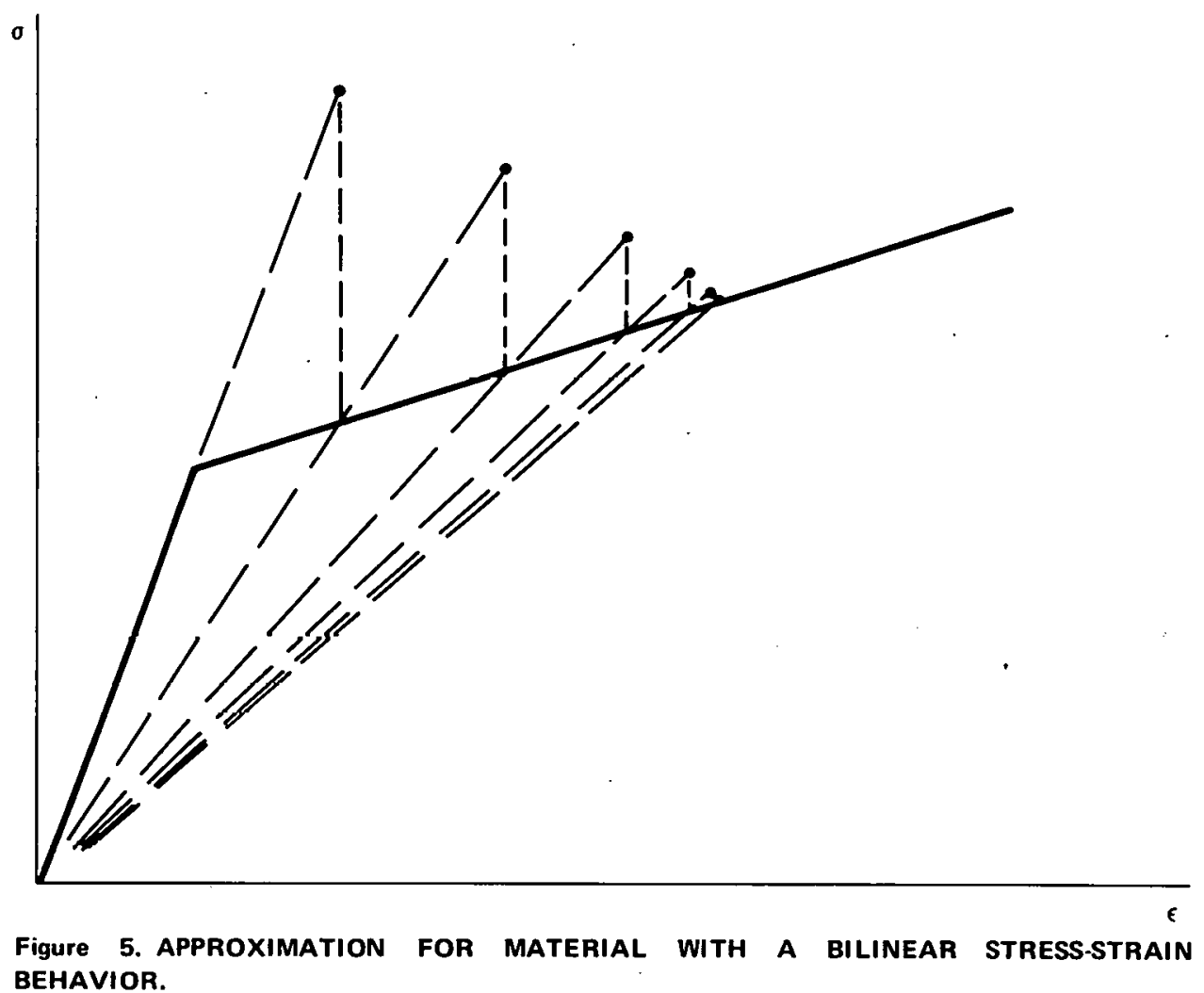

secondary modulus to the primary modulus. The analysis is an iterative procedure and the number of iterations is an input quantity. As noted in Figure 5, the analysis is first run, using the initial modulus; then, if the calculated stress in an element is higher than the yield stress, as evaluated by the Von Mises criterion, the intersection of the calculated strain with the secondary portion of the curve is found. This intersection point defines a new effective secant modulus for that particular element. This procedure is followed for all the elements in the assembly. The analysis is repeated, using the effective modulus of each element, and the stress is reevaluated.

The number of iterations required depends on the type of problem being solved. (The number should be large enough so that the stresses in each element converge to some value.) For the particular problem being investigated here, four iterations were sufficient.

\section{COMPUTER PROGRAM MODIFICATIONS}

\section{Original Program Description}

A finite-element computer program, written by Wilson, (1) was obtained which analyzes plane-stress, two-dimensional structures or axisymmetric bodies subjected to various force or displacement boundary conditions. This program is capable of treating two dimensionally orthotropic bodies with thermal as well as mechanical loads. In general, it is well suited for analyzing problems of complex geometries with material properties varying with temperature and/or position. The program is set up with cylindrical coordinates, with the $Z$ axis as the axis of symmetry for the axisymmetric bodies and the $R-Z$ plane as the 
cross-sectional plane. The two-dimensional plane-stress bodies are defined in the R-Z plane and the material can be orthotropic in this plane. However, the axisymmetric bodies are required to be isotropic in the $R-Z$ plane and may have different properties in the $T$ (circumferential) direction. This program was written for an IBM Model 7090 computer, but it was run on the IBM 360 with few problems. The program was extensively modified to make it more suitable for use on problems of filament-wound composite materials. Input instructions for the original verision are given in Appendix $A$. The program is an earlier version of the program described by Wilson and Jones. (2)

\section{Program Modification}

The program was modified in several respects, including: the stress-strain relations, the spherical-coordinate components of displacement, the program size, and the stress components displayed in the program output. The plane-stress option was deleted in the modified version to shorten the program. Also, the thermal analysis was deleted. These deletions helped reduce the program storage requirements, allowing an increase in the number of elements and nodal points in the program.

As mentioned earlier, the axisymmetric option in the original version required that the material be isotropic in the R-Z plane, which is inadequate for describing filament-wound composites. In order to analyze filament-wound composites, the material-property matrix must be three dimensionally orthotropic. The property matrix was changed to that shown in Equation 24. The matrix is represented in the program by the subscripted variable, $\mathrm{C}$, and it is defined in Subroutine QUAD of the program. The property matrix is described more fully in the section to follow, entitled: DATA PREPARATION PROGRAMS.

The particular problem under consideration here is that of a spherical shell; therefore, coordinate transformations were installed to give the displacements in the radial and tangential components. Displacement is a vector quantity; therefore, the spherical components of displacement (radial and tangential) are computed by a vector transformation. This computation is accomplished in the program by operating on the subscripted variable, $B$, which are the $R-Z$ displacement components.

The material properties of a filament-wound composite are most easily defined in a plane that is tangent to the surface of revolution being wound. As described in the section on DATA PREPARATION PROGRAMS, the material properties are defined for integer values of the helix angle between the fiber and circumferential $(T)$ direction. This relationship defines the properties in the N-S-T coordinate system, where $\mathrm{N}$ is the radial direction from the origin, $\mathrm{S}$ the meridional or tangential direction, and $\mathrm{T}$ still the circumferential direction. These properties must then be transformed to the R-Z-T coordinate system before use in the program. Since the property matrix is a fourth-order tensor, it must be transformed by the appropriate equations through an angle rotating about the $Z$ axis. This transformation is accomplished in Subroutine QUAD by operating on the subscripted variable, $C$, after it is formed in the N-S coordinates.

The program capacity has been approximately doubled by redimensioning the proper variables. The new capacity is 2400 elements, 2500 nodal points, and 96 material types. This size allows a fine subdivision of the thin shell and yet keeps the relative dimensions of the elements reasonable. 
The stress components are first solved for in the R-Z-T coordinate system. As far as the fiber-reinforced composite is concerned, these stress components mean very little. The stresses of greatest importance are those parallel and transverse to the fiber direction. To obtain these components, it is first necessary to transform to the N-S coordinates. This transformation is accomplished in Subroutine STRESS by the second-order tensor transformations since stress is a second-order tensor. The $\mathrm{N}$-direction stress is one of the principal transverse-stress components on the composite. Then, to obtain the parallel stress and other transverse stresses on the fiber in the S-T plane, it would seem, at first glance, that another stress transformation would be sufficient. However, this assumption is incorrect because two complementary layers of fibers exist in the element with plus and minus angular orientations. The stresses resulting from the transformations would be average values. The average for the fiber direction is an average between the fiber-direction stress in one layer and the stress at some angle to the fiber in the other direction; and, a similar condition exists for the average transverse stress. So, the averages are not true parallel and transverse stresses. In order to obtain the actual parallel and transverse stresses, it is necessary to compute the strains in the S-T plane and then transform the strains (a second-order tensor) to the fiber direction, since the same state of strain will exist in both the plus and minus angular orientations. The stresses parallel and transverse to the fiber are then found by matrix multiplication of the unidirectional material property matrix with the strain matrix. The stress components are: output as the $F$ Stress (axial stress), E Stress (transverse stress), and F-E Stress (interfiber shear stress in the F-E coordinates). All of these components are composite values. These stresses, combined with the $\mathrm{N}$-direction transverse stress, give the complete three-dimensional state of stress along the principal material axes of the composite for every element in the composite structure.

\section{Description of Input and Output}

The input data required for the program may be categorized as: model parameters, material properties, geometrical description, and loads. Much of the input is prepared by other computer programs and these programs will be described later. Input instructions and a Fortran listing of the modified program are given in Appendix B.

Model parameters define the data-control values used to describe the model. These parameters include: a job title, the number of nodal points, number of elements, number of different materials, and the number of boundary pressure cards. Material properties are required for each different material. Three-dimensional orthotropic materials may be described by three moduli of elasticity, three Poisson's ratios, and the shear modulus in the cross-sectional plane. (Since the problem is axisymmetric, the other two shear moduli are not used.)

The geometrical description is supplied on nodal-point and element cards. Each nodal point has a number in sequence through the model. Each nodal-point card has the coordinates of the point and, possibly, a boundary. condition descriptor and any nodal-point loads that may be applied. Elements are defined by listing the connected nodal points which form the boundaries of the element. Also, on the element cards are the material type identifier and the material's principal axes orientation angle in that element with respect to the overall coordinate system. 
The loading conditions may be described by nodal-point forces or by boundary pressures, or both. As mentioned, nodal-point forces are supplied on the nodal-point cards. Boundary pressures may be applied with one card for each element boundary to be loaded. The card gives the two nodal-point numbers of the boundary and the magnitude of the pressure.

Nodal-point displacements and element stresses are the main output from the program. All of the input data are printed out initially. The nodal-point displacements are given first in the cylindrical R.Z components and then in spherical N-S components (which correspond to radial-tangential components on the sphere).

The element stresses are given for the element centroidal location. The components in the R-Z-T coordinates are given first; the N-S components in the N-S-T coordinates are given next with the $T$ components unchanged. The fiber direction of the composite is in the S-T plane, and the transformation described earlier is applied to give the longitudinal and transverse stresses on the composite. These stresses, along with the $\mathrm{N}$ components, give the three-dimensional state of stress on the composite in its principal material coordinates. These transformed components are output as the F-E components.

At present, the program has not incorporated any yield or failure criteria for combined stress states. The primary reason for this incompleteness is that no single criterion for all composites has emerged as being satisfactory. The cases studied to date have been evaluated, based on a maximum fiber stress.

Most of the pressure-vessel patterns will not catastrophically fail when the composite fractures transverse to the fiber. Transverse failure for most of the composites studied generally occurs at a low fraction of the ultimate failure load. This phenomenon is known as "crazing"(b) in filament-winding technology.

\section{DATA PREPARATION PROGRAMS}

The finite-element program requires an enormous amount of data for input. Since preparing the data by hand is an almost impossible task, several data-preparation programs were written to automatically produce the data cards. These programs are written for the delta-axisymmetric pattern on a spherical pressı ure vessel

\section{Pattern Definition}

The first step to be accomplished is that of pattern definition. Several factors go into the selection of a pattern: size of the vessel, fill tube size, desired winding thickness, number of shells, and amount of reinforcement at the stem and winding fabrication sequence. $A$ program exists for using these factors to define the pattern. This program was written on the Com-Share time-sharing computer system. A sample input and output are given in Figure 6. This program specifies the winding fabrication sequence and controls for the operator. One

(b) Cracking parallel to the fiber under a transverse load. 
of the outputs available is a list of the coordinate angles for the band positions. These coordinates are indicated in Figure 7; a listing for the pattern designated as the 720A pattern is presented in Figure 8 . The variables listed for each band set are: $\phi$ I, $\phi \phi, N B, N I$, and INC, where:

$\phi \mid$ may be either the polar angle of the band edge nearest the stem $\left(\gamma_{1}\right.$, if $\left.\delta=0\right)$ or the angle to the central plane of the band $\left(\gamma_{2}\right.$, if $\delta=0$ ) keyed on the value of $\phi \phi$.

$\phi \phi \quad$ is either the polar angle of the band edge nearest the south pole, or zero. (If $\phi \phi=0$, it is not used to compute any data and $\delta=0$.

NB is the number of bands in that set needed to produce full coverage at the equator.

NI is the number of bands to be used in that set. If $\mathrm{NI}=0$, $\mathrm{NI}$ is set equal to NB.

INC is the number of strands per inch of band, if 0 in the input INC is set equal to 100.

\section{Pattern Simulation}

Two sets of data which must be input into the finite-element program are: (1) the thickness profile of the wound shell, and (2) the material properties within each element. A pattern-simulation program has been written to satisfy these requirements. In order to specify these data, the program must calculate the thickness buildup for each band set and the fiber orientation angle with respect to the overall spherical coordinates at every point in the composite shell.
INPUT

-EXE /PMP/

WHICH PROGRAMS?DLT, BND

ENTERING DLT

PATTERN TYPE - 2

DESIGN NUMBER - 30

STEM ANGLE - 1.79

NUMBER OF REINFORCING BANDS - 30

OUTPUT

$\begin{array}{rcccc}\gamma_{2} & D_{0} & D_{i} & N C & N B \\ 5.9 & 0.285 & -.409 & 69 & 36 \\ 6.9 & 0.356 & 0.231 & 13 & 30 \\ 18.0 & 0.426 & -.426 & 85 & 28 \\ 30.0 & 0.434 & -.434 & 87 & 25 \\ 42.0 & 0.423 & -.423 & 85 & 22 \\ 54.0 & 0.432 & -.432 & 86 & 17 \\ 66.0 & 0.421 & -.421 & 84 & 12 \\ 78.0 & 0.416 & -.416 & 83 & 6 \\ 90.0 & 0.418 & -.418 & 84 & 1\end{array}$

Where:

$\gamma_{2}$ represents the polar angle to the band generation plane,

$D_{0}$ and $D_{i}$ the distance to the planes of the band edges from the sphere center,

$N C$ the number of fiber circuits in the band, and

NB the number of bands in the set.

Figure 6. PATTERN DEFINITION PROGRAM INPUT AND OUTPUT.

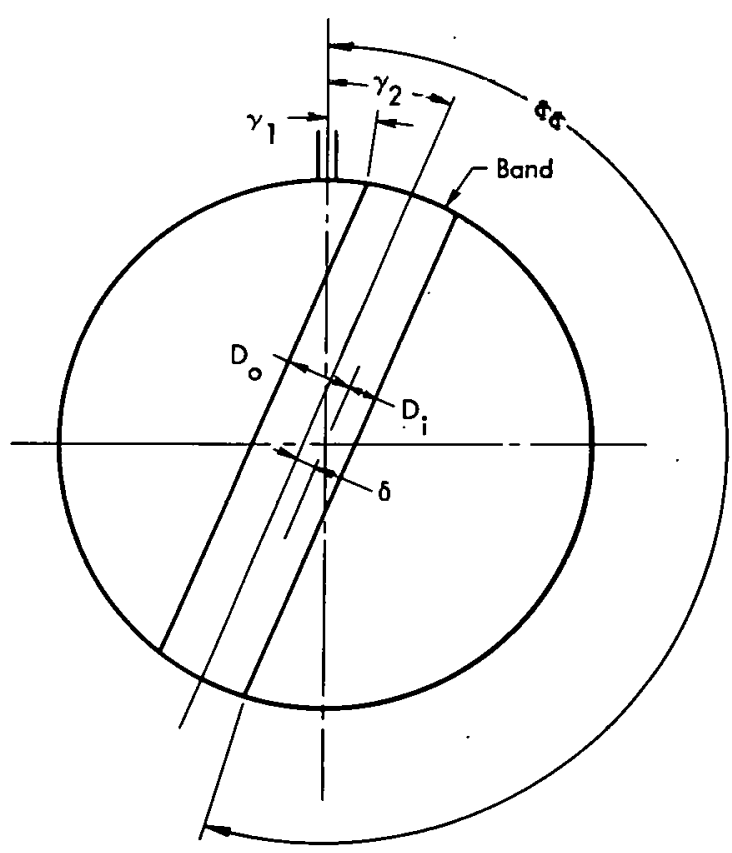

Figure 7. BAND-LOCATION COORDINATES. 


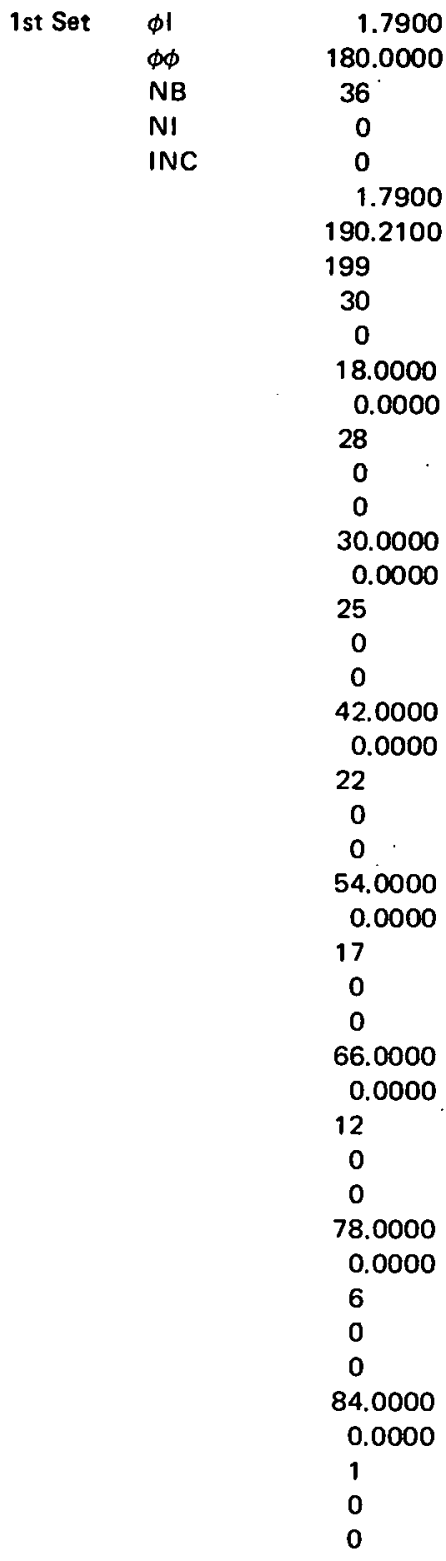

Figure 8. T20A PATTERN DATA. finite-element program will be described later; the mesh-generation program will be described in the paragraphs that follow.

The requirement of closely approximating the contour of complex geometries, together with the desirability of a fine mesh size and its attendant high accuracy, make the use of a large number of nodal points and elements desirable. Obviously, the layout and specification of the locations of such a number of points is a tedious job in which the probability of some human error is high. To minimize the effort, a scheme for the machine generation of much of the required data has been incorporated in a mesh-generation program. 
To layout a nodal-point system for the body to be analyzed, the region of the R-Z plane intersecting the body is covered with an array of quadrilaterals. Each vertex of the quadrilateral is taken to be a nodal point. Each nodal point is identified by an ordered pair of positive integers [denoted by $(I, J)$ in the $\mid-J$ plane]. The scheme for mesh generation may be thought of as representing a one-to-one mapping from the I-J plane into the R-Z plane. As illustrated in Figure 10, each quadrilateral in the R.Z plane is a square in the I-J plane and may be identified by the $1-J$ coordinates (or nodal-point number) of its bottom left-hand corner in the I-J plane. (Figure 10 is illustrative only, since curved boundaries are not used in this finite-element program.)

The mesh generation is accomplished in

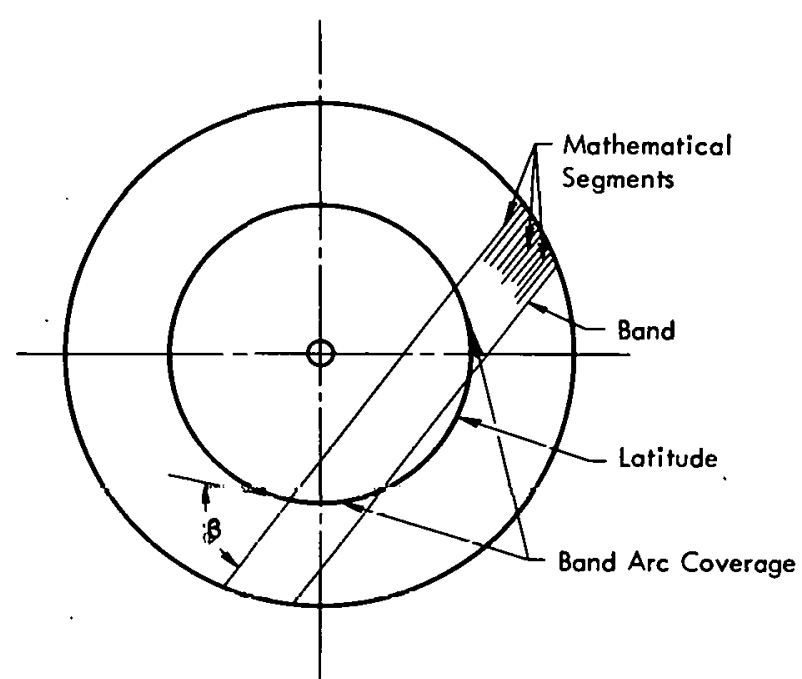

Figure 9. THICKNESS CALCULATION METHOD. (PIane View) the following manner: A data card, containing (among other things) the values of $I$ and $J$ and the $R$ and $Z$ coordinates, in input for each node whose coordinates are to be specified. The specified nodes must at least include all nodes on the boundary of the region. As many other interior nodes as desired may also be specified, but no others are necessary. The calculation, or mapping, of coordinates is achieved by solving twice the finite-difference analog of Laplace's equation on the lattice points in the I-J plane. First, the $R$ coordinates of the boundary points and any specified internal nodes are used as boundary values of the unknown harmonic function, and the functional values obtained on the interior points are taken as the $R$ coordinates of the points in the $\mathrm{R}-\mathrm{Z}$ plane. A similar procedure yields the $Z$ coordinates. In general, this method tends to yield nodal points that are uniformly spaced. If this approach is not
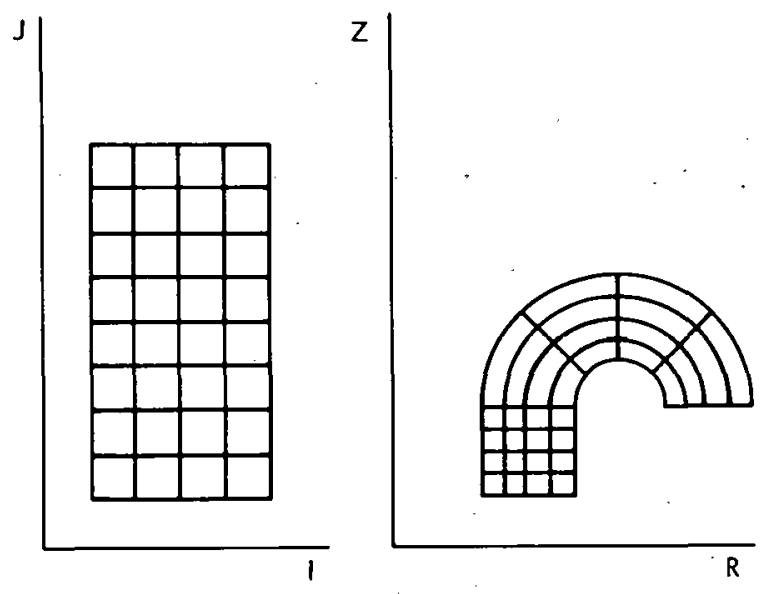

Figure 10. I-J to R-Z MAPPING FOR MESH GENERA: TION. desirable, some of the internal nodal-point coordinates may be specified in order to control the distribution.

The program calculates the location of each point and assigns a nodal-point number. After the output of this information, the program forms quadrilateral or triangular elements by assigning proper nodal-point numbers to the corners of the elements. Output from the program is printed and/or punched onto cards for use in the finite-element program. Input instructions are given in Appendix D. 


\section{Material Property Set}

As mentioned before, the material type within any given element is given a number corresponding to its angle (in integer degrees) between the fiber direction and a latitude (the circumferential direction) on the sphere. This angle lies in a plane which is tangent to the sphere surface at the specific point of interest. Therefore, there are 90 material types to represent the composite material-one for each integer degree of angle. These properties are specified in an N-S-T coordinate system, where T represents the circumferential direction, $S$ the meridional direction, and $N$ the radial direction. $S$ and $T$ lie in the plane tangent to the surface. The relation between the fiber direction and the $S-T$ directions in the tangent plane is illustrated in Figure 11, View a; the relation between the N-S and R-Z coordinates is indicated in Figure 11, View $b$.

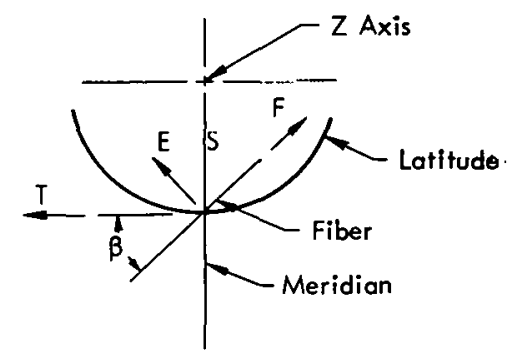

(a) Fiber (F-E) Coordinates With S-T Coordinates.

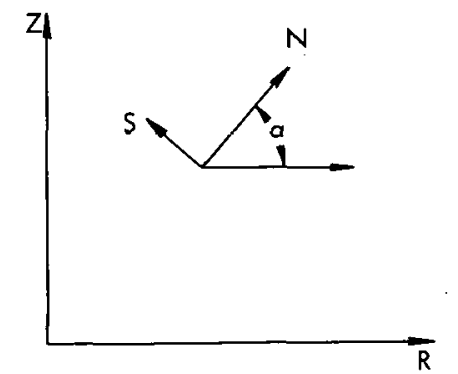

(b) Tangent (N-S) Coordinates With $\mathrm{R}-\mathrm{Z}$ Coordinates.

Figure 11. RELATION BETWEEN PAIRS OF COORDINATES.

The stress-strain relation for three dimensionally orthotropic materials is, in index notation:

$$
\begin{gathered}
\sigma_{i j}=C_{i j k \mid} \mid e_{k l}, \text { or: } \\
e_{i j}=S_{i j k\left|\sigma_{k}\right|},
\end{gathered}
$$

where:

$$
\begin{aligned}
& \sigma_{i j} \text { represents the second-order stress tensor, } \\
& \mathrm{e}_{\mathrm{ij}} \text {.he second-order strain tensor, } \\
& \mathrm{C}_{\mathrm{ijkl}} \text { the fourth-order stiffness tensor, and } \\
& \mathrm{S}_{\mathrm{ijkl}} \text { the fourth-order compliance tensor. }
\end{aligned}
$$

The stiffness and compliance tensors are related.

In matrix notation:

$$
[r .]=[S]-1
$$


The compliance tensor, $S_{i j k l}$, may be written out in terms of common engineering constants for the case of the $Z$ axis being an axis of symmetry. Equation 22 in the N-S-T coordinate system becomes:

$$
\left[\begin{array}{c}
e_{n n} \\
e_{s s} \\
e_{t t} \\
e_{n s}
\end{array}\right]=\left[\begin{array}{cccc}
\frac{1}{E_{n}} & \frac{-\nu_{n s}}{E_{n}} & \frac{-\nu_{n t}}{E_{n}} & 0 \\
\frac{-\nu_{n s}}{E_{n}} & \frac{1}{E_{s}} & \frac{-\nu_{s t}}{E_{s}} & 0 \\
\frac{-\nu_{n t}}{E_{n}} & \frac{-\nu_{s t}}{E_{s}} & \frac{1}{E_{t}} & 0 \\
0 & \dot{v} & \dot{v} & \frac{1}{G_{n s}}
\end{array}\right]\left[\begin{array}{c}
\sigma_{n n} \\
\sigma_{s s} \\
u_{n s}
\end{array}\right]
$$

and the $S$ matrix may be inverted to obtain [C]. For a composite made from continuous unidirectional fibers, the composite properties along the fiber direction and transverse to it may be measured experimentally or determined analytically, and the composite is generally considered to be transversely isotropic. For this case, if $\beta$ in Figure 11, View a is zero, then $T$ corresponds to the fiber direction and $S$ and $N$ are both transverse directions. In this application to wound vessels, $\mathrm{N}$ will always be a transverse direction. When $\beta$ is not zero, the N-S-T properties must be found by use of the transformation equations for a fourth-order tensor. Tsai ${ }^{(3)}$ has tabulated these for the stiffness and compliance matrices.

The property transformations may be made two different ways. One approach involves transforming the $\mathrm{S}$ matrix directly. When the matrix is transformed, terms will appear in the present matrix of Equation 2 where now there are zeros. These terms are known as "shear coupling" terms and will have opposite signs when transformed through a plus or minus Angle $\beta$. By assuming that the state of stress in the plus $\beta$ layer is the same as in the minus $-\beta$ layer, the two equations (same as Equation 22) obtained for plus and minus $\beta$ can be averaged to derive the stress-strain relations for a composite consisting of a mixture of the plus and minus - $\beta$ layers. The effect of this averaging is to cancel the shear-coupling terms and, in this case, the state of strain is such as to allow "scissoring" of the plus and minus layers to occur. The properties which derive from this approach are called "free" elastic properties.

In the second approach, the stress-strain relations in the form of Equation 21 are used. The $S$ matrix is inverted to obtain [C]. Zeros will appear in the same locations as in [S]. Again, when the transformation is made, the terms will appear with plus and minus signs on the shear-coupling terms for the two layers. In this case it is assumed that the same state of strain exists in both layers and the two equations are averaged. This step cancels the shear-coupling terms and the composite behaves as if the two layers were rigidly bonded together (no scissoring occurs). The properties which are derived from this approach are called "restrained" elastic properties. The "restrained" properties are used in most cases since they more likely represent the real composite. Layers in a filament-wound composite are generally well bonded, so this action seems justified. The resulting $\mathrm{C}$ matrix is inverted to obtain [S] so that the moduli and Poisson's ratios may be easily obtained. Input instructions are given in Appendix $E$. 


\section{ANALYSIS PROCEDURE}

\section{Definition of the Problem}

The problem to be investigated is that of a filament-wound, spherical pressure vessel which was wound using the delta-axisymmetric winding pattern. The first assumption is that the problem is axisymmetric with respect to loading, geometry, and material. It is further assumed that the material in a given layer is uniformly distributed around the axis of symmetry. This axis of symmetry is taken to be through the center of the sphere and passing through the center of the fill tube. Furthermore, it is assumed to be symmetric with respect to the equator so that each hemisphere can be considered independently. Even though there may be a fill tube in only one of the hemispheres, the pattern is still very similar on each hemisphere, justifying the separation. This last assumption is not necessary, but it keeps the program size more reasonable.

The finite-element mesh for the hemisphere is seen in Figure 12. In this mesh, starting from the pole, the first two columns of elements represent the fill tube and are assigned elastic properties of the fill-tube material. The third column is a set of interface elements between the tube and composite. These interface elements may have properties which either bond the two materials together or decouple them. (Decoupling is probably more realistic in this case.) Starting from the inside surface of the sphere, the first three elements in each column are used for the liner material. The liner material may be described by a bilinear stress-strain curve to allow the liner to yield plastically. The fourth element in each column is an interface element which may have properties of an adhesive or of the liner to show a bonded condition, or it may have low-modulus, incompressible material properties to allow normal pressure transmission without shear stress, thus modeling the no-bond condition. In the remaining 87 columns of the $90 \times 24$ element array, 20 elements of each column describe the composite material.

Typically the element length along the meridian will vary to allow a finer mesh in the fill-tube region. The elements nearest the tube have lengths corresponding to one-half degree increments along the meridian. This relationship applies out to 10 degrees, polar angle, from the axis of symmetry. The next group of elements have a length of a one-degree increment out to 70 degrees, polar angle. The last group are two-degree lengths and run to the equator. The total number of elements in this case is then $90 \times 24=2160$ elements. These element lengths may be allocated differently, but the overall number of elements should remain the same in order for the various data preparation programs to be compatible. Also, the finite-element program is only dimensioned at 2400 elements.

Loading is provided by a set of pressure cards along the loaded boundary. The pressure acts along the ID of the sphere and tube, and a surface tension acts on the outside of the tube in the axial direction. The resultant of this surface tension is equal to the resultant of the internal pressure acting on the bore cross-sectional area of the tube. The internal pressure listed on the cards is 1000 psi. A multiplier card is added in the program deck to adjust the pressure for the actual pressure to be analyzed, 
26

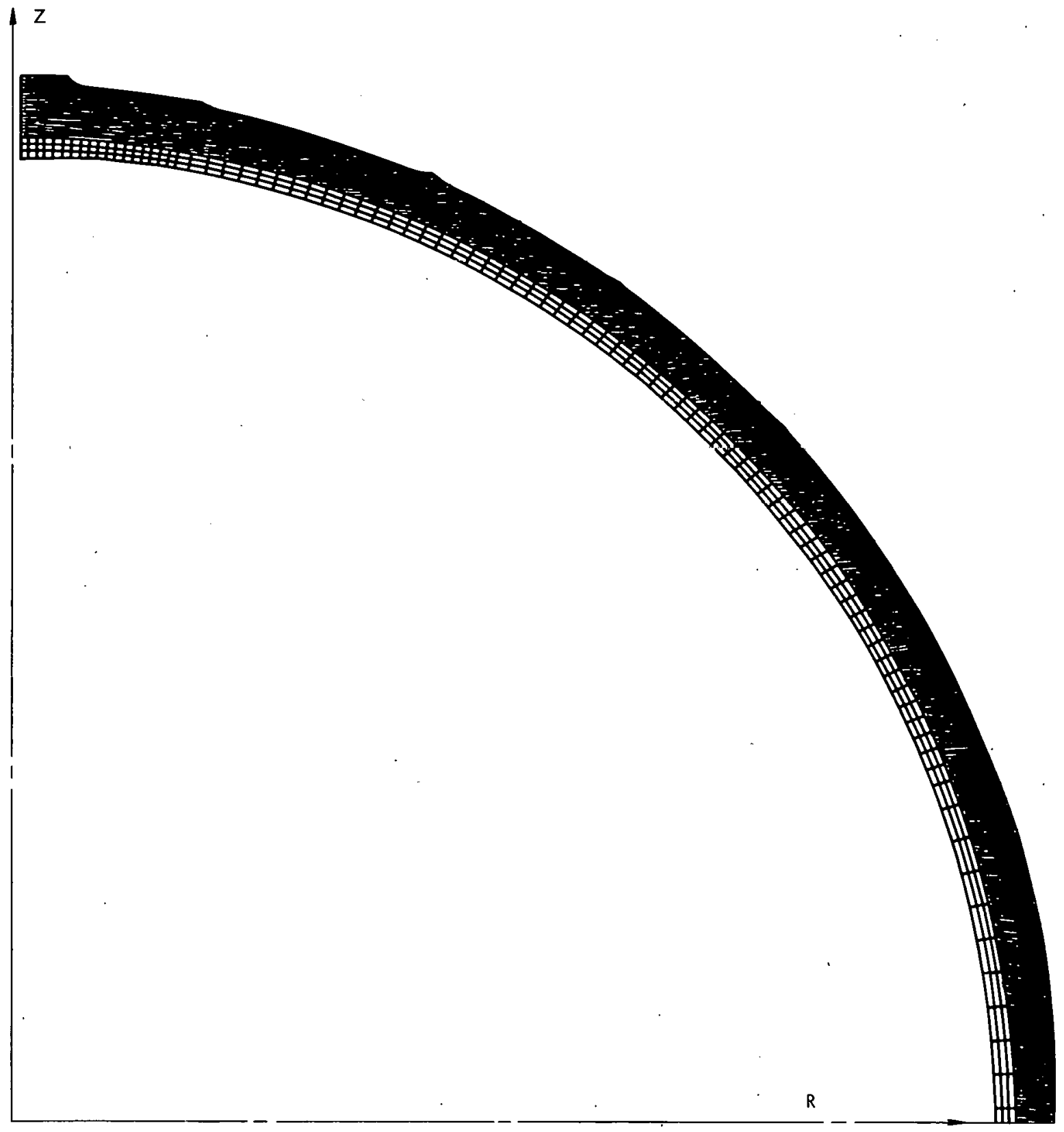

Figure 12. FINITE-ELEMENT MESH FOR THE FILL-TUBE HEMISPHERE OF THE 720A PATTERN.

Run Data Preparation Programs

The programs described in the DATA PREPARATION PROGRAMS section are now used to model the vessel. First, the pattern-design options must be selected. The pattern-definition program, also described in the DATA PREPARATION PROGRAMS section, has three subprograms: DLT, BND, and CHK. Subprogram DLT generates the angular coordinates of the band edges and the number of bands in each set. This information must be generated before running Subprograms BND and CHK. Subprogram BND organizes the 
DLT data into a fabrication sequence and control data for the machine operator. Subprogram CHK computes the check-point information for the use of the machine operator.

After starting the pattern-definition program, the computer prompts for the needed input. The first input in the DLT subprogram is the pattern type. The response is a number corresponding to a cataloged pattern design. For example, Type 1 is a basic pattern with an adjustment for the stem (fill tube) angle. The bands of the first band set are reduced in width to fit between the stem and the normal first latitude of the basic pattern. The number of bands is increased to give side-by-side laydown at the equator. Pattern Type 2 is the same as Type 1 except that the narrow reinforcing bands with a band width equal to the stem angle are applied adjacent to the stem as the second set of bands.

After the pattern type, the next input is the design number. The design number is calculated by dividing the design thickness of one complete basic pattern by the thickness of a single band. The band thickness is determined experimentally for the specific composite material being used. The design thickness of one complete basic pattern is equal to the total design thickness divided by the number of complete patterns in the shell.

The stem angle is requested; and, if the pattern type is Type 2 or any type which uses reinforcing bands, the number of reinforcing bands is requested. The number of bands may be any number desired, but it is normally taken equal to the design number. The DLT subprogram produces a file of pattern data, as was illustrated in Figure 7.

Subprogram BND uses the DLT-produced file and other input data to produce the fabrication data. The radius of the surface to be wound, the number of band sets, and a sequence number is requested. If " 1 " is the number, the sequence will be such that the band sets are applied progressively from the pole to the equator-commonly called a "downwind". If " 2 " is the number, the sets are applied from the equator to the pole-"upwind". Normally, a vessel would have a downwind followed by an upwind to produce a balanced laminate shell. Both the downwind and upwind are complete patterns.

When the Subprogram DLT file is created, the pattern-simulation program uses these data to compute the shell-thickness profile and the material orientations in the shell. Control data for the pattern-simulation program are similar to the BND subprograms of the pattern-definition program. The radius of the sphere, the band thickness, and number of band sets in the part are input. The number of angular increments (number of elements along the meridian) are specified.

Additional information and options are input to further refine the modeling technique. A material-stacking sequence locates the radial position of the material in a segment. The segment nearest the axis of symmetry may be located either at the smallest or largest radial position in its band-set layer. The other nine segments are then progressively positioned toward the largest or smallest radial position. The lengths of elements along the meridian may be specified with up to five different regions. This sequence allows finer grids in areas of likely stress concentrations. Following all this input, the data file created by DLT is input. The data are entered in the order of the winding sequence. 
The program has two output options: Option (IOPT) 0 gives the helix angles (angle between the fiber and latitude in the tangent plane) at the band segment edges and the average thickness contributed by that segement at all calculating positions on the sphere; Option 1 produces an array of material types representative of the material orientations in the shell. The helix angles in a segment are averaged as well as the values for each segment represented in an element, weighted by their thickness fraction to give the computed material orientation for that element. The orientation angle is rounded to the nearest integer and used as the material-type identifier. The array of material types is formatted for a 24-element thick-shell model, with three of these elements for the mandrel and one for the interface. Also, with Option 1, the shell total-thickness profile is computed and a list of the outer-surface nodal points and their coordinates is printed. Thus, Option 1 is selected for production of data cards needed by the finite-element program.

The actual finite-element mesh may be generated by the mesh-generation program, or by hand. When a large number of nodal points and elements are used, hand generation becomes impractical. Portions of the mesh may also be generated internally in the finite-element program. This internal generation is limited to equal spacing between given nodal points. The outer-surface nodal points generated by the pattern-simulation program may be used as input to the mesh-generation program. They may also be direct inputs to the finite-element program, utilizing the internal program node and element generation. The approach used in this study starts with the complete mesh produced by the mesh-generation program. The finite-element program is run with this mesh. If the design needs to be altered, the pattern is changed. Then, all the nodal-point cards in the old mesh for the composite material are removed. These cards are replaced by the outer-contour nodal-point set for the new pattern and the interior nodes are program generated. In this way, redesigned cases may be examined with a minimized effort.

Properties for the composite material types in the material array are found by transformation in the T-S plane. Nine properties of the composite material are required in its principal material directions-three are moduli of elasticity, three are Poisson's ratios, and three are shear moduli of elasticity. The transformed properties are computed at every integer degree between 0 to 90 degrees. A data set of cards is punched in the format. required for input to the finite-element program.

\section{Editing the Assembled Data Set}

It remains to assemble the data sets that have been prepared by running these computer programs, prepare other needed data cards by hand, and edit the complete set for any required corrections. The data sets are assembled in the sequence required for input to the finite-element program. The title card and first control card, giving the number of nodal points, elements, materials, and boundary pressure cards, are prepared by hand. The material cards for the composite are generated in the set, but those cards for the liner, fill tube, interface regions, and any void or resin-filled regions must be prepared by hand. The nodal-point cards are normally computer generated, but may require editing to apply the proper boundary conditions or alter the position of some points. All element cards are computer generated. The material type of each element is generated in the pattern-simulation array. To locate materials, as desired, the array may be edited. Orientation of the $\mathrm{N}-\mathrm{S}$ coordinates of each element with respect to the R-Z coordinates is 
prepared by hand. All the inner-boundary elements are loaded by the internal pressure. The fill tube is usually terminated in the model, flush with the outer contqur adjacent to the tube. An additional tension force on the tube due to the bore pressure acts in the axial direction. This force is added as a negative pressure on the terminated boundary of the tube. After all the cards are prepared and assembled, the finite-element program is now ready to run.

\section{Evaluation of the Results}

The computer run is made and the results may be evaluated. If a vessel pattern design is needed, several runs may be made to check the effects of pattern alterations. A pattern for the part is chosen and the first run analyzes this pattern. Structurally deficient areas may then be recognized and the pattern modified for proper compensation. This process continues until an acceptable pattern is reached. If the other design constraints on the vessel (such as wall thickness or fill-tube diameter) are such that only one pattern may be used, then the results are predicted. In either case, experimental tests follow to assess the accuracy of the analysis.

\section{CASE STUDY OF AN EIGHT-INCH-DIAMETER VESSEL}

\section{Vessel Description and Input Data}

The program was used to analyze an eight-inch-diameter pressure vessel. The vessel is spherical and has a Type 5083.0 aluminum liner that is 0.080 inch thick. There is one fill tube, 0.250 inch in diameter and made from Type 5083- $\mathrm{H} 231$ aluminum. The winding pattern is identified as the "720A" pattern. The composite structure is wound with single-end " $S$ " glass yarn and ERL 2258/MPDA epoxy resin. The composite thickness averages 0.180 inch.

The $720 \mathrm{~A}$ pattern is described in Figure 8 . The band width is nominally 12 degrees arc coverage and the band thickness is 0.0056 inch. The $720 \mathrm{~A}$ pattern was produced by the following input to the pattern definition program: pattern type, 2; design number, 30; stem angle, 1.79 degrees; number of reinforcing bands, 30. When Subprogram DLT is completed, the pattern description may be used in Subprogram BND to calculate the operation control data given in Figure 6.

The pattern description is fed into the pattern-simulation program to calculate the thickness profile and material type (orientation) in each element. The thickness profile is identified in the mesh of Figure 12; the material array is reported in Table 1. The following input data produced these results: radius, 4 inches; thickness factor, 0.0056 inch; number of band sets, 18; number of meridian-angle increments, 90; output option, 1 . The first nine band sets are in a downwind sequence, the second nine sets are in an upwind sequence. The material stacking sequence is specified as 1 for the downwind and 2 for the upwind. The size of the meridian-angle increment is $1 / 2$ degree for the first 10 degrees along the meridian, 1-degree increments for the next 60 degrees, and 2-degree increments for the last 20 degrees. Editing of the material array is needed to correctly model this particular design. In the illustrated array, horizontal lines (rows) go through the vessel wall with the inside surface of the vessel on the right; vertical lines (columns) go along the vessel meridian. As mentioned, the first 
Table 1

MATERIAL ARRAY FOR 720A PATTERN

$\begin{array}{llllllllllllllllllllllll}91 & 91 & 91 & 91 & 91 & 91 & 91 & 91 & 91 & 91 & 91 & 91 & 91 & 91 & 91 & 91 & 91 & 91 & 91 & 91 & 93 & 92 & 92 & 92\end{array}$ $\begin{array}{llllllllllllllllllllllll}91 & 91 & 91 & 91 & 91 & 91 & 91 & 91 & 91 & 91 & 91 & 91 & 91 & 91 & 91 & 91 & 91 & 91 & 91 & 91 & 93 & 92 & 92 & 92\end{array}$ $\begin{array}{lllllllllllllllllllllllllll}91 & 91 & 91 & 91 & 91 & 91 & 91 & 91 & 91 & 91 & 91 & 91 & 91 & 91 & 91 & 91 & 91 & 91 & 91 & 91 & 93 & 92 & 92 & 92\end{array}$ $\begin{array}{llllllllllllllllllllllll}91 & 91 & 91 & 91 & 91 & 91 & 91 & 91 & 91 & 91 & 91 & 13 & 18 & 18 & 16 & 4 & 15 & 18 & 13 & 13 & 93 & 92 & 92 & 92\end{array}$ $\begin{array}{llllllllllllllllllllllll}91 & 91 & 91 & 91 & 91 & 22 & 22 & 22 & 21 & 37 & 22 & 15 & 10 & 11 & 27 & 39 & 22 & 22 & 22 & 22 & 93 & 92 & 92 & 92\end{array}$ $\begin{array}{llllllllllrlllllllllllll}91 & 91 & 38 & 38 & 31 & 11 & 9 & 44 & 31 & 16 & 8 & 8 & 19 & 33 & 46 & 10 & 11 & 36 & 38 & 38 & 93 & 92 & 92 & 92\end{array}$ $\begin{array}{llllllllllllllllllllllll}48 & 48 & 19 & 19 & 27 & 55 & 45 & 32 & 20 & 7 & 7 & 20 & 32 & 45 & 56 & 19 & 19 & 19 & 48 & 48 & 93 & 92 & 92 & 92\end{array}$ $\begin{array}{llllllllllllllllllllllll}55 & 51 & 32 & 32 & 25 & 10 & 7 & 54 & 43 & 32 & 32 & 43 & 54 & 9 & 10 & 25 & 32 & 32 & 51 & 55 & 93 & 92 & 92 & 92\end{array}$ $\begin{array}{lllllllllllllllllllllllllll}59 & 53 & 42 & 34 & 16 & 16 & 21 & 62 & 53 & 42 & 42 & 53 & 63 & 16 & 16 & 16 & 34 & 42 & 53 & 59 & 93 & 92 & 92 & 92\end{array}$ $\begin{array}{lllllllllllllllllllllllll}62 & 54 & 48 & 32 & 29 & 24 & 9 & -\epsilon & 60 & 49 & 49 & 60 & 8 & 9 & 24 & 29 & 32 & 48 & 54 & 62 & 93 & 92 & 92 & 92\end{array}$ $\begin{array}{llllllllllllllllllllllll}65 & 56 & 49 & 38 & 29 & 15 & 15 & 14 & 65 & 54 & 54 & 65 & 14 & 15 & 15 & 29 & 38 & 49 & 56 & 65 & 93 & 92 & 92 & 92\end{array}$ $\begin{array}{llllllllllllllllllllllll}67 & 58 & 50 & 44 & 27 & 27 & 15 & 9 & 67 & 58 & 58 & 69 & 8 & 15 & 27 & 27 & 44 & 50 & 58 & 67 & 93 & 92 & 92 & 92\end{array}$ $\begin{array}{lllllllllllllllllllllllll}69 & 60 & 51 & 42 & 35 & 19 & 14 & 18 & 70 & 62 & 62 & 71 & 14 & 14 & 19 & 35 & 42 & 51 & 60 & 69 & 93 & 92 & 92 & 92\end{array}$ $\begin{array}{llllllllllllllllllllllll}70 & 62 & 52 & 43 & 34 & 25 & 21 & 11 & 72 & 64 & 64 & 73 & 7 & 21 & 25 & 34 & 43 & 52 & 62 & 70 & 93 & 92 & 92 & 92\end{array}$ $\begin{array}{llllllllllllllllllllllll}71 & 63 & 54 & 45 & 34 & 27 & 13 & 13 & 8 & 66 & 66 & 12 & 13 & 13 & 27 & 34 & 45 & 54 & 63 & 71 & 93 & 92 & 92 & 92\end{array}$ $\begin{array}{rlllllllrllrrrrrrrrrrrrr}72 & 63 & 55 & 46 & 38 & 24 & 23 & 9 & 5 & 68 & 68 & 7 & 9 & 23 & 24 & 38 & 46 & 55 & 63 & 72 & 93 & 92 & 92 & 92\end{array}$ $\begin{array}{lllllllllllllllllllllllll}73 & 64 & 55 & 46 & 37 & 31 & 13 & 12 & 10 & 70 & 70 & 12 & 12 & 13 & 31 & 37 & 46 & 55 & 64 & 73 & 93 & 92 & 92 & 92 \\ 73 & 65 & 56 & 47 & 38 & 28 & 22 & 12 & 6 & 71 & 71 & 6 & 12 & 22 & 28 & 38 & 47 & 56 & 65 & 73 & 93 & 92 & 92 & 92\end{array}$ $\begin{array}{llllllllllllllllllllllllllll}74 & 65 & 56 & 47 & 38 & 28 & 22 & 12 & 6 & 71 & 71 & 6 & 12 & 22 & 28 & 38 & 47 & 56 & 65 & 73 & 93 & 92 & 92 & 92 \\ 74 & 67 & 58 & 39 & 29 & 18 & 11 & 11 & 73 & 73 & 11 & 11 & 18 & 29 & 39 & 48 & 57 & 66 & 74 & 93 & 92 & 92 & 92\end{array}$ $\begin{array}{llllllllllllllllllllllll}74 & 66 & 57 & 48 & 39 & 30 & 21 & 14 & 6 & 74 & 74 & 6 & 14 & 21 & 30 & 39 & 48 & 57 & 66 & 74 & 93 & 92 & 92 & 92\end{array}$ $\begin{array}{llllllllllllllllllllllll}75 & 67 & 58 & 50 & 40 & 32 & 20 & 16 & 6 & 75 & 76 & 6 & 16 & 20 & 32 & 40 & 50 & 58 & 67 & 75 & 93 & 92 & 92 & 92\end{array}$ $\begin{array}{llllllllllllllllllllllllll}77 & 69 & 61 & 52 & 44 & 35 & 27 & 19 & 78 & 3 & 4 & 79 & 19 & 27 & 35 & 44 & 52 & 61 & 69 & 77 & 93 & 92 & 92 & 92\end{array}$ $\begin{array}{llllllllllllllllllllllll}77 & 69 & 61 & 53 & 45 & 36 & 30 & 76 & 12 & 12 & 12 & 12 & 76 & 29 & 36 & 45 & 53 & 61 & 69 & 77 & 93 & 92 & 92 & 92\end{array}$ $\begin{array}{llllllllllllllllllllllll}78 & 70 & 62 & 54 & 46 & 38 & 77 & 26 & 10 & 10 & 10 & 10 & 26 & 78 & 38 & 46 & 54 & 62 & 70 & 78 & 93 & 92 & 92 & 92\end{array}$ $\begin{array}{llllllllllllllllllllllll}79 & 71 & 63 & 55 & 47 & 42 & 32 & 24 & 13 & 8 & 8 & 13 & 24 & 33 & 41 & 47 & 55 & 63 & 71 & 79 & 93 & 92 & 92 & 92\end{array}$ $\begin{array}{llllllllllllllllllllllll}79 & 71 & 64 & 56 & 48 & 78 & 34 & 23 & 15 & 7 & 7 & 15 & 23 & 34 & 80 & 48 & 56 & 64 & 71 & 79 & 93 & 92 & 92 & 92\end{array}$ $\begin{array}{llllllllllllllllllllllllll}79 & 72 & 64 & 56 & 50 & 41 & 33 & 23 & 16 & 5 & 5 & 16 & 23 & 33 & 42 & 49 & 56 & 64 & 72 & 79 & 93 & 92 & 92 & 92\end{array}$ $\begin{array}{llllllllllllllllllllllllll}80 & 72 & 65 & 57 & 80 & 42 & 34 & 23 & 10 & 10 & 10 & 10 & 23 & 34 & 43 & 82 & 57 & 65 & 72 & 80 & 93 & 92 & 92 & 92\end{array}$ $\begin{array}{llllllllllllllllllllllll}80 & 73 & 65 & 57 & 80 & 43 & 34 & 24 & 11 & 9 & 9 & 11 & 24 & 34 & .43 & 81 & 57 & 65 & 73 & 80 & 93 & 92 & 92 & 92\end{array}$ $\begin{array}{llllllllllllllllllllllll}80 & 73 & 65 & 58 & 80 & 43 & 33 & 24 & 13 & 8 & 8 & 13 & 24 & 33 & 43 & 81 & 58 & 65 & 73 & 80 & 93 & 92 & 92 & 92\end{array}$ $\begin{array}{llllllllllllllllllllllll}80 & 73 & 66 & 59 & 50 & 43 & 33 & 23 & 14 & 7 & 7 & 14 & 23 & 33 & 43 & 51 & 59 & 66 & 73 & 80 & 93 & 92 & 92 & 92\end{array}$ $\begin{array}{llllllllllllllllllllllll}81 & 73 & 66 & 60 & 51 & 43 & 34 & 23 & 15 & 5 & 5 & 15 & 23 & 34 & 43 & 52 & 60 & 66 & 73 & 81 & 93 & 92 & 92 & 92\end{array}$ $\begin{array}{llllllllllllllllllllllllll}81 & 74 & 67 & 81 & 52 & 43 & 33 & 24 & 13 & 7 & 7 & 13 & 24 & 33 & 43 & 52 & 83 & 66 & 74 & 81 & 93 & 92 & 92 & 92\end{array}$ $\begin{array}{lllllllllllllllllllllllll}81 & 73 & 65 & 55 & 49 & 39 & 29 & 16 & 9 & 3 & 4 & 9 & 16 & 29 & 39 & 49 & 56 & 65 & 73 & 81 & 93 & 92 & 92 & 92\end{array}$ $\begin{array}{llllllllllllllllllllllll}81 & 74 & 67 & 81 & 51 & 42 & 32 & 22 & 8 & 9 & 9 & 9 & 22 & 32 & 42 & 51 & 83 & 67 & 74 & 81 & 93 & 92 & 92 & 92\end{array}$ $\begin{array}{lllllllllllllllllllllllll}81 & 74 & 67 & 58 & 51 & 42 & 33 & 25 & 13 & 7 & 7 & 13 & 25 & 33 & 42 & 51 & 59 & 67 & 74 & 81 & 93 & 92 & 92 & 92\end{array}$ $\begin{array}{llllllllllllllllllllllll}82 & 75 & 68 & 58 & 52 & 42 & 33 & 22 & 14 & 6 & 6 & 14 & 23 & 33 & 42 & 52 & 59 & 67 & 75 & 82 & 93 & 92 & 92 & 92\end{array}$ $\begin{array}{lllllllllllllllllllllllll}82 & 75 & 68 & 59 & 52 & 43 & 34 & 24 & 14 & 5 & 5 & 14 & 24 & 34 & 43 & 52 & 60 & 68 & 75 & 82 & 93 & 92 & 92 & 92\end{array}$ $\begin{array}{llllllllllllllllllllllll}82 & 75 & 69 & 59 & 52 & 43 & 36 & 24 & 14 & 6 & 6 & 14 & 24 & 36 & 43 & 52 & 60 & 69 & 75 & 82 & 93 & 92 & 92 & 92\end{array}$ $\begin{array}{lllllllllllllllllllllllll}82 & 75 & 69 & 60 & 52 & 43 & 31 & 24 & 12 & 8 & 8 & 12 & 24 & 32 & 43 & 52 & 60 & 69 & 75 & 82 & 93 & 92 & 92 & 92\end{array}$ $\begin{array}{llllllllllllllllllllllll}82 & 75 & 70 & 60 & 52 & 43 & 32 & 24 & 13 & 7 & 7 & 13 & 24 & 33 & 43 & 52 & 60 & 70 & 75 & 82 & 93 & 92 & 92 & 92\end{array}$ $\begin{array}{lllllllllllllllllllllllll}82 & 76 & 70 & 60 & 52 & 44 & 33 & 24 & 13 & 6 & 6 & 13 & 24 & 33 & 44 & 52 & 60 & 70 & 76 & 82 & 93 & 92 & 92 & 92 \\ 82 & 76 & 83 & 60 & 52 & 45 & 33 & 24 & 15 & 5 & 5 & 15 & 24 & 33 & 45 & 52 & 60 & 84 & 76 & 82 & 93 & 92 & 92 & 92\end{array}$ $\begin{array}{llllllllllllllllllllllllll}82 & 76 & 83 & 60 & 52 & 39 & 33 & 23 & 14 & 6 & 6 & 14 & 23 & 33 & 40 & 52 & 60 & 84 & 76 & 82 & 93 & 92 & 92 & 92\end{array}$ $\begin{array}{llllllllllllllllllllllll}82 & 76 & 83 & 60 & 52 & 40 & 33 & 23 & 13 & 7 & 7 & 13 & 23 & 33 & 41 & 52 & 60 & 84 & 76 & 82 & 93 & 92 & 92 & 92\end{array}$ $\begin{array}{llllllllllllllllllllllll}82 & 76 & 65 & 59 & 51 & 40 & 31 & 21 & 10 & 7 & 6 & 10 & 21 & 31 & 40 & 51 & 59 & 66 & 76 & 82 & 93 & 92 & 92 & 92\end{array}$ $\begin{array}{llllllllllllllllllllllll}83 & 76 & 65 & 60 & 52 & 41 & 32 & 23 & 15 & 6 & 6 & 14 & 23 & 32 & 41 & 52 & 60 & 67 & 76 & 83 & 93 & 92 & 92 & 92\end{array}$ $\begin{array}{llllllllllllllllllllllllll}83 & 77 & 66 & 60 & 53 & 41 & 32 & 23 & 12 & 5 & 5 & 13 & 23 & 32 & 4 i & 53 & 60 & 67 & 77 & 83 & 93 & 92 & 92 & 92\end{array}$ $\begin{array}{llllllllllllllllllllllll}83 & 77 & 66 & 60 & 53 & 41 & 33 & 24 & 14 & 5 & 5 & 14 & 24 & 33 & 41 & 53 & 60 & 67 & 77 & 83 & 93 & 92 & 92 & 92\end{array}$ $\begin{array}{lllllllllllllllllllllllllll}83 & 77 & 66 & 61 & 54 & 42 & 33 & 20 & 14 & 5 & 5 & 14 & 21 & 33 & 41 & 54 & 61 & 67 & 77 & 83 & 93 & 92 & 92 & 92 \\ 83 & 77 & 66 & 61 & 47 & 42 & 33 & 21 & 13 & 6 & 6 & 13 & 22 & 33 & 42 & 48 & 61 & 67 & 77 & 83 & 93 & 92 & 92 & 92\end{array}$ $\begin{array}{llllllllllllllllllllllllll}83 & 77 & 66 & 61 & 47 & 42 & 33 & 21 & 13 & 6 & 6 & 13 & 22 & 33 & 42 & 48 & 61 & 67 & 77 & 83 & 93 & 92 & 92 & 92\end{array}$ $\begin{array}{llllllllllllllllllllllll}83 & 77 & 67 & 61 & 48 & 42 & 33 & 23 & 13 & 6 & 6 & 13 & 23 & 33 & 42 & 49 & 61 & 68 & 77 & 83 & 93 & 92 & 92 & 92\end{array}$ $\begin{array}{llllllllllllllllllllllll}83 & 77 & 67 & 61 & 48 & 42 & 34 & 23 & 13 & 6 & 6 & 13 & 23 & 34 & 42 & 49 & 61 & 68 & 77 & 83 & 93 & 92 & 92 & 92\end{array}$ $\begin{array}{llllllllllllllllllllllllll}83 & 78 & 67 & 61 & 49 & 42 & 35 & 23 & 14 & 5 & 5 & 14 & 22 & 35 & 42 & 50 & 61 & 68 & 77 & 83 & 93 & 92 & 92 & 92\end{array}$ $\begin{array}{llllllllllllllllllllllllll}83 & 78 & 67 & 61 & 49 & 42 & 29 & 23 & 14 & 5 & 5 & 14 & 23 & 30 & 42 & 50 & 61 & 68 & 78 & 83 & 93 & 92 & 92 & 92\end{array}$ $\begin{array}{llllllllllllllllllllllll}83 & 78 & 67 & 61 & 49 & 42 & 30 & 23 & 13 & 5 & 5 & 13 & 23 & 31 & 42 & 50 & 61 & 68 & 78 & 83 & 93 & 92 & 92 & 92 \\ 83 & 78 & 67 & 61 & 50 & 42 & 30 & 23 & 13 & 6 & 6 & 13 & 23 & 31 & 42 & 50 & 61 & 68 & 78 & 83 & 93 & 92 & 92 & 92\end{array}$ $\begin{array}{lllllllllllllllllllllllll}83 & 78 & 67 & 61 & 50 & 42 & 30 & 23 & 13 & 6 & 6 & 13 & 23 & 31 & 42 & 50 & 61 & 68 & 78 & 83 & 93 & 92 & 92 & 92\end{array}$ $\begin{array}{llllllllllllllllllllllll}83 & 78 & 67 & 61 & 49 & 41 & 29 & 20 & 9 & 6 & 5 & 9 & 20 & 29 & 41 & 48 & 61 & 67 & 78 & 83 & 93 & 92 & 92 & 92\end{array}$ $\begin{array}{llllllllllllllllllllllll}83 & 78 & 68 & 62 & 50 & 43 & 31 & 23 & 14 & 5 & 5 & 14 & 23 & 31 & 43 & 50 & 62 & 68 & 78 & 83 & 93 & 92 & 92 & 92\end{array}$ $\begin{array}{lllllllllllllllllllllllll}83 & 79 & 68 & 62 & 50 & 44 & 32 & 24 & 17 & 5 & 5 & 17 & 24 & 32 & 44 & 50 & 62 & 68 & 79 & 83 & 93 & 92 & 92 & 92\end{array}$ $\begin{array}{llllllllllllllllllllllll}83 & 79 & 68 & 63 & 51 & 44 & 32 & 24 & 12 & 5 & 5 & 13 & 24 & 32 & 44 & 51 & 63 & 68 & 79 & 83 & 93 & 92 & 92 & 92\end{array}$ $\begin{array}{llllllllllllllllllllllllll}83 & 79 & 69 & 63 & 51 & 45 & 32 & 25 & 14 & 5 & 5 & 14 & 24 & 32 & 45 & 51 & 63 & 69 & 79 & 83 & 93 & 92 & 92 & 92\end{array}$ $\begin{array}{llllllllllllllllllllllll}83 & 79 & 69 & 63 & 51 & 38 & 33 & 25 & 14 & 5 & 5 & 14 & 25 & 33 & 39 & 51 & 63 & 69 & 79 & 83 & 93 & 92 & 92 & 92\end{array}$ $\begin{array}{llllllllllllllllllllllll}83 & 79 & 69 & 64 & 51 & 38 & 33 & 26 & 14 & 5 & 5 & 13 & 26 & 33 & 39 & 51 & 64 & 69 & 79 & 83 & 93 & 92 & 92 & 92\end{array}$ $\begin{array}{llllllllllllllllllllllll}84 & 80 & 69 & 64 & 51 & 39 & 33 & 20 & 14 & 5 & 5 & 14 & 21 & 33 & 40 & 51 & 64 & 69 & 79 & 84 & 93 & 92 & 92 & 92\end{array}$ $\begin{array}{llllllllllllllllllllllll}84 & 80 & 69 & 56 & 52 & 39 & 33 & 21 & 14 & 5 & 5 & 14 & 22 & 33 & 40 & 52 & 57 & 69 & 80 & 84 & 93 & 92 & 92 & 92\end{array}$ $\begin{array}{llllllllllllllllllllllll}84 & 80 & 69 & 56 & 52 & 40 & 33 & 22 & 14 & 5 & 5 & 14 & 22 & 33 & 40 & 52 & 57 & 69 & 80 & 84 & 93 & 92 & 92 & 92\end{array}$ $\begin{array}{llllllllllllllllllllllllll}84 & 80 & 69 & 56 & 52 & 40 & 34 & 22 & 14 & 5 & 5 & 14 & 22 & 34 & 40 & 52 & 57 & 69 & 80 & 84 & 93 & 92 & 92 & 92\end{array}$ $\begin{array}{llllllllllllllllllllllll}84 & 80 & 69 & 56 & 52 & 41 & 34 & 22 & 14 & 5 & 5 & 14 & 22 & 34 & 41 & 52 & 57 & 69 & 80 & 84 & 93 & 92 & 92 & 92\end{array}$ $\begin{array}{llllllllllllllllllllllllll}84 & 84 & .69 & 56 & 52 & 40 & 34 & 21 & 13 & 4 & 4 & 13 & 21 & 35 & 40 & 52 & 57 & 69 & 84 & 84 & 93 & 92 & 92 & 92\end{array}$ $\begin{array}{lllllllllllllllllllllllll}84 & 84 & 69 & 57 & 53 & 41 & 35 & 23 & 14 & 3 & 4 & 14 & 22 & 35 & 41 & 52 & 57 & 69 & 84 & 84 & 93 & 92 & 92 & 92\end{array}$ $\begin{array}{llllllllllllllllllllllll}84 & 84 & 69 & 57 & 53 & 42 & 28 & 23 & 15 & 5 & 5 & 15 & 23 & 29 & 41 & 53 & 58 & 69 & 84 & 84 & 93 & 92 & 92 & 92\end{array}$ $\begin{array}{llllllllllllllllllllllll}84 & 84 & 69 & 57 & 53 & 42 & 29 & 24 & 17 & 5 & 4 & .17 & 24 & 30 & 41 & 53 & 58 & 69 & 84 & 84 & 93 & 92 & 92 & 92\end{array}$ $\begin{array}{llllllllllllllllllllllll}84 & 84 & 70 & 57 & 54 & 42 & 29 & 24 & 11 & 5 & 5 & 12 & 24 & 30 & 42 & 54 & 58 & 69 & 84 & 84 & 93 & 92 & 92 & 92\end{array}$ $\begin{array}{llllllllllllllllllllllll}84 & 84 & .70 & 57 & 54 & 42 & 29 & 24 & 12 & 5 & 5 & 13 & 24 & 30 & 42 & 54 & 58 & 70 & 84 & 84 & 93 & 92 & 92 & 92\end{array}$ $\begin{array}{lllllllllllllllllllllllll}84 & 84 & 70 & 58 & 54 & 42 & 30 & 24 & 12 & 5 & 5 & 13 & 24 & 31 & 42 & 54 & 58 & 70 & 84 & 84 & 93 & 92 & 92 & 92\end{array}$ $\begin{array}{llllllllllllllllllllllllll}84 & 84 & .70 & 58 & 55 & 42 & 30 & 25 & 13 & 5 & 5 & 13 & 24 & 31 & 42 & 54 & 58 & 70 & 84 & 84 & 93 & 92 & 92 & 92\end{array}$ $\begin{array}{llllllllllllllllllllllll}84 & 84 & 70 & 58 & 55 & 43 & 30 & 25 & 13 & 5 & 5 & 13 & 25 & 31 & 42 & 55 & 58 & 70 & 84 & 84 & 93 & 92 & 92 & 92\end{array}$ $\begin{array}{llllllllllllllllllllllll}84 & 84 & 70 & 58 & 46 & 43 & 31 & 26 & 13 & 5 & 5 & 13 & 26 & 31 & 42 & 46 & 58 & 70 & 84 & 84 & 93 & 92 & 92 & 92\end{array}$ $\begin{array}{llllllllllllllllllllllll}84 & 83 & 70 & 59 & 46 & 43 & 31 & 26 & 13 & 5 & 5 & 13 & 26 & 31 & 43 & 47 & 59 & 69 & 84 & 84 & 93 & 92 & 92 & 92\end{array}$ $\begin{array}{llllllllllllllllllllllll}84 & 83 & 70 & 59 & 46 & 43 & 32 & : 19 & 13 & 5 & 5 & 13 & 20 & 31 & 43 & 47 & 59 & 70 & 84 & 84 & 93 & 92 & 92 & 92\end{array}$ $\begin{array}{llllllllllllllllllllllll}84 & 83 & 71 & 59 & 46 & 44 & 32 & 20 & 15 & 2 & 3 & 15 & 21 & 32 & 44 & 47 & 59 & 70 & 84 & 84 & 93 & 92 & 92 & 92\end{array}$ $\begin{array}{llllllllllllllllllllllll}84 & 83 & 71 & 59 & 17 & 45 & 33 & 21 & 16 & 3 & 3 & 16 & 21 & 33 & 45 & 47 & 59 & 70 & 84 & 84 & 93 & 92 & 92 & 92\end{array}$ $\begin{array}{llllllllllllllllllllllllll}84 & 83 & 71 & 59 & 17 & 45 & 33 & 22 & 8 & 3 & 3 & 9 & 21 & 33 & 45 & 48 & 59 & 70 & 83 & 84 & 93 & 92 & 92 & 92\end{array}$

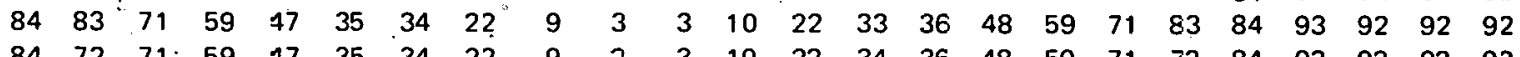
$\begin{array}{llllllllllllllllllllllll}84 & 72 & 71 & 59 & 77 & 35 & 34 & 22 & 9 & 2 & 3 & 10 & 22 & 34 & 36 & 48 & 59 & 71 & 72 & 84 & 93 & 92 & 92 & 92\end{array}$ $\begin{array}{lllllllllllllllllllllllll}84 & 72 & 71 & 60 & 77 & 35 & 34 & 22 & 10 & 4 & 4 & 10 & 22 & 34 & 36 & 48 & 60 & 71 & 72 & 84 & 93 & 92 & 92 & 92\end{array}$ $\begin{array}{llllllllllllllllllllllll}84 & 83 & 72 & 60 & 18 & 47 & 35 & 24 & 11 & 9 & 9 & 12 & 24 & 35 & 47 & 48 & 60 & 71 & 83 & 84 & 93 & 92 & 92 & 92\end{array}$ $\begin{array}{lllllllllllllllllllllllll}84 & 83 & 72 & 60 & 48 & 48 & 36 & 23 & 11 & 10 & 10 & 12 & 24 & 36 & 47 & 48 & 60 & 71 & 83 & 84 & 93 & 92 & 92 & 92\end{array}$ $\begin{array}{lllllllllllllllllllllllllll}84 & 83 & 72 & 60 & 47 & 48 & 36 & 23 & 11 & 11 & 11 & 11 & 24 & 36 & 47 & 48 & 60 & 71 & 83 & 84 & 93 & 92 & 92 & 92\end{array}$ 
two rows of the array represent the fill tube, so all the material-type numbers in these rows should be Number 95. The third row represents the tube-composite interface (bonded or. free) up to the liner outside surface. These material numbers should be Number 94 . The fill tube is fabricated from a forging and machined with a 0.750 -inch-diameter flange. The liner is welded to the flange. Since the fill tube material is as train-hardened version of the same aluminum in the liner, it has a different yield strength and is, thus, identified as a different material. The last three elements in each row represent the liner or fill-tube flange. Then, in the first 10 rows (to the flange edge) the last three elements are Material Number 95. Liner material is Number 92, so the remainder of the rows are correct. The fourth row begins the filament-wound composite material. As mentioned, the composite material is numbered correlatively with the fiber orientation in the tangent plane. All the material types from 1 to 90 are oriented composite. Material Number 91 is the epoxy-resin component of the wound structure and is used to model any fiber voids which might occur in the pattern. These fiber voids are filled with the epoxy resin. The illustrated array shows 11 elements in the fourth row, 5 in the fifth row, and 2 in the sixth row that are resin filled. In this case, for a downwind followed by an upwind, the filling would be between the two winds. Therefore, the fourth, fifth, and sixth rows are edited to move the filled elements midway between the composite elements of the row.

The thickness profile is fed into the mesh-generation program along with other data to produce the node and element cards which describe the mesh. The polar section of the generated mesh for the first 20 rows of composite elements is illustrated in Figure 13. This drawing provides a closer view of the same general model shown earlier in Figure 12.

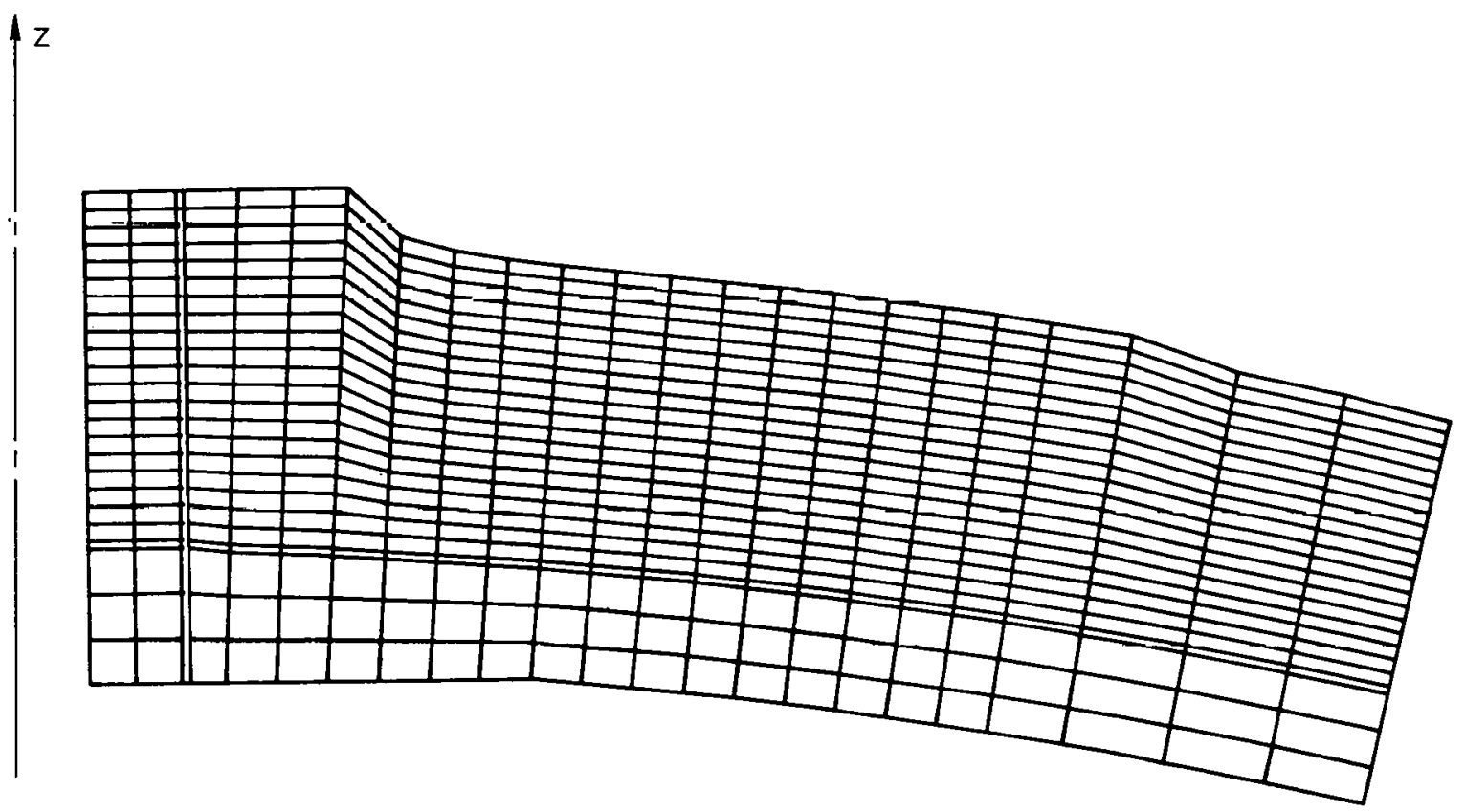

Figure 13. POLAR REGION OF THE 720A PATTERN MESH.

The composite-material property cards are generated in the transformation program. Material types from 1 to 90 are calculated and a set of cards are punched for input to the finite-element program. The composite material is " $\mathrm{S}$ " glass/epoxy resin with the following principal N-S-T direction properties when the fiber is in the T direction (property values in 
parentheses denote values used for an analysis of a "crazed" vessel): moduli of elasticity, $E_{N}=3.15 \times 10^{6}$ psi, $E_{S}=3.15 \times 10^{6}$ psi $\left(1 \times 10^{3}\right.$ psi for "crazed" material), and $E_{T}=8.60 \times 10^{6}$ psi. Poisson's ratios are: $\nu_{N S}=0.245(0.0), \nu_{N T}=0.090(0.090)$, and $\nu_{S T}=0.090$ (0.0); all shear moduli (GNS, $G_{N T}$, and $G_{S T}$ ), $0.95 \times 10^{6}$ psi.

Additional material cards are prepared by hand, including: the epoxy resin material, Type 91; the liner material, Type 92; the liner/composite interface material (bonded or incompressible fluid sliding), Type 93; the fill tube/composite interface (uncoupled), Type 94; and the fill tube material, Type 95.

The boundaries of all elements on the inside of the vessel are loaded with a pressure of 15 kpsi; the outside elements of the fill tube are loaded with a negative pressure of $4.894 \mathrm{kpsi}$. These pressures balance the axial thrust on the tube due to bore pressure, as described earlier.

The title card is prepared with the title: "Axisymmetric Shell - 90 degr. segment - 1.79 degr. opng. - 720A pattern". The control card specifies 2275 nodal points, 2160 elements, 95 materials, 116 boundary pressure cards, and 4 nonlinear material approximations. A partial listing of the program output is given in Appendix $F$. Where node or element numbers are not in sequence, the data have been omitted.

\section{Experimental and Analytical Results}

Stresses and deformations are computed for this eight-inch vessel based on "crazed" properties. The output from the program and results from experimental tests are compared.

In studying the finite-element results, the fiber-stress values are checked for peak values. As mentioned before, no combined stress-failure criteria have been incorporated in the program. Therefore, maximum stress or maximum strain values are the most practical method of assessment of the ultimate structural capability. In this case, the "crazed" material simulates a transversely failed condition, so the maximum fiber stresses are evaluated. This model has peak fiber stresses on the composite inner surface located at meridian angles from the polar axis of approximately 3, 24, and 90 degrees. The highest fiber stress occurs at the 3 degree location.

Using an ultimate fiber strength of $320 \mathrm{kpsi}$, the pressure capacity of this vessel is estimated. By linear interpolation, using the peak stress of $360 \mathrm{kpsi}$ at a $15-\mathrm{kpsi}$ internal pressure, the calculated burst pressure is $13.3 \mathrm{kpsi}$. This value compares very well with the experimental value. Several experimental vessels were pressure tested to failure. These tests gave an average burst pressure for this design of $13.850 \mathrm{kpsi}$.

In addition, the failure location in the experimental units may be discussed. In general, a post-failure observation does not indicate a precise location of the initial failure (sometimes not even an imprecise location). The majority of failed units did indicate failure near the fill-tube pole. This observation concurs with the maximum fiber-stress location.

The nodal-point displacements in the R-Z coordinate system are transformed to the N-S components. This transformation is shown in the partial program output listing in Appendix $\mathrm{F}$. The $\mathrm{N}$ component is in the radial direction of the sphere. 
Radial displacement is measured experimentally by a sweep-type gage operated at incremental values of internal pressure. The sweep gage rotates an arm around the part along a meridian from the fill tube. The arm carries a calibrated linear potentiometer which measures the radial displacement. The sweep data are compensated for any center shift of the unit on its mount during pressurization. The data are then reduced to a displacement profile. The experimental and analytical results for this vessel are plotted in Figure 14. As can be seen, the agreement is good and well within the range of variation of elastic-property values.

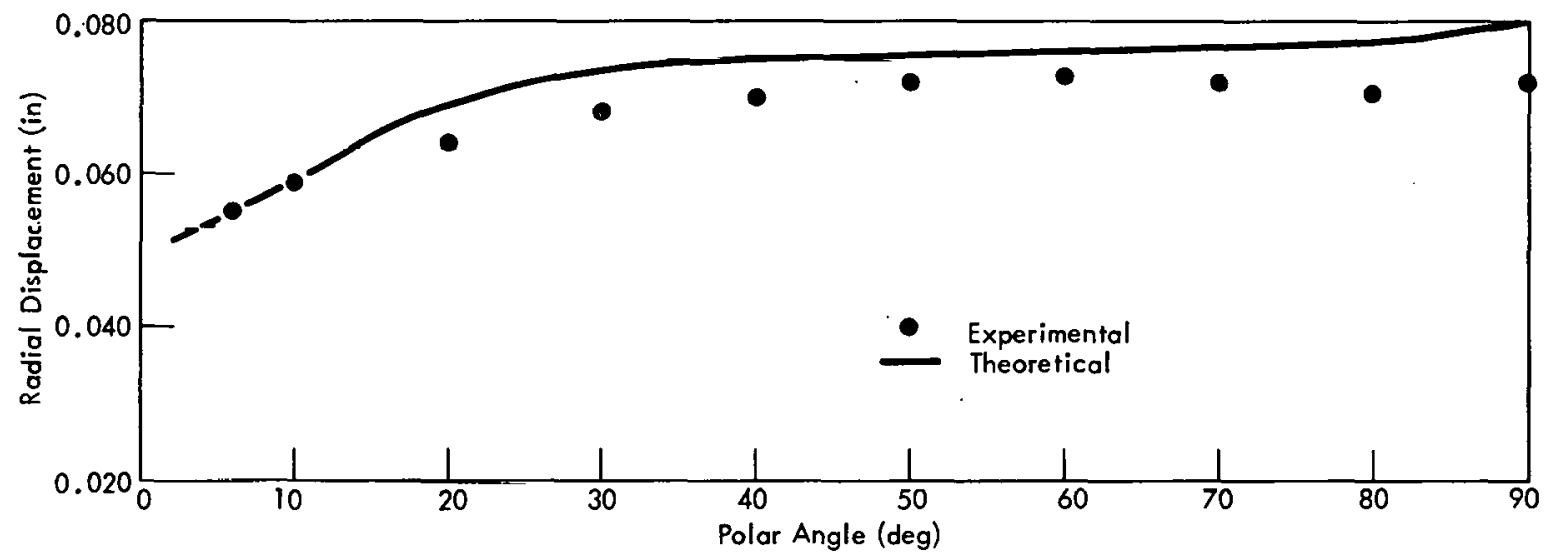

Figure 14. EXPERIMENTAL AND THEORETICAL RADIAL DISPLACEMENTS AT A 9000-pSi INTERNAL PRESSURE.

Additional results from the analysis reveal some interesting facts about the fill tube/composite interaction. The internal pressure is transmitted to the composite through the interface between the fill-tube-flange liner and the composite. The pressure is uniform over most of the sphere until the fill tube is approached. Near the fill-tube-flange outer diameter the pressure decreases and then increases again just across the flange/liner joint. The pressure builds up to approximately $20 \mathrm{kpsi}$ adjacent to the fill tube when the internal pressure is $15 \mathrm{kpsi}$. The pressure distribution in indicated in Figure 15.

One of the important considerations in: fabricating a vessel is the liner-to-composite bond. The purpose of the bond is to use the composite to prevent any defects in the liner from allowing local yielding and failure of the liner. This provision is especially important for thin liners. The analysis shows no significant stress on the bond over most of the sphere due to known discontinuities. The fill-tube flange area again has a different response. The shear stress builds up over this area to an elastic stress value of $10 \mathrm{kpsi}$ which, obviously, the adhesive cannot hold. Therefore, the fill-tube-flange area is most likely unbonded in all cases.

\section{Conclusions}

The following conclusions can be stated as a result of this study:

1. The finite-element method is well suited for an analysis of orthotropic composite material structures. The analytical results are reasonable even though the material properties vary greatly from element to element in a filament-wound structure. 


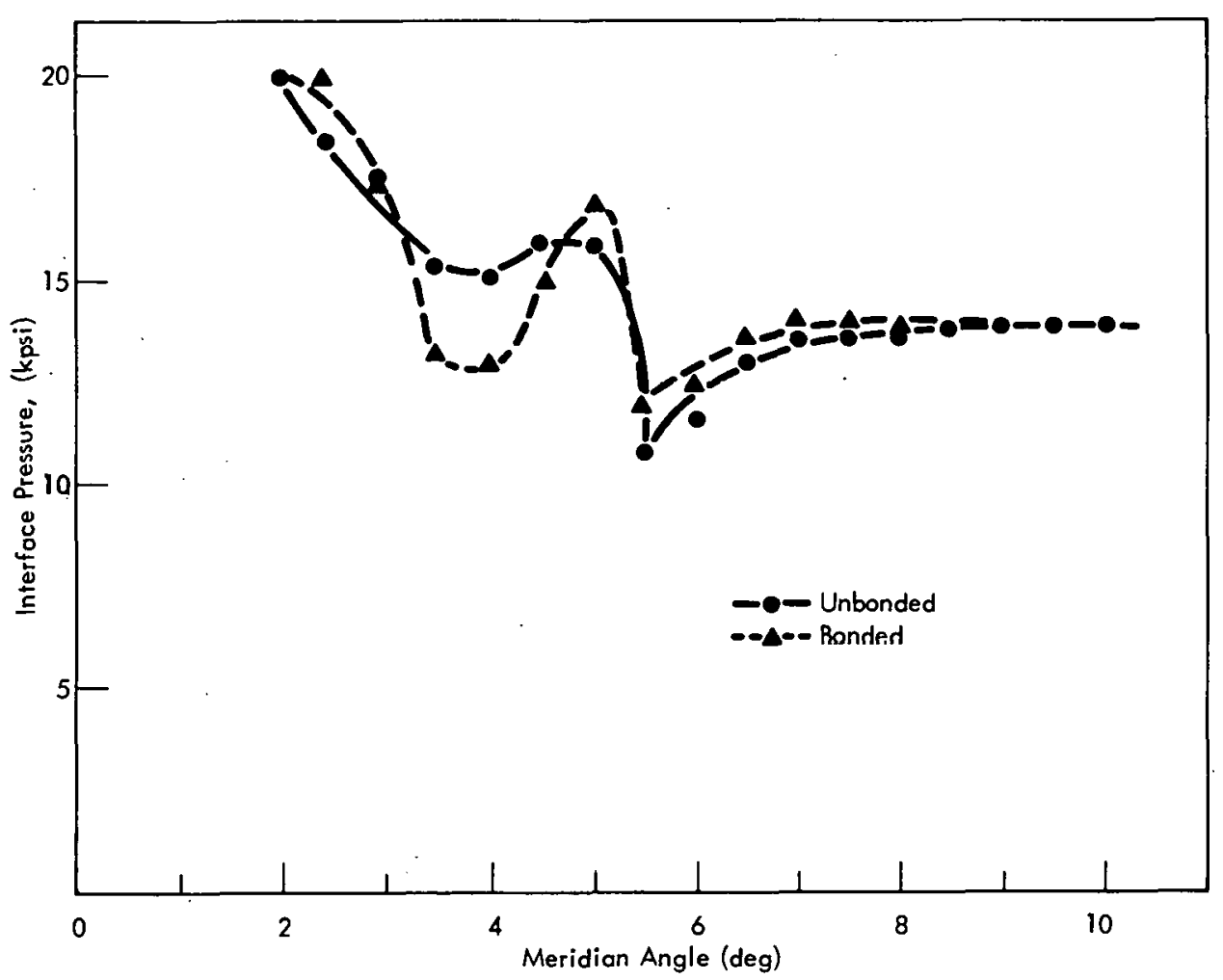

Figure 15. INTERFACE PRESSURE AS A FUNCTION OF THE POSITION. (AT $P=15 \mathrm{kpsi}$ ).

2. The material transformation producing "restrained" elastic properties correlates the data best for the case studied here. This observation indicates that even though the composite "crazes" (cracks parallel to the fiber under a transverse load), the layers remain bonded, thus preventing a "scissoring" of the layers.

3. Mathematical description of the pattern yields models which adequately describe the resulting structure with respect to layer thickness and fiber orientations.

4. Fiberglass-epoxy vessels may be analyzed by this program and produce reliable evaluations of a design. Pattern design could probably be optimized for a specific vessel although the case studied here was not optimized. An optimization of this case would likely result in less than a $10 \%$ increase in efficiency. 


\section{REFERENCES}

(1) Wilson, E. L.; "Structural Analysis of Axisymmetric Solids", AlAA Journal, 3, (12) pp 2269 - 2274; December 1965.

(2) Wilson, E. L. and Jones R. M.; Finite Element Stress Analysis of Axisymmetric Solids, Aerospace Corporation Report TR-0158, Air Force Report BSD-TR-67-228; September 1967.

(3) Tsai, S. W.; , Mechanics of Composite Materials, Part II - Theoretical Aspects, Technical Report AFML-TR-66-149; Air Force Materials Laboratory; November 1966. 


\section{APPENDIX A}

APPENDIX A

ORIGINAL PROGRAM INPUT INSTRUCTIONS

IDENTIFICATION:

ANALYS IS OF PLANE STRESS AND AXISYMMETRIC SOLIDS

(Programmed by E. L. Wilson, University of Callfornia, February 1967)

PURPOSE:

The purpose of this computer program is to determine deformations and stresses within axisymetric structures of arbitrary shape. The effects of displacement or stress boundary condition, concentrated loads, gravity forces and temperature changes are included. In addition, nonIInear material properties are Included by a successive approximation technique.

COMPUTER PROGRAM INPUT:

The first step in the structural analysis of an axisymetric solid is to select a finite element representation of the two-dimensional cross-section of the body. Elements and nodal points are then numbered in two numerical sequences each starting with one. The following group of punched cards numerically define the two-dimensional structure to be analyzed.

A. IDENTIFICATION CARD - (72H)

Columns 1 to 72 of this card contain information to be printed with results.

B. CONTROL CARD - $(415,3$ F10.2, I5).

$$
\begin{aligned}
& \text { Columns } 1 \text { - } 5 \text { Number of nodal points (900 maximum) } \\
& 6 \text { - } 10 \text { Number of elements ( } 800 \text { maximum) } \\
& 11 \text { - } 15 \text { Number of different materials (12 maximum) } \\
& 16 \text { - } 20 \text { Number of boundary pressure cards (200 max1mum) } \\
& 21 \text { - } 30 \text { Axtal acceleration In the z-direction } \\
& 31 \text { - } 40 \text { Angular velocity } \\
& 41 \text { - } 50 \text { Reference temperature (stress free temperature) } \\
& 51 \text { - } 55 \text { Number of approximations } \\
& 56 \text { - } 60 \mathrm{NPP} \quad\left\{\begin{array}{ll}
0 & \text { Axisymetric Prob. } \\
1 & \text { Plane Stress Structure }
\end{array}\right\}
\end{aligned}
$$


C. MATERIAL PROPERTY INFORMATION

The following group of cards must be supplied for each different material:

First Card - $(2 \mathrm{I} 5,2 \mathrm{~F} 10.0)$

Columns 1 - 5 Materials identification - any number from 1 to 12

6 - 10 Number of different temperatures for which properties are given - 8 maximum

11 - 20 Mass density of material

21 - 30 Rat1o of plastic modulus to elast1c modulus

Following Cards - One card for each temperature Axisymmetric property (plane stress property)

Columns 1 - 10 Temperature

11 - 20 Modulus of elasticity $-E_{r}$ and $E_{z}\left(E_{r}\right)$

21 - 30 Poisson's rat10 - vrz (vrz)

31 - 40 Modulus of elasticity - $E_{\theta}\left(E_{z}\right)$

41 - 50 Polsson's ratio - $v_{\theta r}$ and $\nu_{\theta z}\left(G_{r z}\right)$

51 - 60 Coefficient of thermal expansion $-\alpha_{r}$ and $\alpha_{2}\left(\alpha_{r}\right)$

61 - 70 Coefficient of themal expansion $-\alpha_{\theta}\left(\alpha_{z}\right)$

71 - 80 Y1eld stress - $\sigma_{y}$

D. NODAL POINI CARDS - $(2 \mathrm{I5}, 5 \mathrm{~F} 10.0)$

Ong card for earh nodal point with the following information:

Columens

1 - 5 Nodal point number

6 - 10 Number which Indicates if displacements or forces are to be specified

11 - 20 R - ordinate

21 - $30 \quad z$ - ordinate

$31 \cdot 40 \quad X R$

$41-50 \quad x 2$

51 - 60 Temperature 
If the number in column 10 is

0 XR is the specified $R-1$ oad and $X Z$ is the specifled $Z$-load.

$1 \mathrm{XR}$ is the specifled R-d1splacement and $X Z$ Is the specified $Z-10 a d$.

2 XR Is the spectfled R-load and $X Z \cdot 1 s$ the specifled Z-displacement.

3 XR is the specified R-displacement and $X Z$ is the specified 2-d1splacement.

All loads are considered to be total forces acting on a one radian segment.

Nodal point cards must be in numerical sequence. If cards are omltted, the omitted nodal points are senerated at equal intervala along a stralght line between the defined nodal points. The necessary temperatures are determined by linear interpolation. The boundary code (colum 10), $X R$ and $X Z$ are set equal to zero.

E. ELEMENT CARDS - (6I5)

One card for each element

Colums

$\begin{aligned} 1 & -5 \text { Element number } \\ 6 & -10 \text { Nodal Point } \mathrm{I} \\ 11 & -15 \text { Nodal Point } \mathrm{J} \\ 16 & -20 \text { Nodal Point } \mathrm{R} \\ 21 & -25 \text { Nodal Point } \mathrm{L} \\ 26 & -30 \text { Material Identification }\end{aligned}$

1. Order nodal points counterclockwlse around element.

2. Maximum difference between nodal point I. D. must be less than 27.

Element cards must be in element number sequence. If element cards are omitted, the program automatically. generates the omitted Information by Incrementing by one the preceding $I, J, K$ and $L$. The material identification code for the generated cards is set equal to the value given on the last card. The last element card must always be supplied.

Triangular elements are also permissible, and are Identified by repeating the last nodal point number (1.e., $I, J, K, R$ ). 
P. PRESSURE CARDS - (2IS, 1F10.0)

One card for each boundary element which is subjected to a normal pressure.

Columins 1 - 5 Nodal Point I

6 - 10 Nodal Point J

11 - 20 Normal Pressure

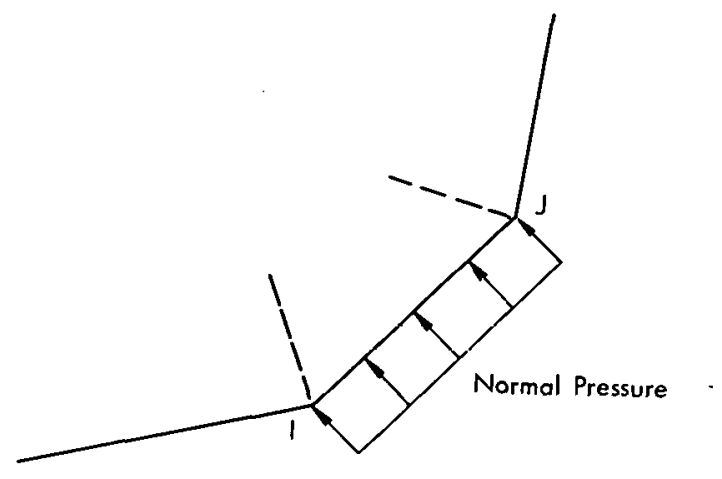

As shown above, the boundary element must be on the left as one progresses from I to J. Surface tensile force 18 input as a negat1ve pressure.

AUUITIUNAL KiEMARKS ON USE OF THE PROGRAM:

The previous sectim contains a schematic description of the program input. The purpose of this section $1 \mathrm{~s}$ to explain in greater detall the various options of the program.

A. OUTPUT INFORMATION

The following information 18 developed and printed by the program:

1. Reprint of input data

2. Nodal point displacements

3. Stresses at the center of each element

4. An approximate fundamental frequency. (The displacements for the given load condition are used as an approximate mode shape in the calculation of a frequency by Raleigh's procedure. A considerable amount of engineering judgment must be used in the interpretation of this frequency.) 


\section{APPENDIX B}

\section{APPENDIX B}

MODIFIED COMPUTRR PROGRAM INSTRUCTIONS

IDENTIFICATION:

ANALYSIS OF AXISTMMETRIC SOLIDS

(Programed by E. L. Wilson, Univeraity of Californ1a, February 1967;

Modifled Version 4, July 8, 1971, C. E. Knight, Jr.)

PURPOSE:

The purpose of this program is to determine the deformntions and stresses within a solid of revolution that is loaded axisymetrically and has an arb1trary cross-section and general axisymetric materlal properties. The program includes the effects if displacement, force, or pressure boundary conditions.

INPUT DATA:

The two-dimensional cross-gection of the solid is subdivided, by means of a network of straight lines, Into a number of quadrilateral (or triangular) elements. The elements and their assoclated (corner) nodal points are numbered in two numerical sequences each starting with one. The following cards define the problem to be analyzed.

A. IDENTIFICATION CARD - (72H)

Columns 1 to 72 contain the problem title and other information to be presented with the results.

B. CONTROL CARD - (5I5)

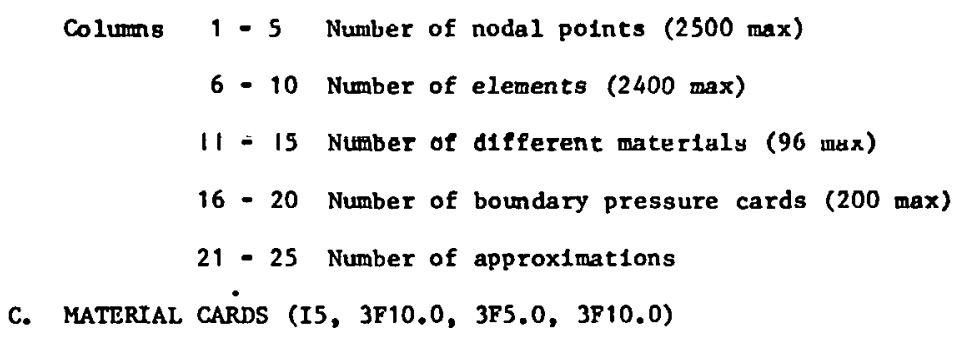

C. MATERTAL CARDS (I5, 3F10.0, 3F5.0, 3F10.0)

One card must be supplied for each different material. The cards do not have to be in order. 


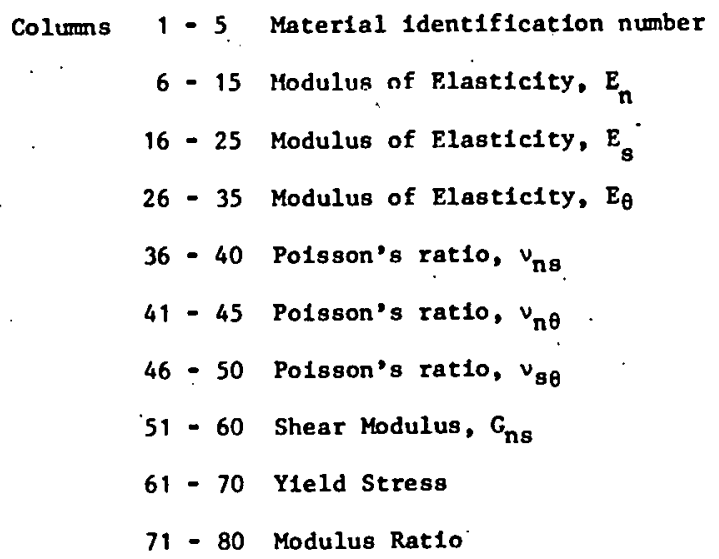

D. ELFMENT MATERIAL TYPES (24I3)

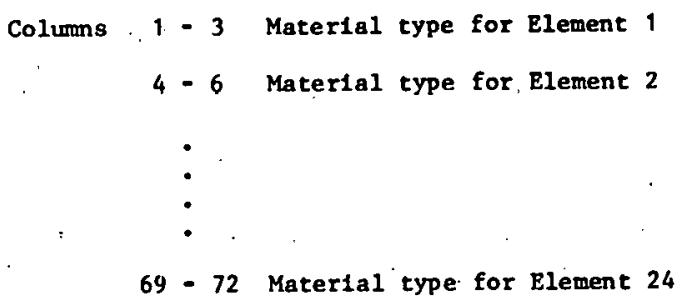

next card

-

- Material type for Element NUMEL

Material types are supplied for the elements in an array 24 wide. The number of cards needed 18 then NUEL/ $/ 24$ rounded up to the nesrest whole number. If the materlal type for Element $I$ is omitted then $\operatorname{IX}(I, 5)$ is set equal to $\operatorname{IX}(I-1,5)$. 
E. ELEMENT MATERIAL TRANSFORMATION ANGLES (24F3.1)

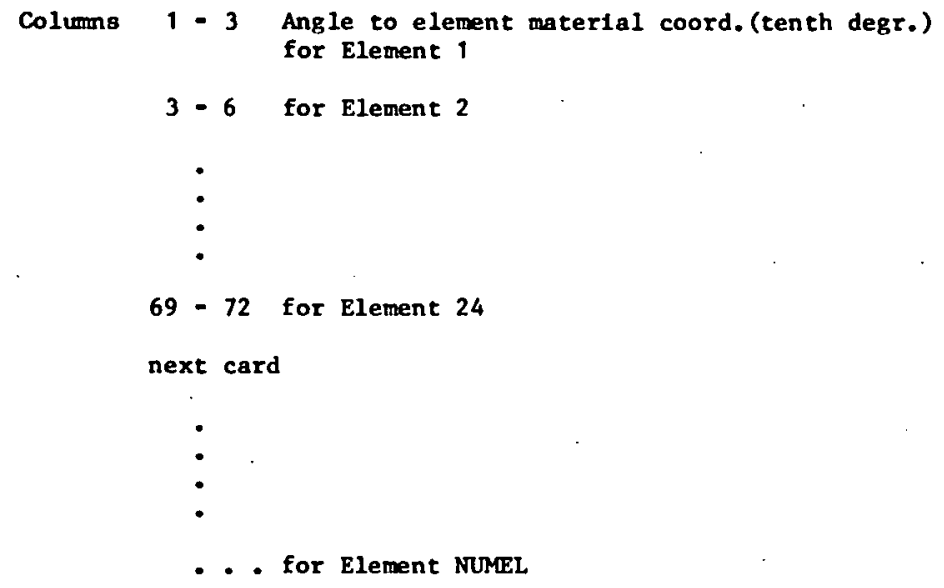

Transformation angles are supplfed for the elements in an array 24 wide. The number of cards needed 1s the NUMEL/24 rounded up to the nearest whole number. If the angle for Element I 18 omitted then WANG (I) is set equal to WANG $(I-1)$.

F. NODAL POINT CARDS (I5, F5.0, 4F10.0)

The nodal point cards must be numbered such that the maximum difference between the node numbers of any element is less than or equal to 26 (the maximum half band width).

The nodal point cards must be in numerical sequence. If nodal point cards are omitted the omitted points are generated at cqual Intervals along a stralght Ine between the defined nndal points. For the generated nodal points CODE (N), XR, and XZ (discussed below) are set equal to zero. The first and last nodal points must be supplied.

One card is supplied for each nodal point 1nput to the program. The card contains

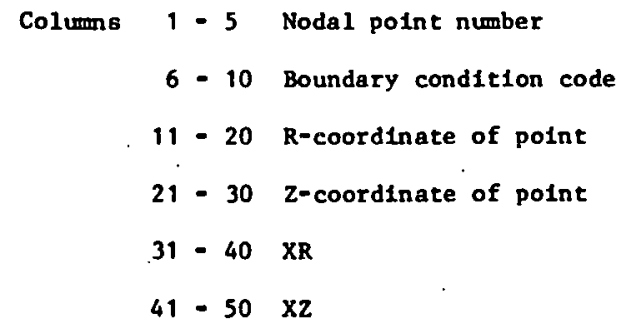




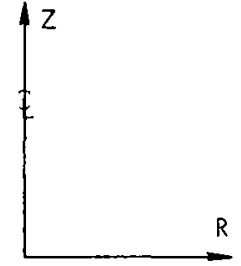

Global Coordinate

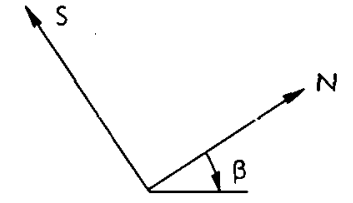

Material Coordinate

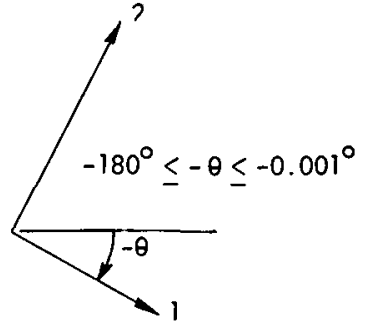

Boundary Coordinate

If the number in column 10 is:

0 then $X R=$ spectfied $R$ load

$X Z=$ specified $Z$ load

1 then $X R$ a specified $R$ displacement

$X Z$ - spectfied $Z$ load

2 then $X R=$ specified $R$ load

$X Z=$ specified $Z$ displacement

3 then $X R=$ specified $R$ displacement

$X Z=$ spectfied $Z$ displacement

If the number in colums $6-10$ of the nodal point card is negative it is interpreted as the magnitude of an angle in degrees. The angle of the skew boundary is shown above. The other parameters are then Interpreted as follows:

XR to the epertfied lnad in the 1-direction.

$X Z$ is the specifled displacement in the 2-direction.

(The output un Llie skew boundarice are interpretad as follows:

$U_{r}$ is the displacement in the 1-direction.

$U_{z}$ is the displacement in the 2-direction.)

Note: The speclfied boundary conditions must ellminate the possibility of a rigid body motion in the 2 direction.

The load data are interpreced to be the total forces acting on a one-radian segment of the solid. 
G. ELEMENT CARDS (5I5)

Element cards must be in numerical sequence. If any element cards are omitted the omitted data are generated by incrementing the preceding values of $I, J, K$, and $L$ by one. The materlal number and angle assigned to the generated elements is the same as that of the last element preceding the missing data.

An element is defined by listing its nodal point numbers in an order obtained by proceeding around the element in a counter-clockwise direction (for a right-handed coordinate system). A triangular element is denoted by repeating the last nodal point number (ie, I, J, K, K).

The flrse and lasc element must be supplied. The element card contalns:
Columens

$$
\begin{array}{r}
1-5 \text { Element Number } \\
6-10 \text { Nodal point I } \\
11-15 \text { Nodal point } \mathrm{J} \\
16-20 \text { Nodal point } \mathrm{K} \\
21-25 \text { Nodal point } \mathrm{L}
\end{array}
$$$$
6 \text { - } 10 \text { Nodal point I }
$$

H. PRESSURE CARDS (2I5, F10.0)

One card must be supplied for each element edge which is subjected to a uniform normal pressure. The pressure is assumed to act on the edge of the element (which must be on the left as one progresses along the edge) fror nodal point I to nodal point J. A suction is input as a negative pressure.

The edge preesurc card contains

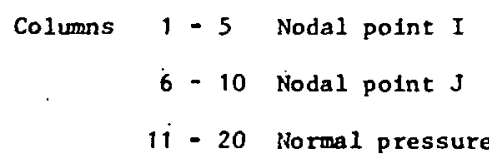

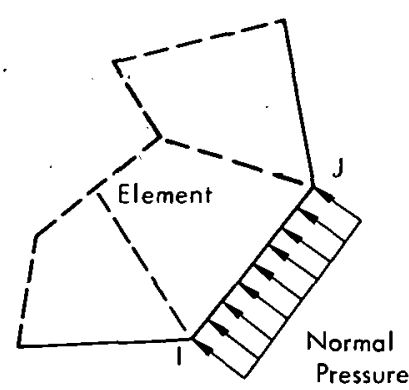


MODIFIED PROGRAM FORTRAN LISTING

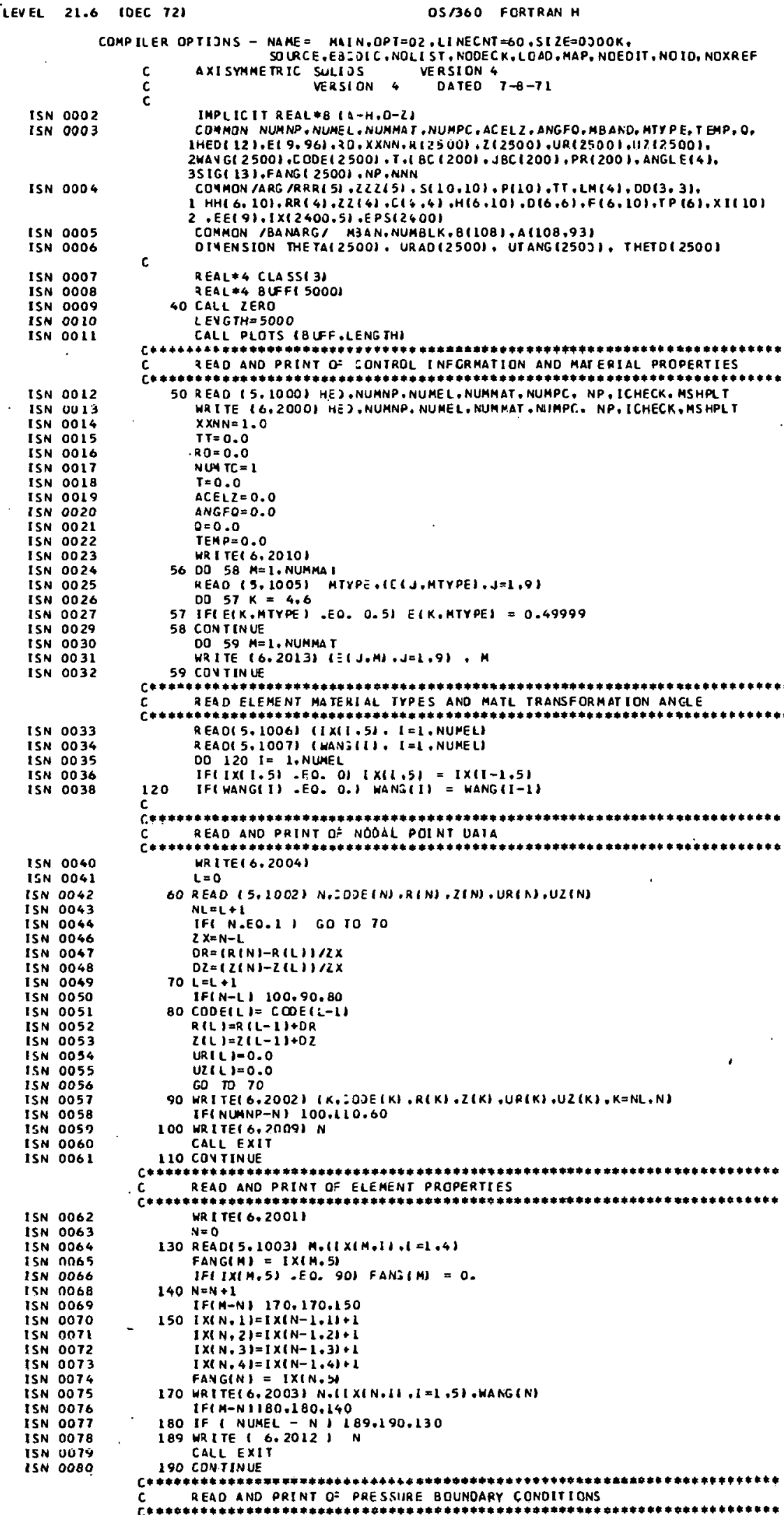

COMP ILER OPTIJNS - NAME $=$ MAIN,OP T=02, LINECNT $=60,5 I Z E=0500 \mathrm{~K}$. SOLRCE, EA:DIC, NOLI ST, NODECK, LOAD, MAP, NOEDIT, NO IO, NOXREF

ISN 0002 IMPLIC IT REAL*B $(4-H, 0-2)$

ISN 000

COAMON NUMNP. NUMEL . NUMMAT N NUMPC. ACELZ . ANGFO, MBANO, MTY PE, T EMP, $O$,

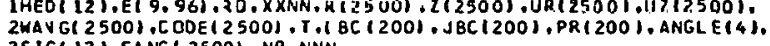

ISN 0004 COYMON AARG /RRR(5), Z2Z $251,5(10,10), P(10), T T, L M(4), 00(3,3)$, I HH(6, 10),RR (4), $22(4), C(;, 4), H(6,10), 0(6,6), F(6,10), T P(6), \times 1110)$ .EEI 91 . IX 12400.51 .EPS 126001

ISN 0005

ISN 0006

ISN 0007

ISN 0008

ISN 0009

ISN 0011 CINENSION THETAL 25001. URAD(2500), UTANG (2503), THETOI 25001

ISN 0012

ISN OUI3

ISN 0014

ISN 0015

ISN 0016

ISN 0017

ISN 0018

ISN 0019

ISN 0020

ISN 0021

ISN 0022

ISN 0023

ISN 0024

ISN 0026

ISN 0026

ISN 0027

ISN 0030

ISN 0030

ISN 0032

REAL*4 CLA SSI 3:

TEAL *4 BUFFI 5000

40 CALL ZERO LEVGTH $=5000$

CALL PLOTS IBUF. LENG THI

PEAD ANO PRINT O= CONTRDL I NFCRMATION AND MAT ERIAL PROPERTIES

50 READ $(5,1000)$ HE) , NUANP. NUMEL . NUMMAT, NUMPC, NP, ICHECK. MSHPL T WR I TE $(6,2000)$ HE 2 , NUANP, NUMEL, MUMMAT , NAIMPC. NP, ICHECK, MS HPL $X X N N=1.0$

$T T=0.0$

$R O=0.0$

NUM $T C=1$

$T=0.0$

$\triangle C E L Z=0.0$

$\triangle N G F O=0.0$

$P=0.0$

TERP $=0.0$
HR I TEC 6,20101

56 DO 58 M=1, NUMMAI

MEAO $(3,1005)$ MTYPE . (C T J, MTYPE), J $=1,9)$

DO $57 \mathrm{~K}=4.6$

57 IFI E(K,MTYPE) $-E O, 0.51$ E (K. MTYPE) $=0.49999$

58 CONTINUE

OO $59 \mathrm{M}=1$, NUMAA $T$

HRITE $(6,2013)(\equiv(J . M) . J=1,9), M$

59 COVTIN UE

READ ELEMENT MATERI AL IYPES AND MATL TRANSFORMATION ANGLE

REAO $(5,1006)$ (IXII,5), I = I, NUMEL

REAO 5,1007$)$ (HANBII), I =l, NUMEL)

OO $120 \mathrm{H}=1$. NLWEL

ISN 0034

ISN 0035

ISN 0036

ISN 0038

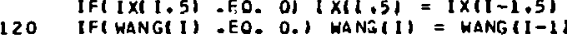

SN 0040

ISN 0041

ISN 0042

ISN 0043

ISN 0044

ISN 0046

ISN 0047

ISN 0048

ISN 0050

ISN 0051

ISN 0052

ISN 0053

ISN 0054

ISN 0055

ISN 0056

ISN 0057

ISN 0058

ISN 005T

ISN 0060

ISN 0061

ISN 0062

ISN 0063

ISN 0064

ISN 0065

ISN 0066

ISN 0068

ISN 0069

ISN 0070

ISN OOT

ISN 0072

ISN 0074

ISN 0075

ISN 0076

ISN 0076

ISN 0077

ISN 0078

ISN OOBO

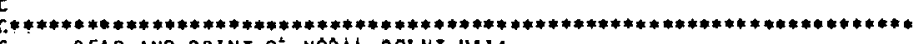

C READ ANO PRINT OF NOOAL POINT UAIA

KRITE $(0,2004)$

$M=0$
$L=0$

$60 R E A O(5,1002)$ N.:ODE (N) .R(N), $2(N), U R(N), U Z(N)$

$N L=L+1$

IFI N.EO.1, GO JO 70

$2 x=N-L$
$0 R=\ln (N)-1$

$O R=(R I N)-R(L)) / Z X$

$70 \begin{array}{ll}D \\ L=L+1\end{array}$

IF(N-L) 100.90 .80

80 CODEILI $=$ CODE $1 L-11$

$R(L)=R(L-1)+D R$

$2(L)=2(L-1)+02$

URI $L I=0.0$

$u z(C)=0.0$

Go 1070

90 WRITE(6,2002) (K, OOJE $(K), R(K), Z(K), U R(K), U Z(K), K=N L, N)$

IFINUANP-N I 100.410 .60

100 WRITE(6, 2009) N

CALL EXIT

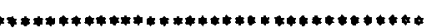

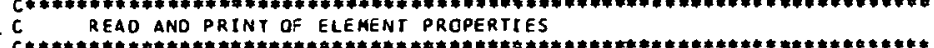
WR I TE 6.2001$)$

$N=0$

130 READ 5,1003$)$ M. $\left(1 \times 1 M_{0}, 11,1=1.4\right)$

FANGIM) $=I X(M, 5)$

(MANSIM) $=0$

$0 N=N+1$

IFIM-N) 170.170 .150

$1501 \times(N, 1)=1 \times(N-1,1)+1$

$1 \times(N, 2)=1 \times(N-1,2)$.

$1 \times(N, 3)=1 \times(N-1,3)$.

$\mid X(N, 4)=1 \times(N-1.4)+$

FANGIN $|=| X|N, S|$

170 WRITE $(6,2003)$ N.1I XIN, I1, I =1, 5), HANG IN)

IFI $H-N \mid 180,180,140$

180 IF ( NUMEL - N, 189.190 .130

189 WRITE I 6.2012, N

CALL EXIY

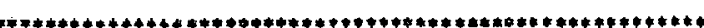

C READ AND PRINT O= PRESSIURE BOUNDARY CONDITIONS

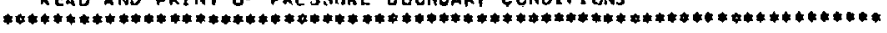


IFINUMPC) 290.310 .290

290 WR T TE $(6,2005)$

DO 300 L $=1, N U M P C$

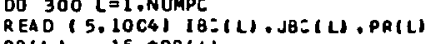

PR(L) $=15 . * P R(L)$

ISN 0087

300 NRITE(6,2007) IB:(L).JB:IL),PRIL)

$c$

CONTINUE

ISN 0088

ISN 0090

ISN 0091

ISN 0092

ISN 0093

ISN 0094

ISN 0096

ISN 0097

ISN 0098

ISN 0099

ISN 0101

ISN 0102

ISN 0103

ISN 0104

ISN 0105

ISN 0106

ISN 0107

ISN 0108

ISN 0109

ISN 0111

ISN 0112

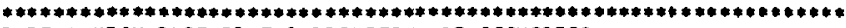
C PLOT A MESH,PLOT OF THE SEOMETRY, IF REOUESTEO.

C (N 1.N2) ARE FIR ST ANJ LAST ELEMENTS NUMBERS TO BE PLOTTEO

C: SCALE IS FACTOR TO NAKE VERTICAL OIMENSION TLE. 10.0 INCHES

C CLASS CONTAINS 0-12 TOLLERITH CHARACTERS. WRITIEN ON LEFT EOGE.

IF IMSHPLT.LE. OI SO TO 346

OO $345 \mathrm{M}=1 . \mathrm{HSHPLT}$

TEAO (5,1008) NI.NZ, SCALE, XO, YO.CLASS

CALL GROPL I INUMNP , NUMEL, NI, NZ , SCALE, XD, YD, HED,CLASS, IX, R, ZI

345 CON TINUE

c.

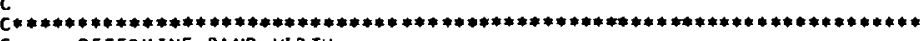

C DEIERMINE BAND WIOTH

$J=0$

DO $340 \mathrm{~N}=1$, NUMEL

DO $340 \quad I=1.4$

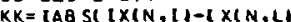

IF(KK-J) 325, 325.320

$320 J=K K$

325 CONTINUE

MBAND $=2 * J+2$

MBAN - MBAND SOL VE NON-LINEAR STRUETURE BY SUCCESSIVE APPROXIMAT IONS

DO 350 N=1, NUMEL.

350 EP SIN $)=0.0$

IF ( NP.EQ.O I NP $=$

, $D O 500 \mathrm{NNN}=1$. NO

C FORM STIFFNESS MATRIX

CALL STIFF

C SOL VE FOR OI SPLAEEMENTS

ISN 0113

ISN 0114
ISN 0116

ISN 0117

ISN 0117

ISN 0118

ISN 0120
ISN 0121

ISN 0122

ISN 0123

ISN 0124

ISN 0125

ISN 0126

ISN 0127

ISN 0128

$\begin{array}{lll}\text { ISN } & 0129 \\ \text { ISN } 0130\end{array}$

ISN OIBI

ISN 0132

ISN 0133

ISN 0134

ISN 0135

ISN 0136

ISN 0138

ISN 0139

ISN 0140

ISN 0141

CALL BANSOL

IFINNN .NE - NPI 50 TO 401

OO $400 i=1$. NUMNP

THETAII) = DATAN2 $(21\{1,, R(1)$

THE TOI I ) = THE TA( I $+\$ 57.29578$

URAD( $t)=B(2 * 1-1) *) \operatorname{COS}($ THETA(I)) + B(2*1)*DS IN(THETA(II)

400 UTANGI TI $=8(2 * 1 \rightarrow 13$ \#OSINT THETAII

WR ITE $(6,2006)(N, B(2 * N-1), B(2 * N)$, THETO(N), URAD (N),UTANG $(N)$, NE I,

INUMNP)

401 CONTINUE

C COMPUTE STRESSES

CALL STRESS

C 500 CONTINUE GO TO 40

**********************10

1002 FORMA T 155 F 500.4

DOO3 rORMA T 51 5I

1004 FORMAT I $215 . F 10.01$

1005 FORHAT I I I. 3F10.0. 3F5.0.3F10.0)

1006. FORHATI24131

1007 FORMATI24F 3.11

1008 FORMATI $215,3 F 10.0 .346)$

2000 FORMAT I 2 H 1 1246/

$130 H O$ NUHB ER OF NDOAL POINTS-- I4

3OHO NUMBER OF ELEMENTS---TSAR

3OHO NUMBER OF JIFF. MATERIALS- 13

3OHO NUMBER OF PRESSURE CARDS--- 13

3OHO NUAB ER OF APPROXIMA II ONS- 13

6 3OHO OA TA CHECK ONLY $(0=N O)=-13 \prime$

2001 FORMAT (58HIELEMENI NO. LGLE)

2002 FORMAT (112.F12.2.2F12.3.2E24.7)

2003 FORHAT I I13, 416 . 112 F9.11 F 2004 FORMAT 2004 FORMAT 9 THINOOAL. POINT TYPE R-OROINATE 2-ORCINATE R LO

2005 FDRMAT I 29HOPRESSURE BOUNDARY CONDITICNSI $24 \mathrm{H}$, J PRESS

2006 FORMÁT (12HIN.P. NUMBER $18 \times$ X 2 HUR $18 \times 2$ HUZ 15X 5HANGLE $16 \times$ 4HURAD

$115 X$ SHUTANG,$(1112$, SE20.6)

F 12.3

2009 FORMAT 126 HONODAL POINT CARD ERROR $N=151$

2010 FORMAT I $4 X$, SH E (N), BX, 4HE(S), BX, 4HE(T), 8X, 6 HNU(NS), $6 X$,

1 GHNUTNTI, 6X. GHNUTST), 6X. SHG(NS). $5 X$. 10HYIELD STR, $12 H$ MOD

2ATIO - IOH MATERIAL $i$ 
ISN 0144

$\begin{array}{ll}\text { ISN } & 0165 \\ \text { ISN } & 0146\end{array}$

ISN 0147
2011 FORAAT 11 THOMATERIAL NUMBER= 131

2012 FORMAT 2 HHOELEMENT EKROR FOR $N=$. 15

2013 FORMAT( $9 E 12.3$. $6 X$. (4)

END

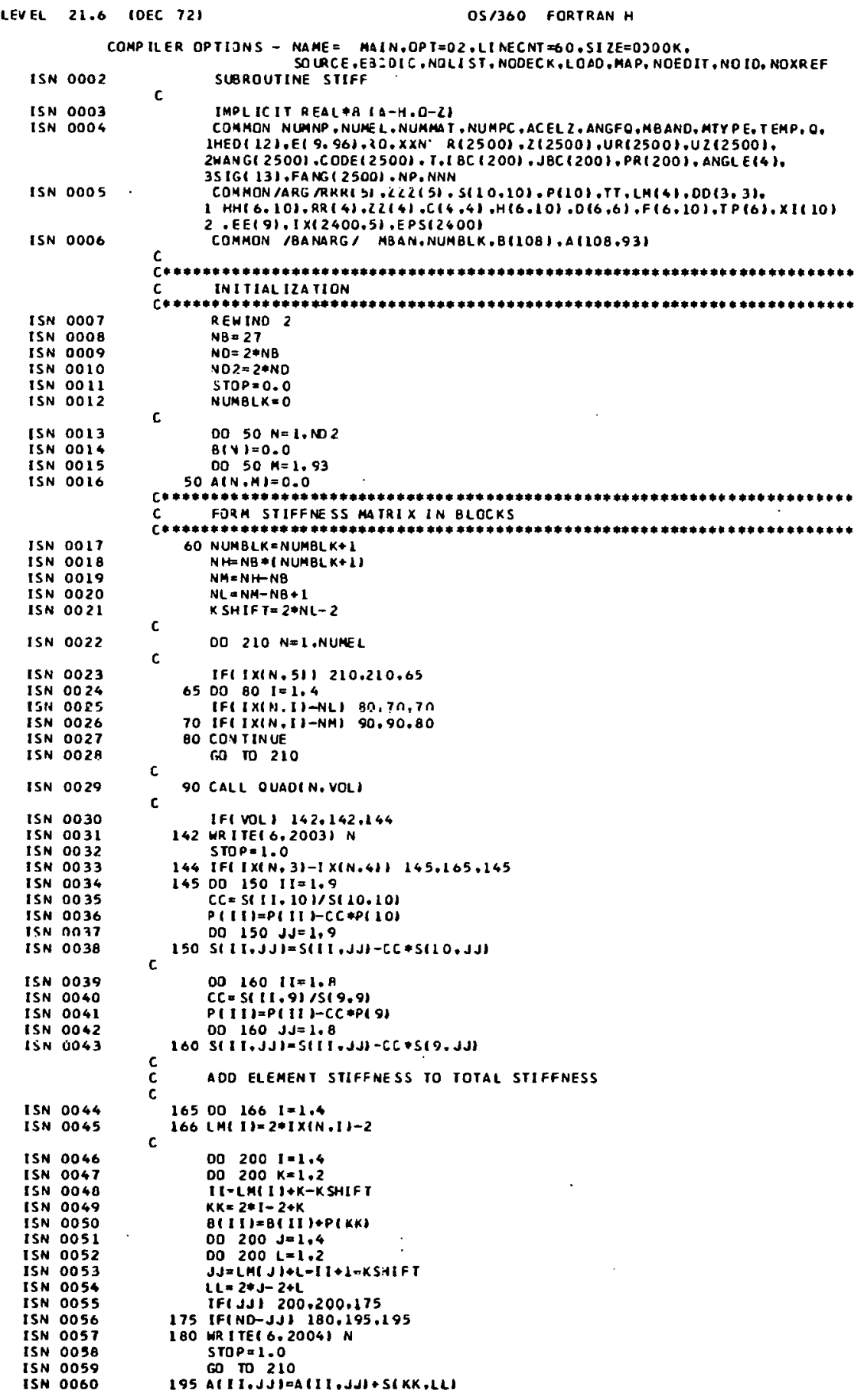

COMPILER OPTIJNS - NAME = MAIN,OP T=02, LI NECNT $=60$, SI ZE=0J0OK,

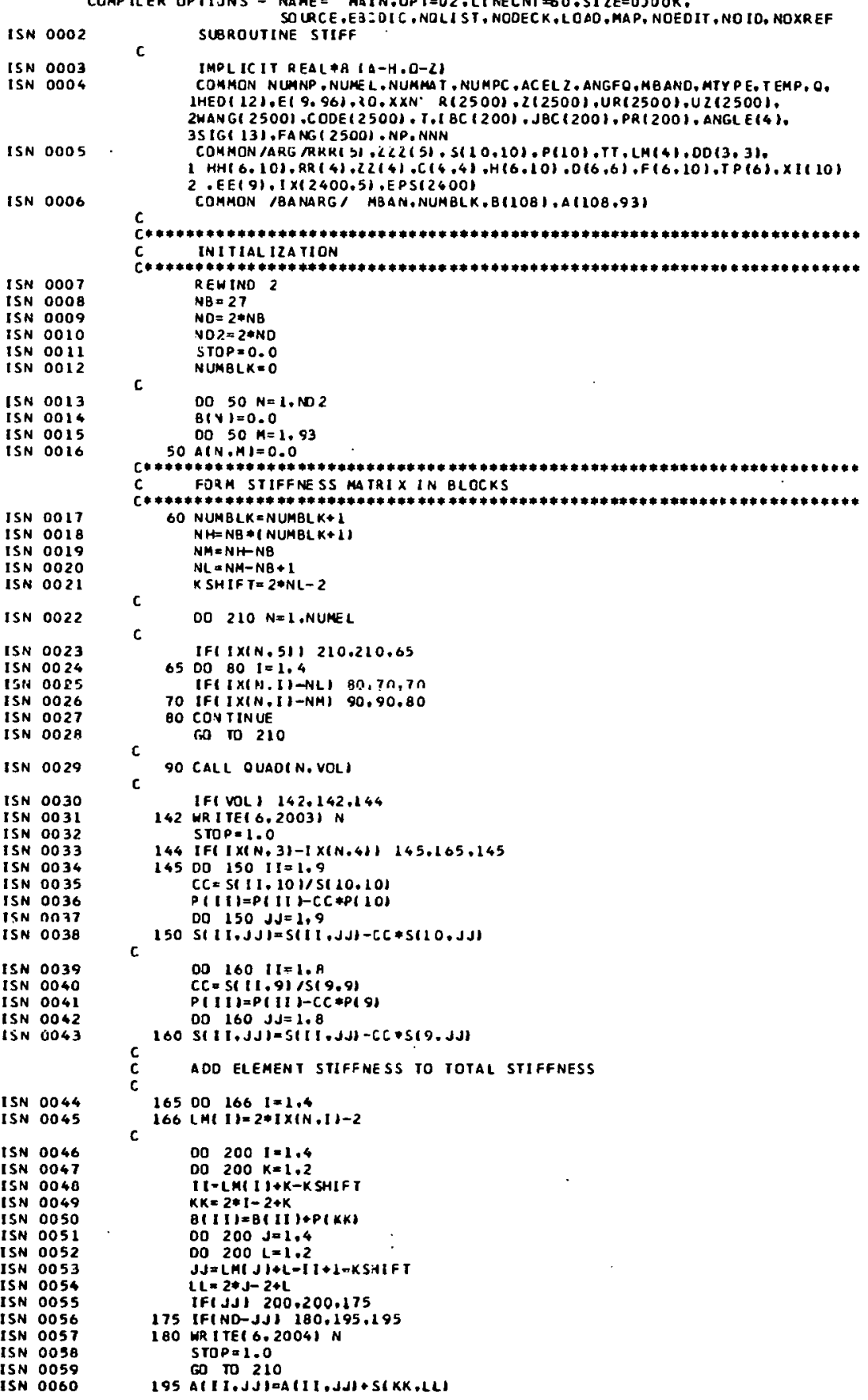




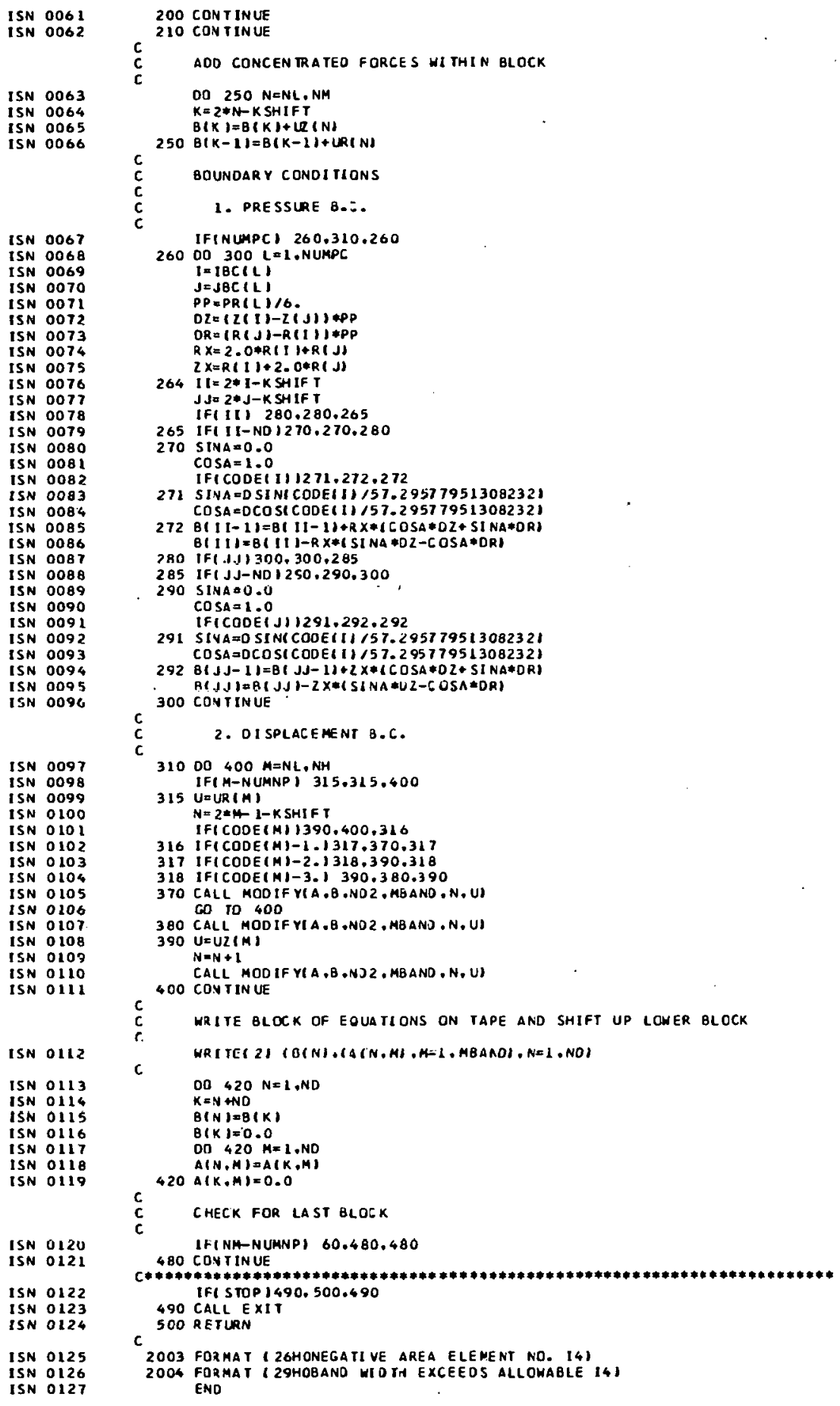




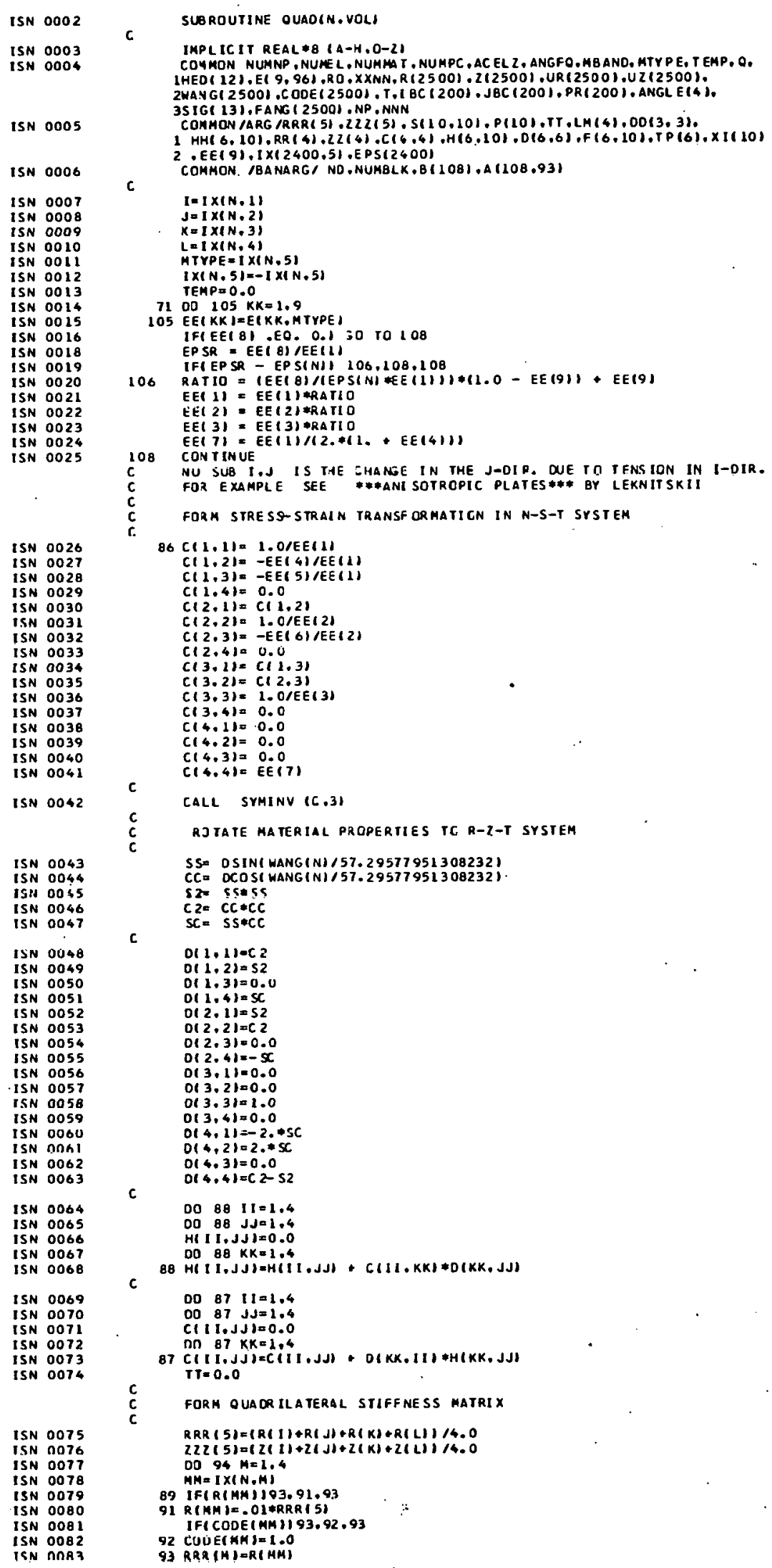


ISN 0084

ISN 0085

ISN 0087

ISN 008

ISN 0090

ISN 009

ISN 0092

ISN 0093

ISN 009

ISN 0095

ISN 0096

ISN 0097

ISN 0098

ISN 0099

ISN O10

ISN 0105

ISN 0107

ISN 010

ISN 0109

ISN 0110

ISN 0111

ISN 0112

ISN 0113

ISN 0114 $c$

$P(I)=0.0$

00 O5 $J J=1.6$

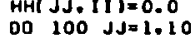

$100 \mathrm{~S}(1), J])=0.0$

DO 119 II $=1.4$

$J J=I X \mid N, I I\}$

119 ANGLE ( I i $)=$ CODE $(J J) / 57,29577951308232$ $\mathrm{VOL}=0.0$

120 CALL

CALL TRISTFI $1.2,3$ I

RRQ ( 5$)=(R R R I) 1+R R R(2)+R R R(3)) / 3.0$

$222(5)=(22211)+222(2)+222(3)) / 3.0$

$\mathrm{VOL}=\mathrm{X} 1(1)$

125 VOL $=0.0$

CALL TR I STFI 4.1.5)

CALL TRISTFI 1

VOL $=$ VLL $x$ IIII)

CALL $=$ VOL tXTYII

VAL $=$ VOL $* x 1111.3 .51$

VOL $=$ VOL $+X I 11$

VAL $=$ TRL $+x(1,1,1,4,5)$

$00.140 \quad I I=1.6$

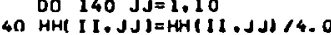

130 RE TURN

END

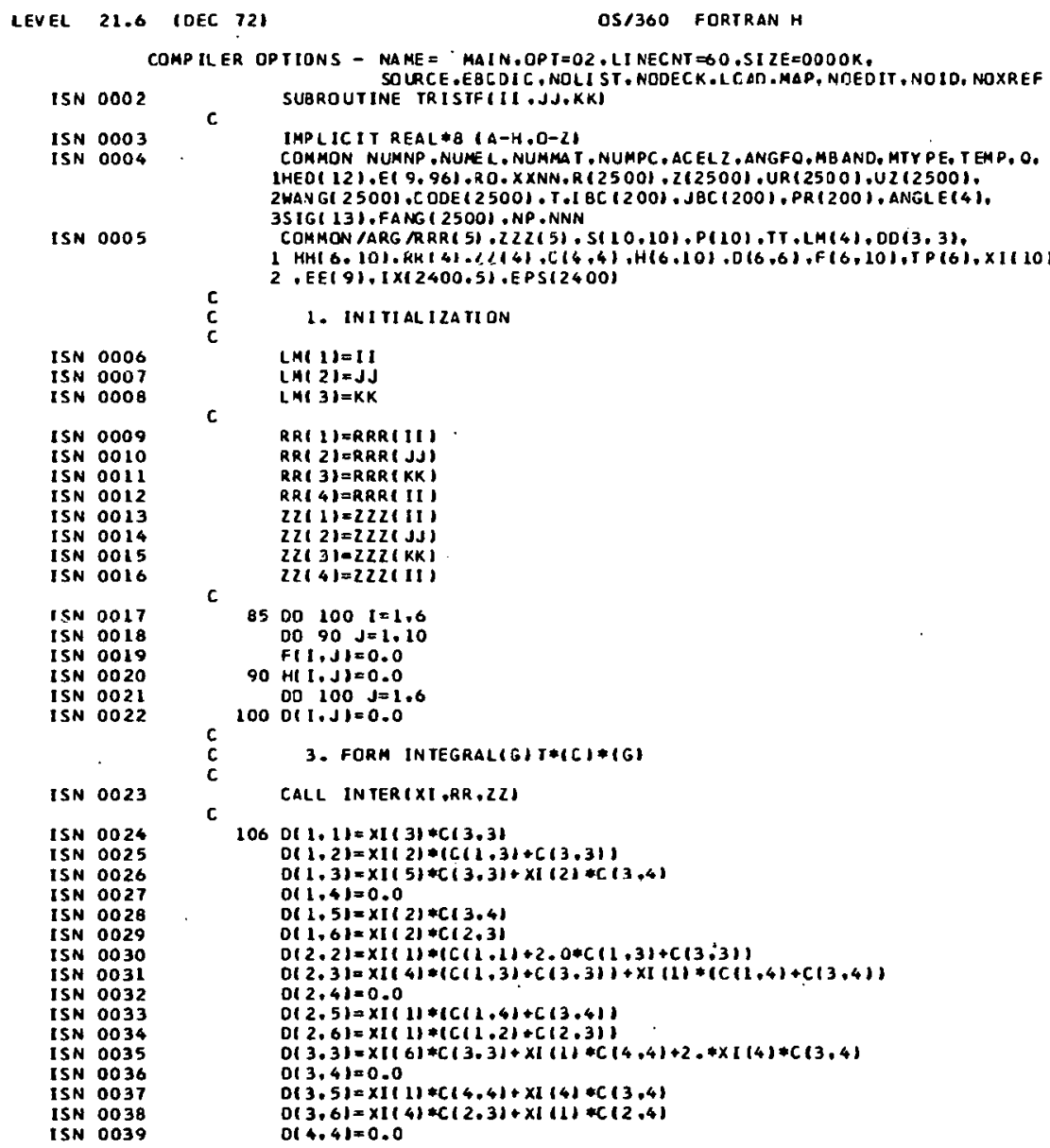

COMP ILER OPIIONS - NAME = MAIN.OP T $=02$, LI NECNT $=60.5 I Z E=0000 \mathrm{~K}$.

ISN 0003

IMPLICIT REAL $\# B$ (A-H,O-Z

COMMON NUNNP , NUMEL. NUMMA T . NUMPC, ACELZ , ANGFO, MB AND, MTY PE, TEMP, $O$.

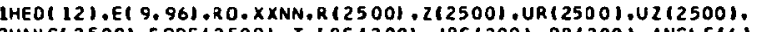
2HANGI 2500$)$. C ODE $(2500)$. T.1

ISN 0005 35IG(13).FAAG $(2500)$. NP. NNN

1 HHI 6, IOI. RK $141,1,161, C(6,4), H(6), 10), 0(6,6), F(6,10), 1$ P $(6), \times 1410)$

c . EE(9), $\{x(2400,5\}$. EPS $(2400)$

ISN 0006

ISN 000

IS 0008

ISN 0009

ISN 0010

ISN 0011

ISN OOI

ISN 0013

ISN 0014

ISN OOIS

ISN 0017

ISN 0018

ISN 0019

ISN 002

ISN 0022

ISN 0023

ISN 0026

ISN 002

ISN 0026

ISN 002

ISN 002

ISN 0029

ISN 0030

ISN 003

ISN 0032

ISN 0033

ISN 0034

ISN 0035

ISN 0036

ISN 0037

ISN 003$$
\text { 1. INITIALIZATION }
$$

LM( 1$)=I 1$

LAI 2 J $=$ J J

c

RR( I)=RRRIII)

RR( 2$)=R R R(J)$

$\operatorname{RR}(3)=\operatorname{RRR}(K K)$

RR ( 4$)=R R R$ ( II

$2211)=222111$

$22(2)=222(\mathrm{~J})$

$2214)=222(11)$

$8500100 \quad t=1.6$

DO $90 \mathrm{~J}=1.10$

$F(1, J)=0.0$

$90 \mathrm{H}(\mathrm{I}, J)=0.0$

00 i $100 \mathrm{~J}=1.6$

100 O (1,J) $=0.0$

3. FORM INTEGRAL(G) $I *([) *(G)$

CALL IN TER IXI, RR,ZZ)

$106 \mathrm{D}(1,1)=x 1(3) * C(3,3)$

$0(1,2)=x(1)=(C(1), 3)+(2,3)$,

$0(1,3)=x I(5) * C(3,3)+x((2) * C(3,4)$

$0(1,4)=0.0$

$D(1.5)=X I(2) * C(3.4)$
$0(1.61=x I(2) * C(2.3)$

$0(2,2)=x(1) *(C(2, \cdot 1)+2,0 * C(1,3)+C(3 * 3))$

$0(2,3)=x(14) *(C(1), 3)+C(3,3))+x[(1) *(C(1), 4)+C(3,4)$

$0(2,4)=0.0$

$0(2.5)=x I(1) *(C(1)+4)+C(3.4))$

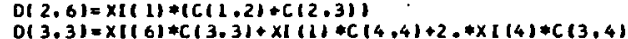

o( 3.3$)=x(1,1)$

$0(3,4)=0.0$

D(3,5) $=x(1) * C(4,4)+x(14) * C(3,4)$

$0(3.6)=\times 11$
$0(4.4)=0.0$ 

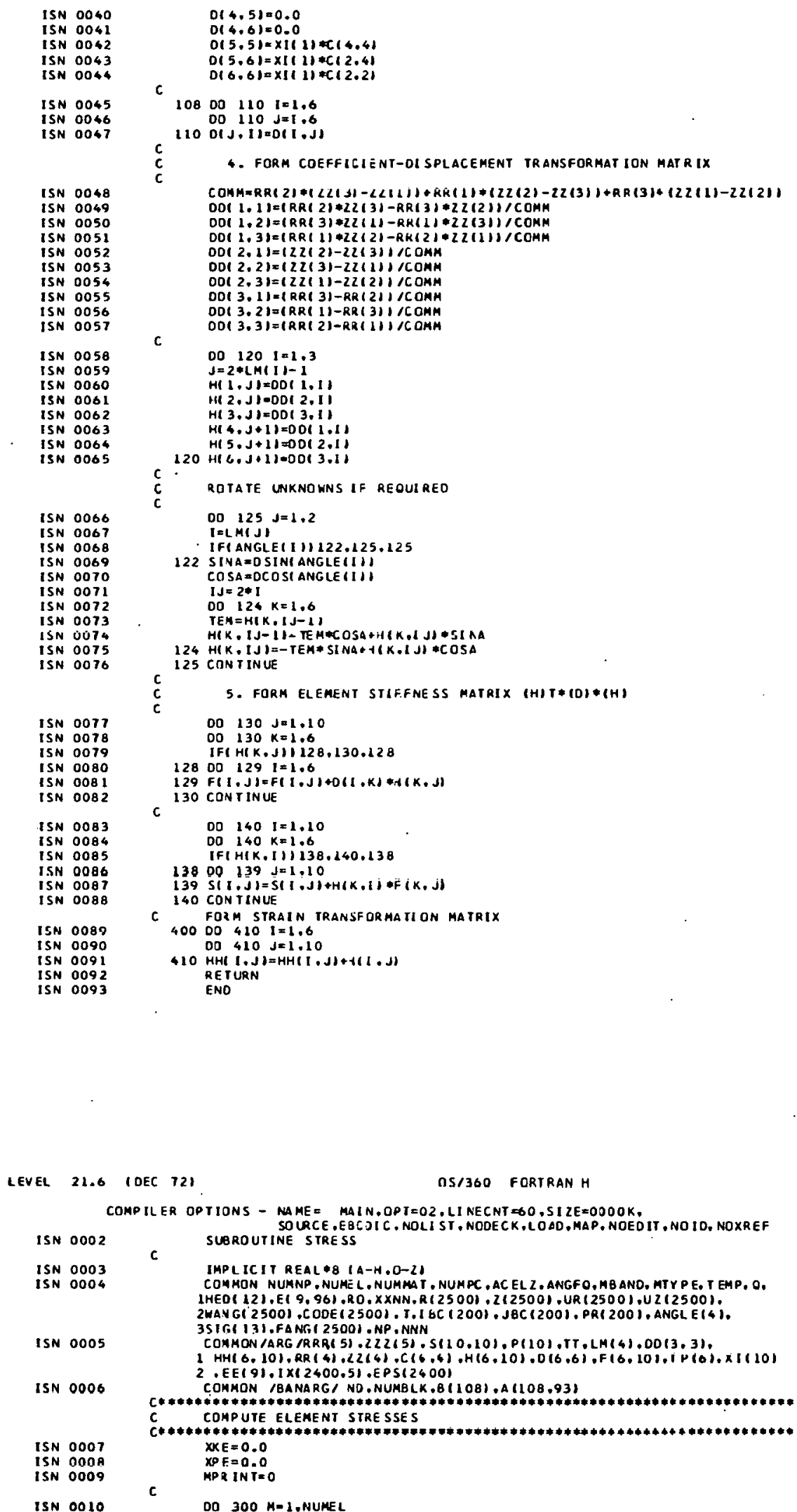


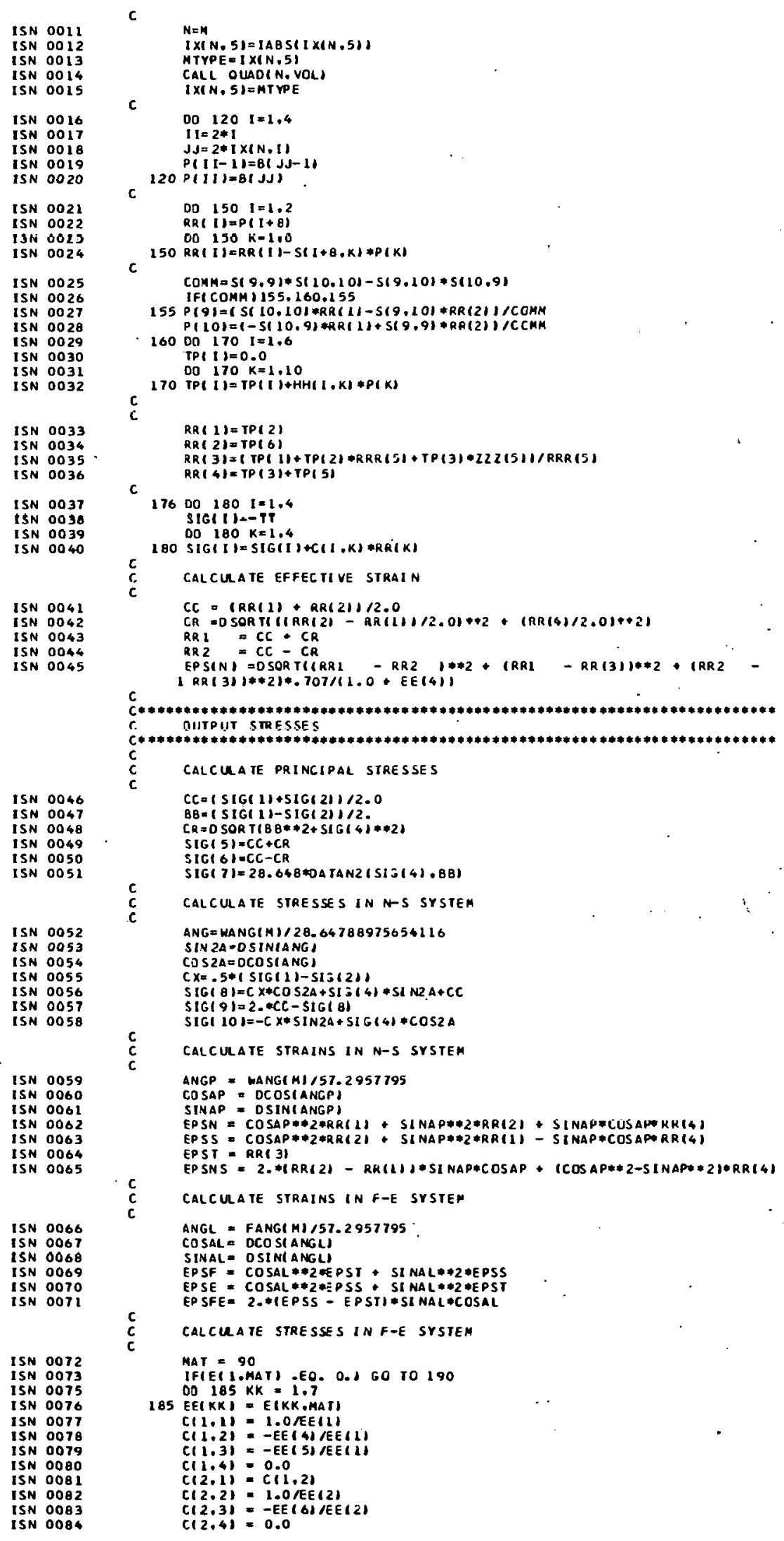




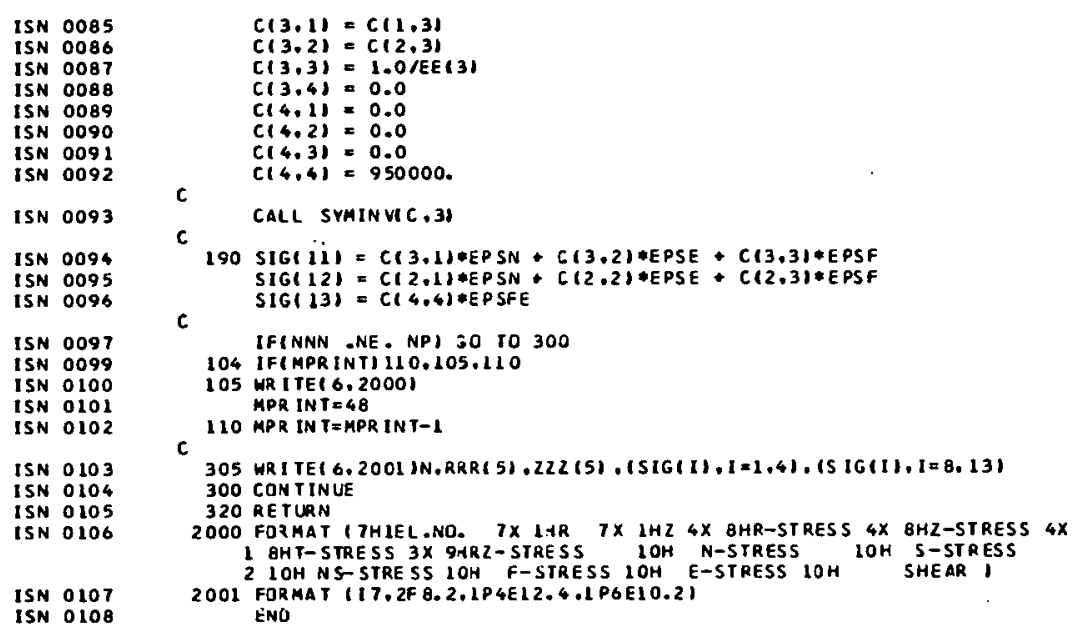

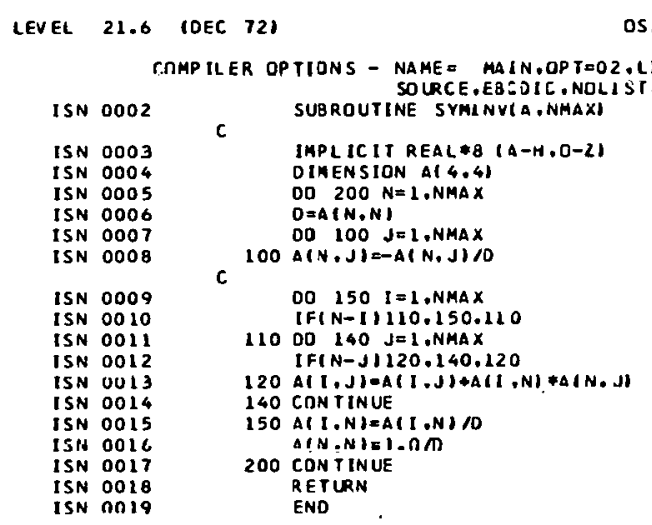

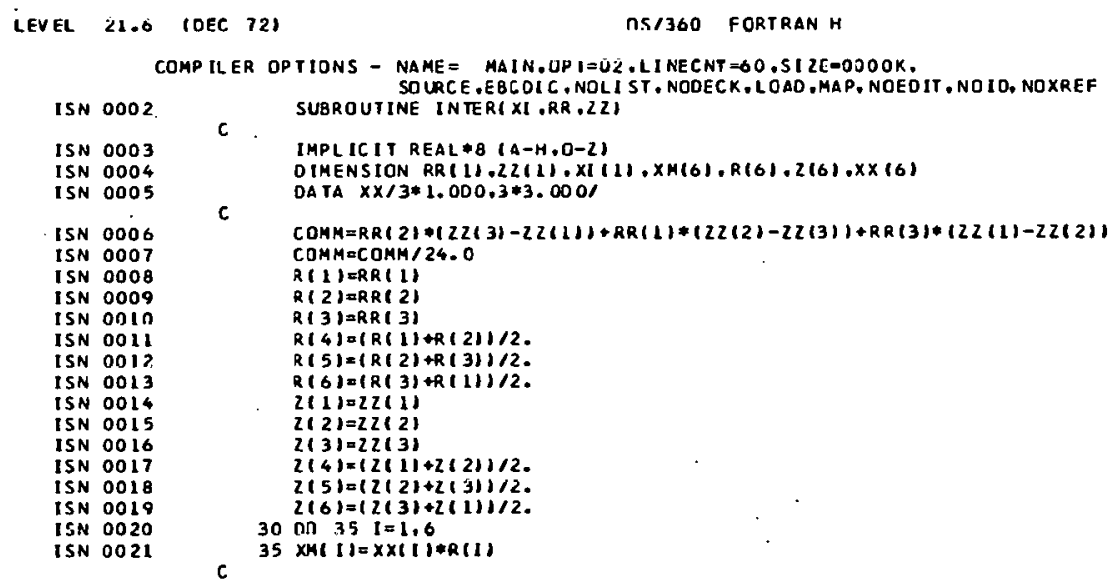

DA TE $74.248 / 04,45,03$

DATE $74.248 / 04.43 .11$ 

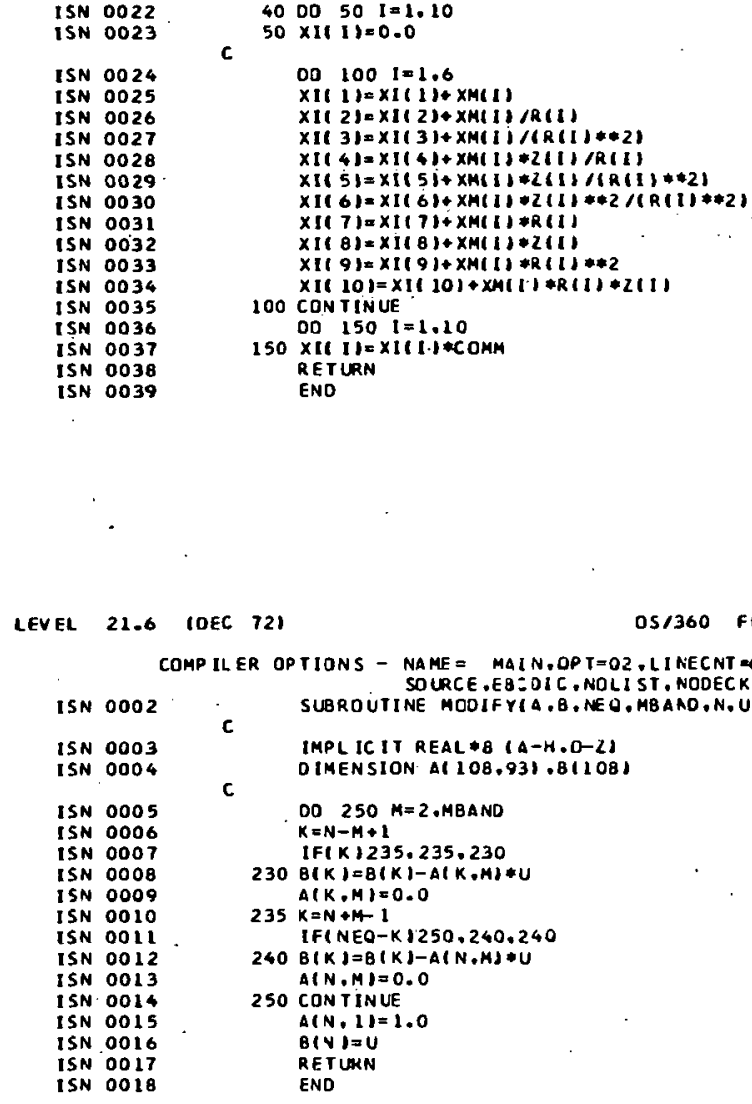

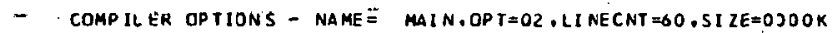

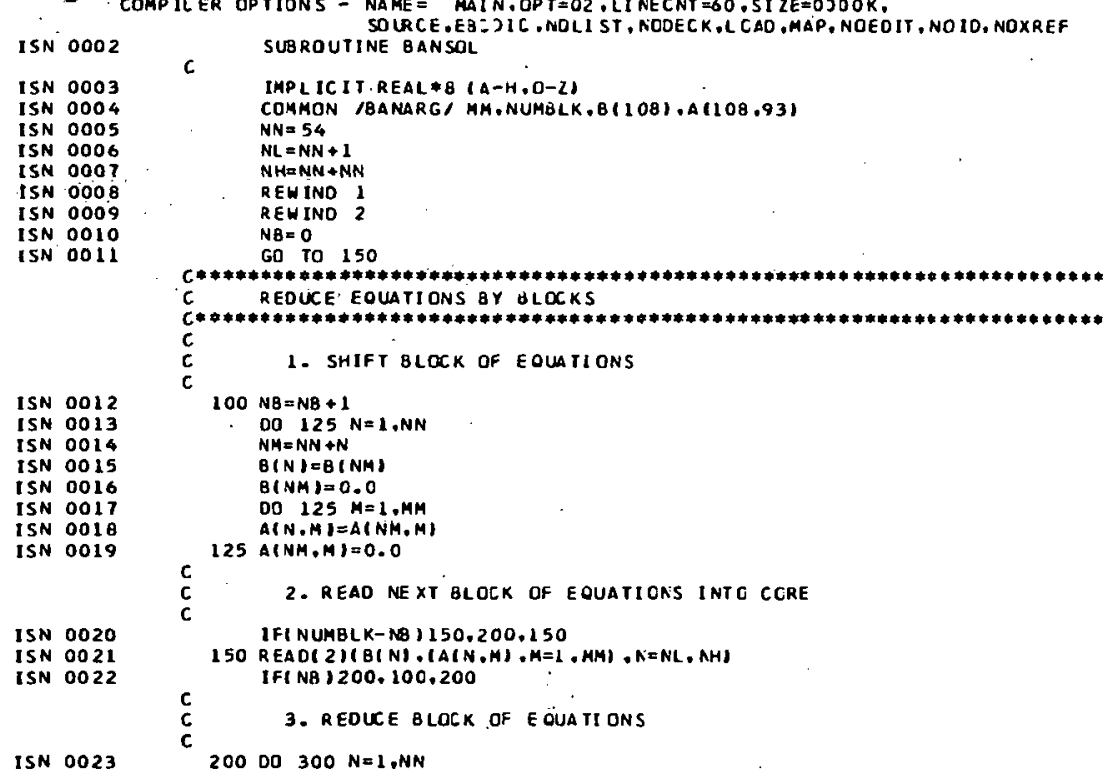


ISN 0023 ISN 0024 ISN 0025
ISN 0026

ISN 0027

ISN 0028

ISN 0029

ISN OOSO

ISN 0031

ISN 0033

ISN 0033

ISN 0034

ISN 0037

ISN 0037

ISN 0039

ISN 0040

ISN 0041

ISN 0042

ISN 0044

ISN 0046

ISN 0047

ISN 0048

ISN 0049

ISN 0050

ISN 0051

ISN 0052

ISN 0053

ISN 0054

ISN 0055

CALL SYMBOLI-1.0.4.0.0.105.CLASS(1),90.0.12)

CALL IDAYIOATEI

CALL SYMBOLI-1.0.6.0.0.105.DATE(1).90.0.8I

CALL SYMBOL $10.0 .0 .5 .0 .105 . \mathrm{HEO}(11.0 .0 .72)$

C**** PLOY THE ELEMENTS.

DO $200 \quad M=N 1 . N 2$

$I=\mid x(M, 1)$

$J=\{x(M+2)$

$R=1 \times 1 M, 3\}$

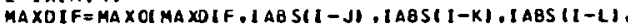

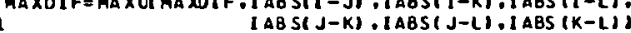

$L=4$

I ABS $(J-K) \cdot$ IABS $(J-L), 1$ ABS $(K-L)$

IF $(I X \mid M, 4), E 0.1 \times(M, 3)\} L=3$

IF IKLLTEI OR. K. $3 T$. NN GO 10200

$X P=S C A L E+(R I K)-X M(N)+X D$

GALL PLOT IXP, YP, 31

$00150 \quad I=1 . \mathrm{L}$

$X=1 X(M, I)$

IF (K.LT.I .OR. K.JT.NN) GO TC 200

$X P=S C A L E *(R(K)-X M I N)+X$

$Y P=S C A L E *(Z(K)-Y M(N)+Y O$

150 CONTINUE

WRITE $(6,2000)$ MAXDLF

2000 FORMATI OGRIO PLOI FINISHEO. MaXIMUM NODE OIFFERENCE HAS, $13 \%$,

CALL PLOT I17.0.0.0.03

END

LEVEL 21.6 IOEC 721

OS/360 FORTRAN H

DATE $74.248 / 04.45 .46$

COMP ILER OPTIONS - NAME = MAIN.OPI=02. LINECNT $=60,5 I Z E=0300 \mathrm{~K}$

ISN 0002

ISN 0003

ISN 0004

ISN 0005

ISN 0006

ISN 0007

ISN 0008

ISN 0009

ISN 0010

ISN 0011

ISN 0012

ISN 0013

ISN 0014

SLBROUTINE ZERO

IMPLICIT REAL $* B$ IA-H,O-Z

COMMON ZEROLI18805)

COMMON /ARG /2ERO21 87971

COMMON/BANARG/2ERO3(10153)

DO $I \quad I=1.18805$

1 ZEROLI(I) $=0.0$

DO $2 \mathrm{I}=1.8797$

2 ZERO2111 $=0.0$

OD $3 t=1.10153$
ZERO3(I) $=0.0$

RERO 3 (I) 


\section{APPENDIX C}

\section{DELTA PATTERN SIMULATION}

This program computes the helix angles and thickness for a delta-axisymmetric pattern. The band width is subdivided into 10 segments and the helix angles at the edge of each segment are computed along with the average thickness of coverage for each band segment as a function of meridional position. These data are used to determine the average helix angle of the material which is included in each element of a 20-element division of the total thickness. This set of 20 angles for each meridional position stimulates a complete shell produced by the delta-axisymmetric pattern. The order of the band data is the same as the fabrication sequence, thus providing the proper model for the shell. The program input and output is described below.

\section{Input}

I. Control data

\section{First Card}

Field (type)

$1-10(F)$

$11-20(F)$

$21 \cdot 25(1)$

$26-30(1)$

$31-35(1)$
MM

Variable

$\mathrm{R}$

TF

NBS

IOPT
Definition

Radius

Thickness factor $=$ thickness for one band

Number of band sets in the patterr to the limiting meri. dional position

Number of increments of meridional angle to the limiting meridional position. $(20 \leqslant M M \leqslant 90)$

Option on program output $=0$ gives helix angles on edges and thicknesses for each band segment. $=1$ computes average helix angle and thickness for each segment and determines element average helix angle in each element. A material array is generated for a 24-element thick shell. Four elements per position are used to describe the mandrel and interface. 


\section{Second Card}

Field (type) Variable Definition

$1-5$ (1) IB BAND SET NUMBER

6-10 (1) ISS Material stacking sequence within a segmented band $=1$, Material in band segment closest to axis of symmetry lies nearest the inside radius. $=2$, Material in band segment closest to axis of symmetry lies fartherest from the inside radius.

Additional cards as needed

These cards specify the stacking sequence for all band sets between the previous IB and the current IB. Normally ISS $=1$ for downwinds and ISS $=2$ for upwinds. IB on the last card must equal NBS.

Third Card
$1-5(1)$
$\operatorname{IP}(1)$
Integer value of position along the meridian.
0
0
0
0
$6-10(1)$
$41 \cdot 45$ (1)
IP(5)
$180 / \mathrm{M}$ gives the value of the meridional angular increment in degrees for the regjion up through IP(1)
Integer value of final position along the meridian. Must equal MM.
$46 \cdot 50$ (I)
$180 / \mathrm{M}$ gives the value to the meridional angular increment in degrees for the region between the preceding $I P(4)$ and $I P(5)$.

This third card specifies the element length in degrees along the meridian coordinate for regions along the meridian. Any of the five IP values may be equal to MM and the remaining data omitted if five regions are not needed. Thišallows a finer element grid in areas where desired. 
II. Band data

One card for each band set in order of wind sequence.

Field (type) Variable Definition

$1-6(F) \quad 01 \quad$ Angle between part axis and inner edge of band set in north hemisphere. If $00=0$ : Ol $=$ angle between part axis and center of band. If $N B=1: \quad$ Ol $=$ one half the band width angle.

$7 \cdot 12(F) .00$

$13-15(1)$

$16-18(1)$
NB

NI

Angle between part axis and inner edge of band set in south hemisphere.

Number of bands for full coverage of the equator.

Number of bands used in this band set. (If equal to NB does not need to be input.)

\section{Output}

I. Control data is printed out.

11. Band set output (one set for each band set)
A. Band data
B. If IOPT $=0$

1. Helix angles at each segment edge and average thickness coverage of each segment normalized to a total unit thickness for each meridional position.

C. If IOPT $=1$

1. Average helix angle for the material within the region of each element of a 20-element thickness for each meridional position. If the computed thickness does not cover all the elements, the remaining elements have material set at 91 .

III. Pattern simulation

A deck of cards is punched of the final material array, MATL (MM,24), after all band sets have been applied. This deck is used as input for the mesh generation program. Material types in columns 21 - 24 are used for the mandrel and interface elements. 


\section{APPENDIX D}

\section{MESH GENERATION PROGRAM}

I. Input Data

1. Total number of problems (15)

2.: The following set of data are used for each problem to be run.

A. Title, or description of problem $(72 \mathrm{H})$

B. Problem codes (9BI5)

Column $\quad 1.5$ Number of nodal point data cards ied

6. 10 Maximum number of rows in $\mid-J$ R....

11 - 15 Maximum number of columns in I-J plane, I max

20 Code for output of nodal points

$=0$ print

$=1$ print and punch

25 Code for output of quadrilateral elements

$=0$ print

$=1$ print and punch

30 Code for output of triangular elements

$=0$ print

$=1$ print and punch

35 Restriction of element type

$=0$ calculate both if col. 40 zero

$=1$ calculate quadrilateral elements only

40 Restriction of element type

$=0$ calculate both if col. 35 zero

$=1$ calculate triangular elements only

45 linear $=1$ gives eq. spaced mesh

C. Nodal Point Input Data 11 1, 12, 12, 2F 10.0, F5.0, 12, 2F 10.0, 12, $2 F$ 10.0). One card for each specified nodal point..

$\begin{array}{ccl}\text { Column } & 1- & \text { INTEST } \\ & 2-3 & \mathrm{l} \text {-coordinate } \\ 4-5 & \mathrm{~J} \text {-coordinate } \\ 6-15 \mathrm{R} \\ 16 \cdot 25 \mathrm{Z} \\ 26-30 \mathrm{CODE} \\ 31-32 \text { KDELTA } \\ 33-42 \text { RNEXT } \\ 43-52 \text { ZNEXT } \\ 53-54 \text { POLAR } \\ 55-64 \text { RSUBO } \\ 65-74 \text { ZSUBO }\end{array}$




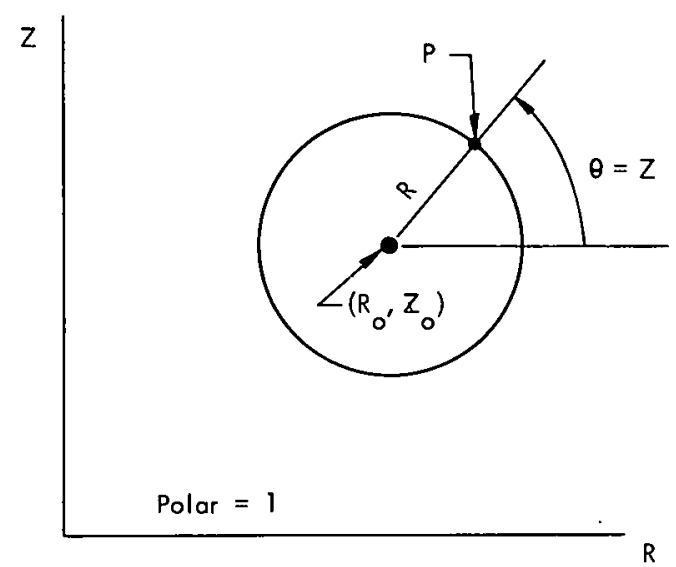

$P O L A R=0$ implies rectangular coordinates, so $R=$ cylindrical radius.

$Z=$ axial coordinates (RSUBO, ZSUBO are not used).

POLAR $=1$ implies polar coordinates relative to a circle whose center is at (RSUBO, ZSUBO). $R$ is the radius of the circle and $Z$ is the angle (in degrees) that a line from the center of the circle to the point in question makes with the R-axis.

II. Program Output

1. Problein number, and listing of input data.

2. Nodal Point Output - The program calculates the rectangular coordinates of every point and assigns a nodal number to each point.

A. Printed

Number of iterations required for given accuracy.

The following data is printed for each node: I, J-coords; R, Z-coords; nodal point number.

The above set ends with a statement giving the total number of nodal points.

B. Punched (if so desired)

The nodal points are punched in a format so that they can be directly used in Wilson's finite element code. The following data are punched for each nodal point:

Column

1 - 5 nodal point number (15)

100 (note, this is a boundary code)

11 - 20 R - coord. (F 10.4)

21 - $30 \mathrm{Z}$ - coord. (F 10.4)

$.38-40 \quad 0.0$ 
$48-50 \quad 0.0$

58. -600.0

3. Element Output Data - The following data are the output for the quadrilateral and/or triangular shaped elements.

A. The program prints the type of element, then lists (one line for each element) the element number, the I, J, K, and I nodal point numbers, and sets the MATERIAL equal to one.

B. The punched data (if used) is as follows (one card for each element):

$\begin{array}{rl}\text { Column } & 1-5 \text { Element number } \\ & 6-10 \\ 11-15 & \mathrm{~J} \\ 16-20 \mathrm{~K} \\ 21-25 \mathrm{~L} \\ 30\end{array}$




\section{APPENDIX.E}

\section{ORIENTED FILAMENT-WOUND COMPOSITE MATERIAL PROPERTIES SET.}

This program produces a data set for oriented orthotropic material with the material type identified by the integer values of the orientation angle. Properties of the unidirectional material are input. The transformation occurs around the $\mathrm{N}$ axis by angle beta from the $\mathrm{T}$ axis in the T-S plane.

\section{INPUT}

1 card - unidirectional properties (3F 10.0, 3F5.0, 3F 10.0, 15)

Columns $\quad 1-10$ Modulus of Elasticity, $E_{11}$ (fiber direction)

11- 20 Modulus of Elasticity, $E_{22}$ (transverse direction in tangent plane)

21 - 30 Modulus of Elasticity, $E_{33}$ (transverse radial direction) -

31 - 35 Poisson's ratio, $\nu_{12}$

$36 \cdot 40$ Poisson's ratio, $\nu_{13}$

41 - 45 Poisson's ratio, $\nu_{23}$

46- 55 Shear Modulus, $\mathrm{G}_{12}$

56 - 65 Shear Modulus, $\mathrm{G}_{13}$

66 - 75 Shear Modulus, $\mathrm{G}_{23}$

$76 \cdot 80 \cdot 10 P T=0$ "Restrained" Elastic properties

$=1$ "Free" Elastic Properties

\section{OUTPUT}

I. Input Data

II. Listing of the transformed data set

III. Punched data set for finite element program input 
APPENDIX F

PARTIAL PROGRAM OUTPUT

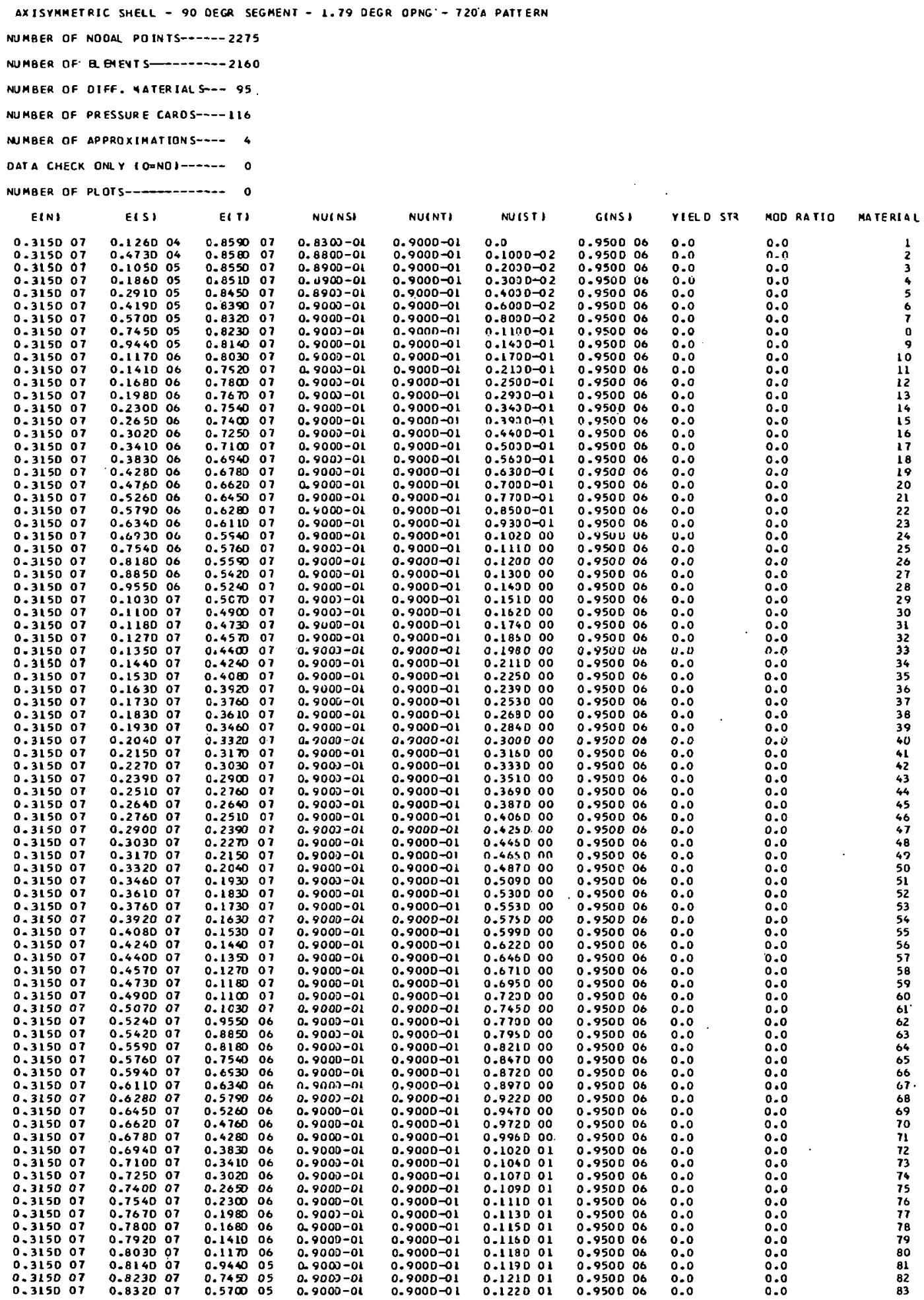




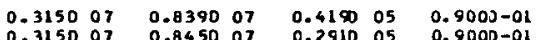
$\begin{array}{lllll}0.315007 & 0.845007 & 0.2910 & 05 \\ 0.315007 & 0.851007 & 0.1860 & 0.5\end{array}$ 0.315007 0.31500 0.315007 0.100008 $0.1000 \quad 03$ 0.1000
0.1000 $0.100003 \quad 0.860004$ $\begin{array}{lll}06 & 0.3500 & 00\end{array}$ $\begin{array}{lll}03 & 0.3300000\end{array}$

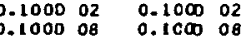
$9003-0$ (a) (a. 0.330000

$0.9000-01$ $0.8900-01$ $0.8900-0$ $0.0300=01$ 0.350000

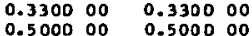
0.0

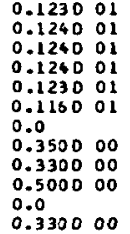

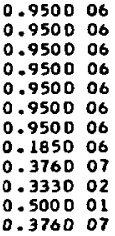
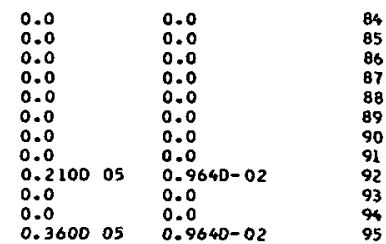

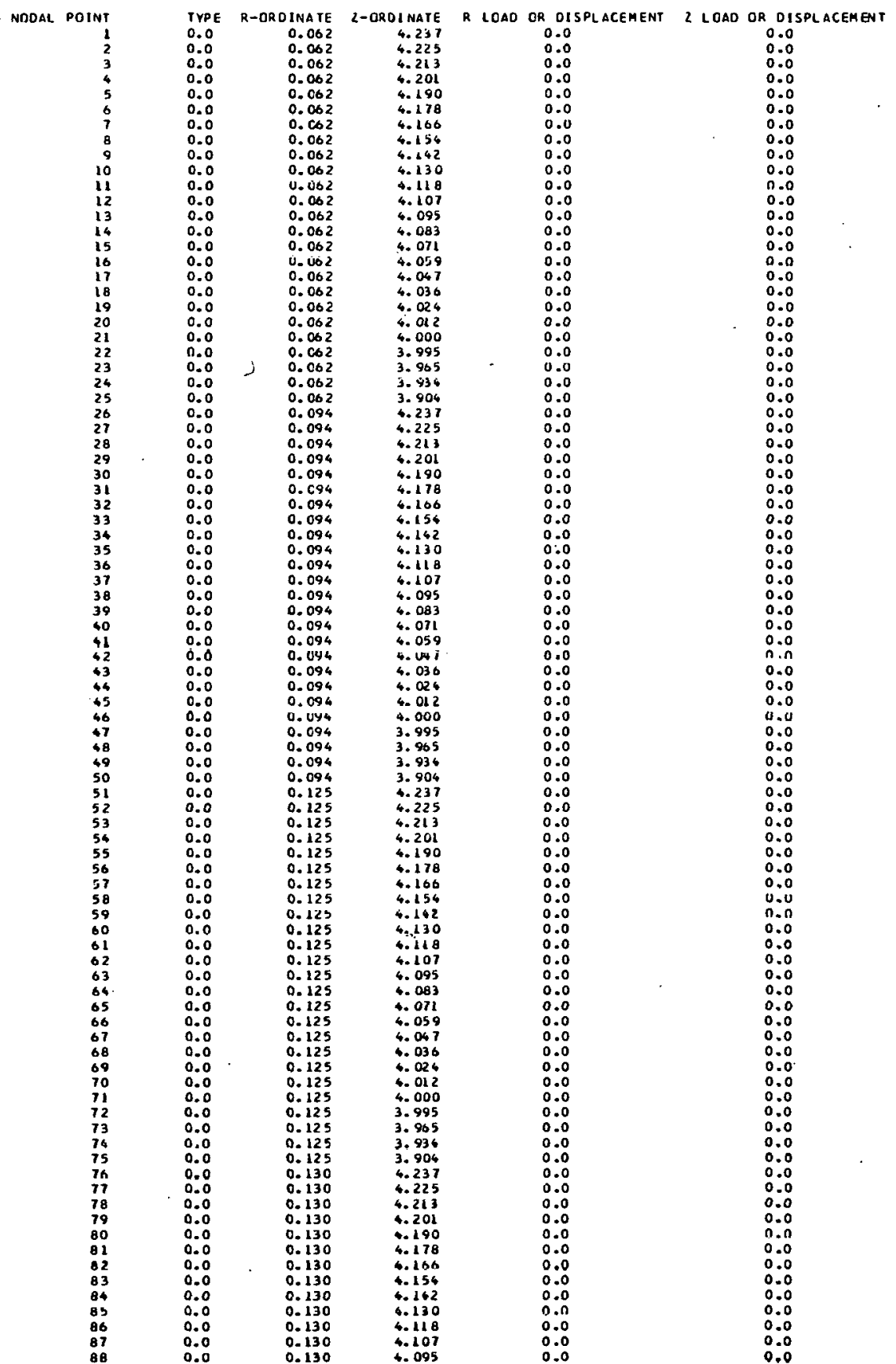




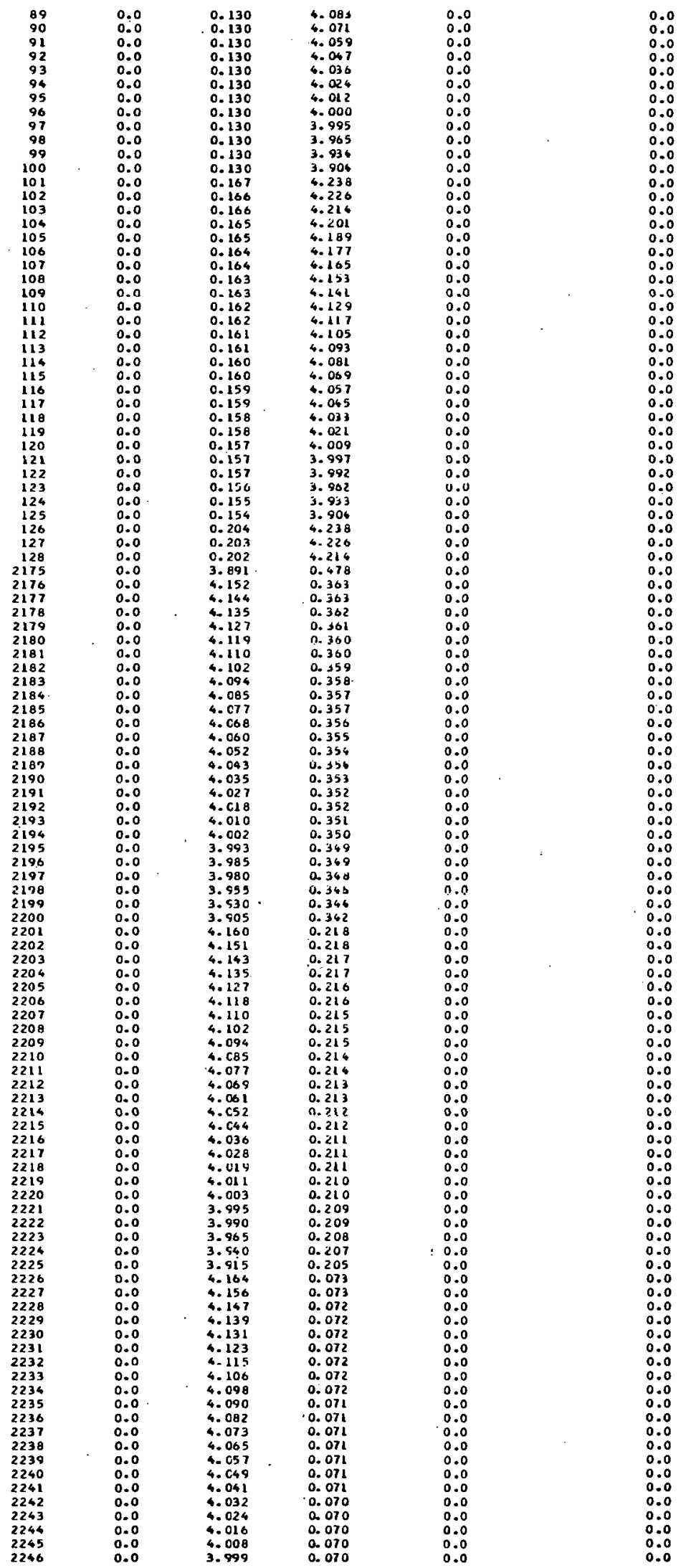




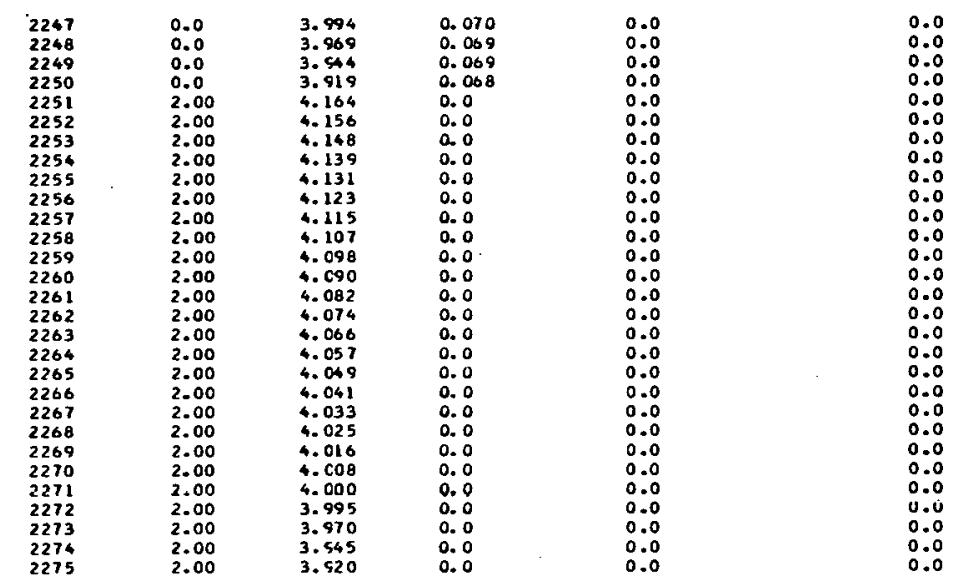


$2059 \quad 2144 \quad 2145 \quad 2170 \quad 2169$ $\begin{array}{lllll}2060 & 2145 & 2146 & 2171 & 2170 \\ 2061 & 2146 & 2147 & 2172 & 2171\end{array}$ $\begin{array}{lllll}2062 & 2147 & 2148 & 2173 & 2172\end{array}$ $\begin{array}{lllll}2063 & 2148 & 2149 & 2174 & 2173\end{array}$ $2064 \quad 2149 \quad 2150 \quad 2175$ 211 $2066.2152 \quad 2153 \quad 2178 \quad 217$ $\begin{array}{lllll}2067 & 2153 & 2154 & 2175 & 2178 \\ & 2156 & 218 & & \end{array}$ 208 215421552180 21179 2070 2156 2157 2182 218 $\begin{array}{lllll}2071 & 2157 & 2158 & 2183 & 218\end{array}$ $2073 \quad 2159 \quad 2160 \quad 2185 \quad 2186$ $207421602161 \quad 2186 \quad 2185$ $2075 \quad 2161 \quad 2162 \quad 2187 \quad 2186$ $2076 \quad 2162 \quad 2163 \quad 2188 \quad 2187$ 2078 2164 $2165 \quad 2190 \quad 2189$ $207921652166 \quad 2191 \quad 2190$ $\begin{array}{lllll}2081 & 2167 & 2168 & 2193 & 2192\end{array}$ $2082 \quad 2168 \quad 2169 \quad 2154 \quad 2193$ $\begin{array}{lllll}2083 & 2169 & 2170 & 2195 & 2194\end{array}$ $2084217021712196 \quad 2195$ $208521712172 \quad 21972196$ 2086 2172 2173 2190 2196

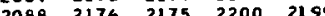
$\begin{array}{lllll}2009 & 2176 & 2177 & 2202 & 2201\end{array}$ $2090 \quad 2177 \quad 2178 \quad 2203 \quad 2202$ $\begin{array}{lllll}2091 & 2178 & 2179 & 2204 & 2203\end{array}$ $\begin{array}{lllll}2092 & 2179 & 2180 & 2205 & 2204\end{array}$ 2093 2160218022062204 2094 2101 $2102 \quad 2209 \quad 2205$ 2095 2182 $2103 \quad 2200 \quad 2207$ $2097 \quad 2184 \quad 2185 \quad 2210 \quad 2209$ $\begin{array}{llll}2098 & 2185 & 2186 & 2211 \\ 2210\end{array}$ $\begin{array}{lllll}2099 & 2186 & 2187 & 2212 & 2211\end{array}$ $\begin{array}{lllll}2100 & 2187 & 2188 & 2213 & 2212 \\ 2101 & 218 & 2189 & 2214 & 2213\end{array}$ $\begin{array}{lllll}2101 & 2188 & 2189 & 2214 & 2213 \\ 2102 & 2189 & 2190 & 2215 & 2214\end{array}$ $\begin{array}{lllll}2103 & 2189 & 2190 & 2215 & 211 \\ 2103 & 2191 & 2216 & 2215\end{array}$ $\begin{array}{lllll}2104 & 2191 & 2192 & 2217 & 2216\end{array}$ $210521922193 \quad 2218 \quad 2217$ $\begin{array}{lllll}2100 & 2193 & 2194 & 2219 & 2219 \\ 2104 & 2195 & 2220 & 221 & \end{array}$ $\begin{array}{lllll}2108 & 2195 & 2196 & 2221 & 2220\end{array}$ $\begin{array}{lllll}2109 & 2196 & 2197 & 2222 & 2221 \\ 2110 & 2107 & 2198 & 2223 & 2222\end{array}$ $\begin{array}{llllll}2110 & 2197 & 2198 & 2223 & 2222 \\ 2111 & 2198 & 2199 & 2224 & 2223\end{array}$ $\begin{array}{lllll}2111 & 2199 & 2199 & 2225 & 2223 \\ 2113 & 2199 & 2200 & 225 & 2224\end{array}$ $\begin{array}{lllll}2113 & 2201 & 2202 & 2227 & 2226\end{array}$ $\begin{array}{lllll}2114 & 2202 & 2203 & 2228 & 2227\end{array}$ $\begin{array}{lllll}2115 & 2203 & 2204 & 2229 & 2228\end{array}$ $\begin{array}{lllll}2116 & 2204 & 2205 & 2230 & 2229 \\ 2117 & 2205 & 2206 & 2231 & 2230\end{array}$ $\begin{array}{lllll}2117 & 2205 & 2206 & 2231 & 2230\end{array}$ $\begin{array}{lllll}2119 & 2207 & 2207 & 2232 & 2231 \\ 2230 & 2232\end{array}$ $\begin{array}{lllll}2120 & 2208 & 2209 & 2234 & 2233\end{array}$ $2122 \quad 22102211 \quad 2236 \quad 2235$ $\begin{array}{lllll}2123 & 211 & 2212 & 2237 & 2236\end{array}$ $\begin{array}{lllll}2124 & 2212 & 2213 & 2238 & 2237\end{array}$ $\begin{array}{llllll}2126 & 2214 & 2215 & 2240 & 2239\end{array}$ 2127221522162241 2128 2215 $22172242 \quad 224$ $2130 \quad 2218 \quad 2219 \quad 2244 \quad 2243$ $\begin{array}{llllll}2131 & 2219 & 2220 & 2245 & 2244\end{array}$ $\begin{array}{lllll}2132 & 2220 & 2221 & 2246 & 2245\end{array}$ $\begin{array}{lllll}2133 & 2221 & 2222 & 2247 & 2246\end{array}$ $\begin{array}{lllll}2135 & 2223 & 2224 & 2248 & 2247\end{array}$ $\begin{array}{lllll}2136 & 2224 & 2225 & 2250 & 2249\end{array}$ $\begin{array}{lllll}2137 & 2226 & 2227 & 2252 & 2251\end{array}$ $\begin{array}{lllll}2138 & 2227 & 2228 & 2253 & 2252 \\ 2139 & 2228 & 2229 & 2254 & 2253\end{array}$ $\begin{array}{lllll}2140 & 2229 & 2230 & 2255 & 2254\end{array}$ $\begin{array}{lllll}2141 & 2230 & 2231 & 2256 & 2255 \\ 214 & 2231 & 2232 & 2257 & 2250\end{array}$ $\begin{array}{lllll}2142 & 2231 & 2232 & 2257 & 2250 \\ 2143 & 2232 & 2233 & 2258 & 2257\end{array}$ $\begin{array}{llllll}2143 & 2232 & 2233 & 2258 & 2250\end{array}$ $\begin{array}{lllll}2145 & 2236 & 2235 & 2260 & 2259\end{array}$ $\begin{array}{llllll}2146 & 2235 & 2236 & 2261 & 2260 & \text {. } \\ 2147 & 2236 & 2237 & 2262 & 2261\end{array}$ $\begin{array}{lllll}2148 & 2237 & 2238 & 2263 & 2262\end{array}$ $\begin{array}{llllll}2149 & 2238 & 2239 & 2264 & 2263\end{array}$ $\begin{array}{lllll}2150 & 2239 & 2240 & 2265 & 2264 \\ 2151 & 2240 & 2241 & 2266 & 2265\end{array}$ $\begin{array}{lllll}2151 & 2240 & 2241 & 2266 & 2265 \\ 2152 & 2241 & 2242 & 2267 & 2266\end{array}$

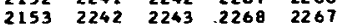
$\begin{array}{lllll}2154 & 2243 & 2244 & 2269 & 2268\end{array}$ $\begin{array}{llllll}2155 & 2244 & 2245 & 2270 & 2269 \\ 215 & 2245 & 2246 & 2270 & 2270\end{array}$ $\begin{array}{llllll}2156 & 2245 & 2246 & 2271 & 2270\end{array}$ $\begin{array}{lllll}2157 & 2246 & 2247 & 2272 & 2271 \\ 2158 & 2247 & 2248 & 2273 & 2272 \\ 2159 & 2248 & 3249 & 2274 & 2273\end{array}$ $\begin{array}{lllll}2159 & 2248 & 2249 & 2274 & 2273 \\ 2160 & 2249 & 2250 & 2275 & 2274\end{array}$

PRES SURE BOUNDARY CONDIIIONS

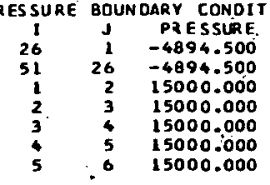

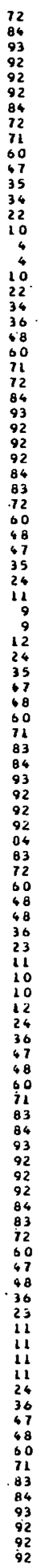

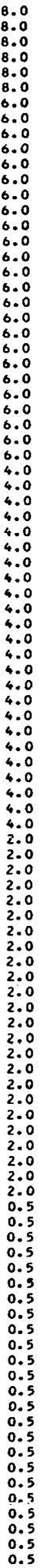

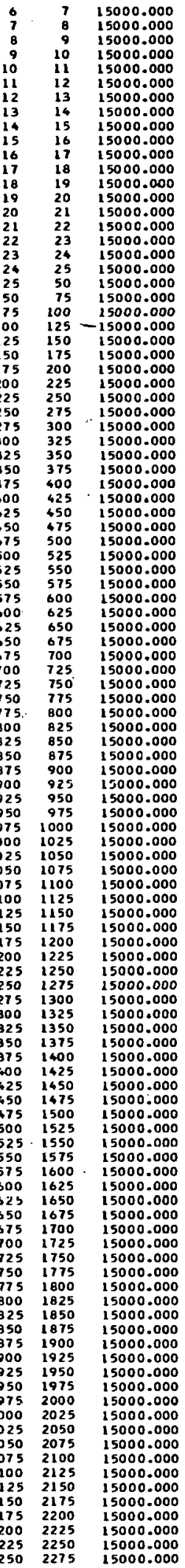




\begin{tabular}{|c|c|c|c|c|c|}
\hline 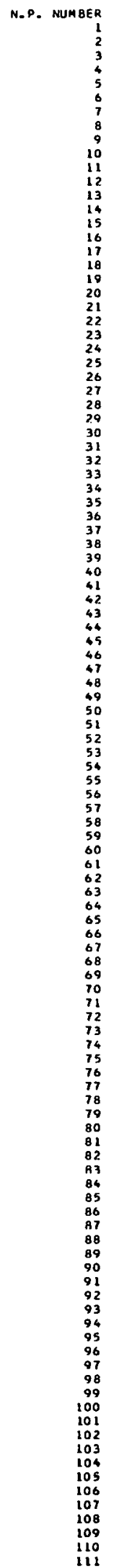 & 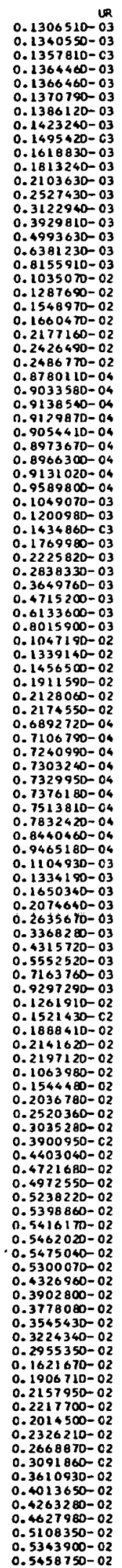 & 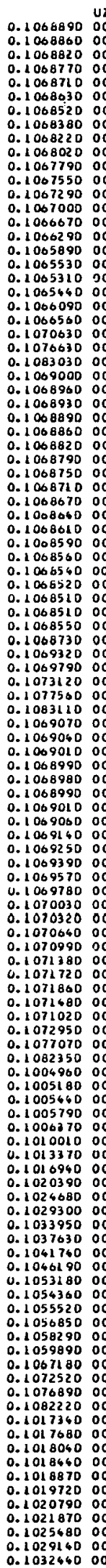 & 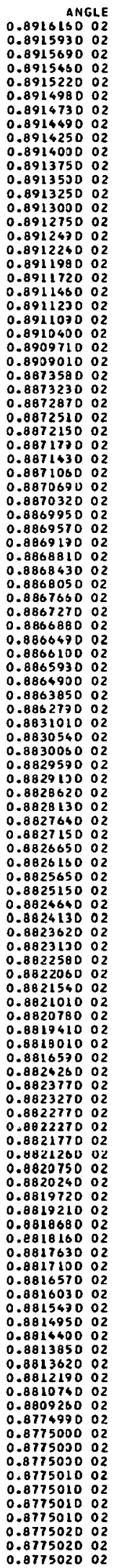 & 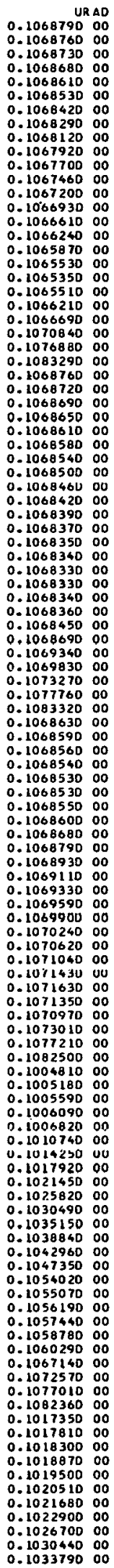 & 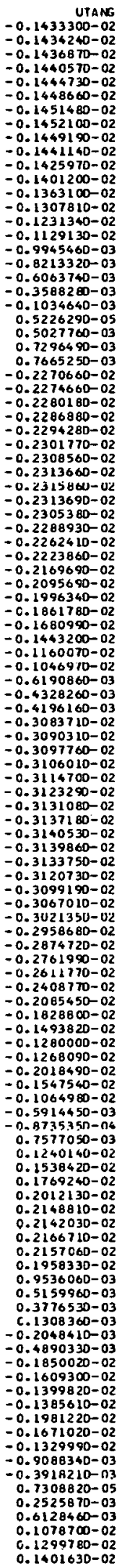 \\
\hline
\end{tabular}




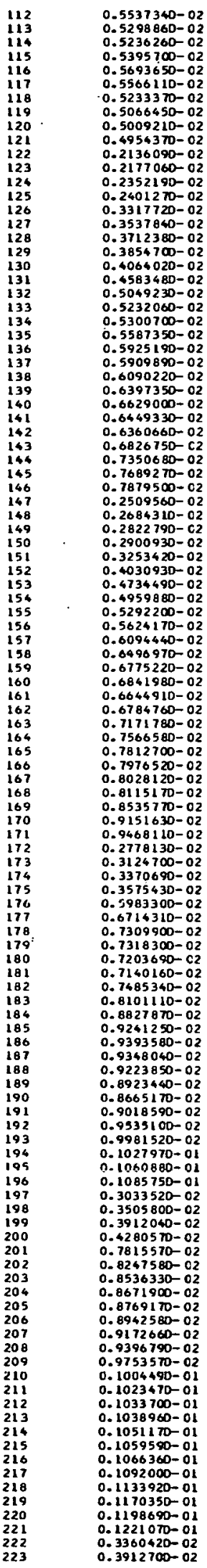

0.103596000 0.106042000 0.104369000 0.104553000 0.1047100
0.1048770
0.100 0.105053000 0.105265000 0.105666000 0.106062000 0.106858000 . 0.108159000 0.102511000 0.102603000 0.102691000 0.102765000 0.102821000 0.102913000 0.103030000 0.103298000 0.103693000 0.106085000 0.104341000 0.104478000 0.104621000 0.1047360
0.10463200
0.100 0.106958000 0.105128000 0.105333000 0.105952000 0.100044000
0.107373000
0.100340 0.107373000 0.103460000 0.103395000 0.103411000 0.103535000 0.103634000 0.103741000 0.103788000 0.103893000 0.104070000 0.1040060 0.104718000 0.104822000 0.104902000 0.104978000 0.105121000 0.105282000 0.105543000 0.105705000 0.100373000 0.1008870
0.1075180
0.100 0.108265000 0.104493000 . 104460000 0.104535000 0.104658000 0.106768000 0.104792000 .1067810
0.1047760
0.100 0.104777000 0.109945000 0.105086000 0.105260000 0.105608000 0.105565000 0.105590000 0.105002000 0.1057010
0.1058940
0.105
0.106150 0.105894000
0.1060330 0.106150000 0.106965000 0.107964000 0.107964000 0.105165000 0.105183000 0.105217000
0.105253000
0.10030 0.10531000 0.105405000 0.105476000 0.105532000 0.105535000 .105551000
0.1056010
0.100 0.105689000 0.105762000 0.105815000 0.106060000 0.106184000 0.106283000 0.106390000 0.106509000 0.106636000 0.107551000
0.2080090

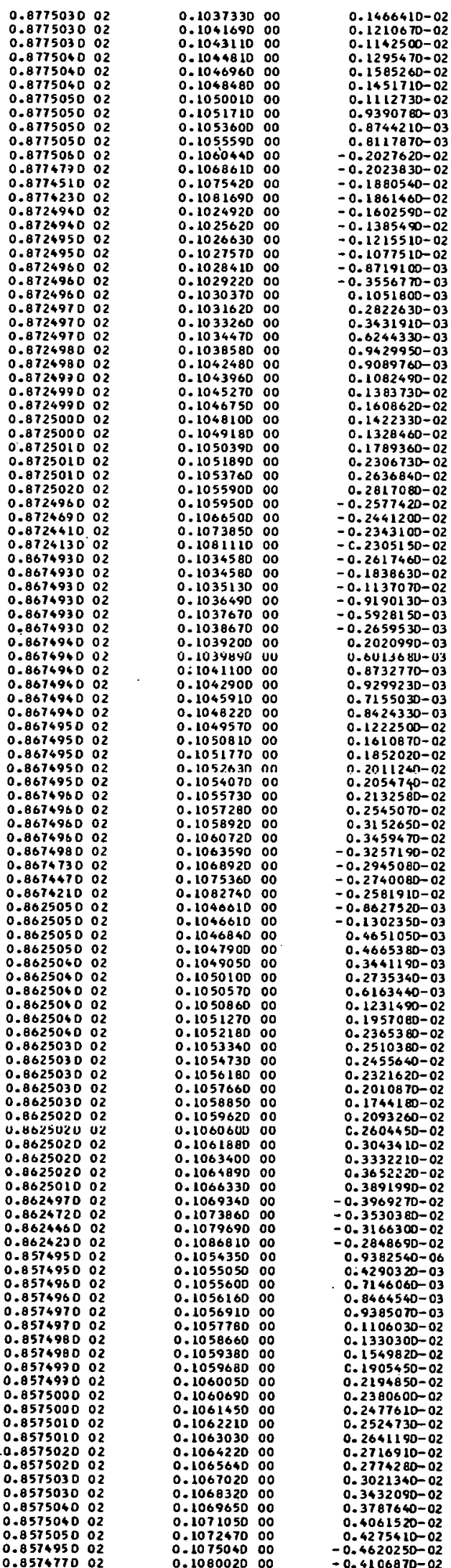




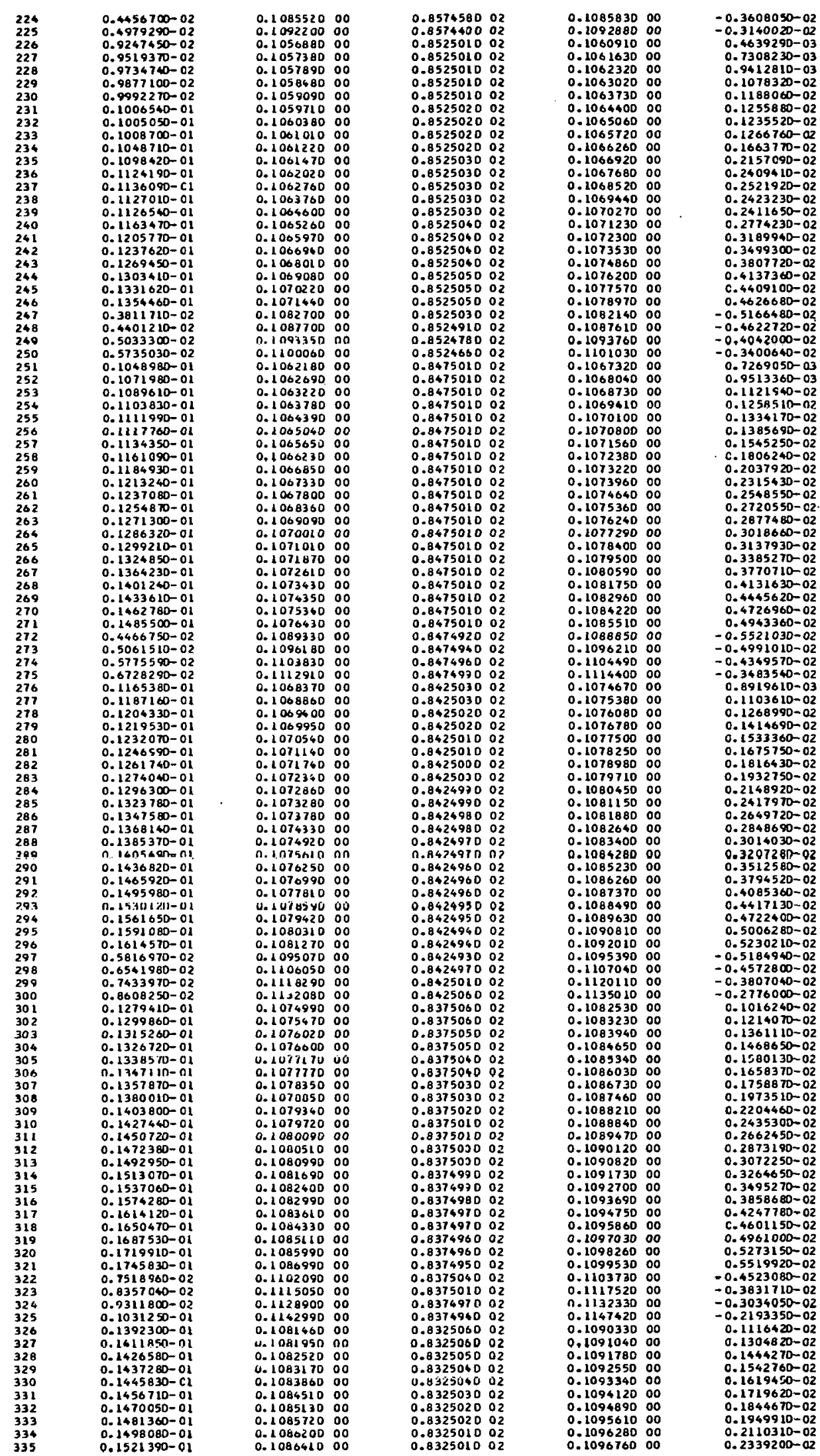




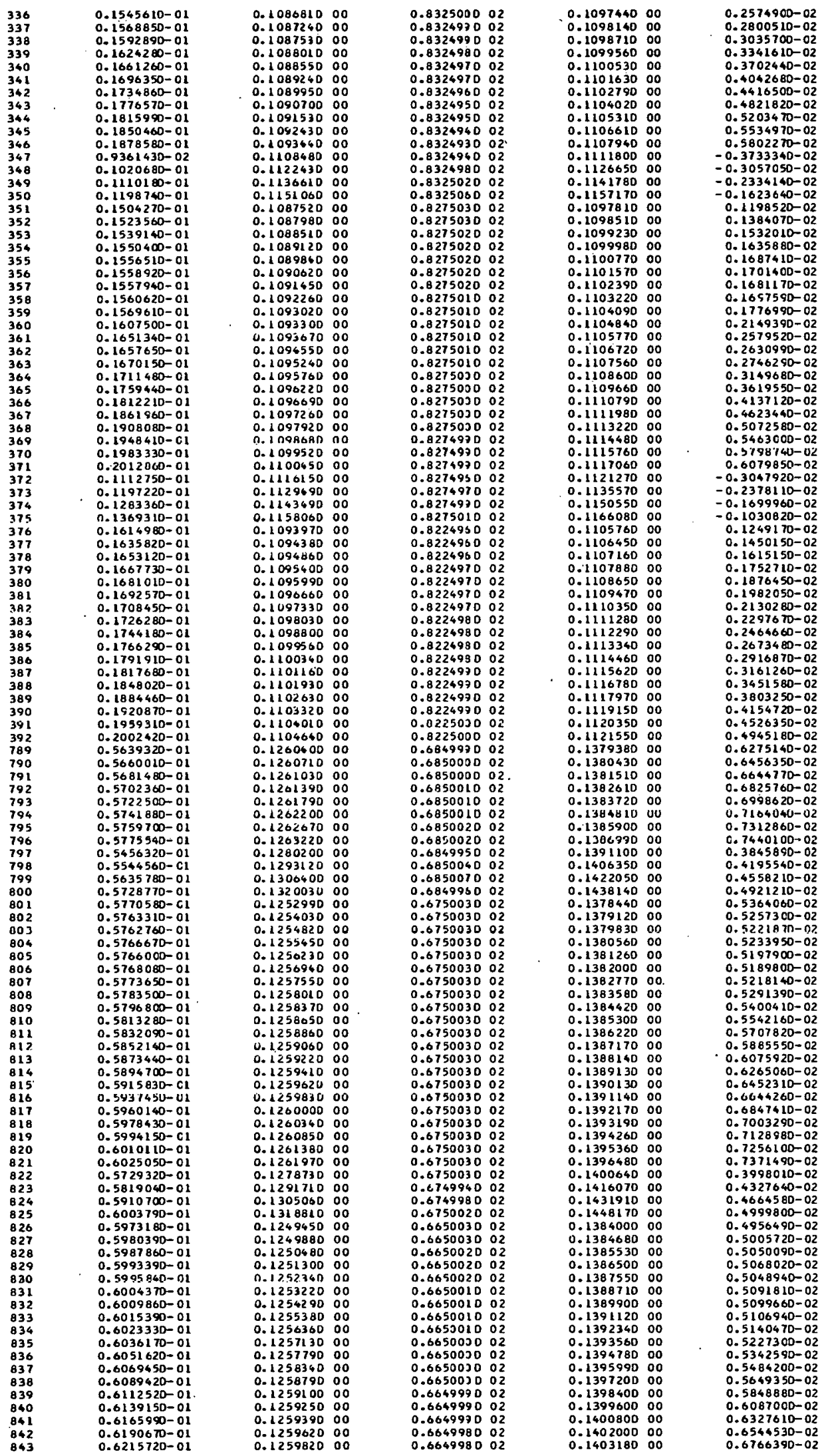




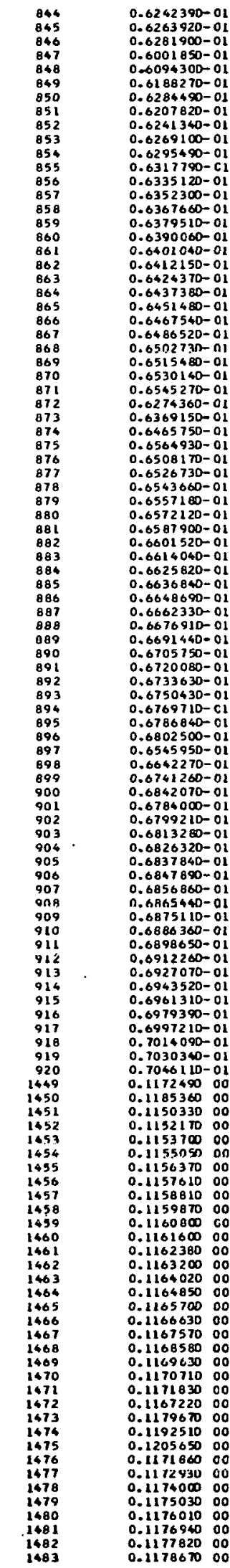

0.125997000 0.126035000 0.127746000 0.129023000 0.130338000 0.131696000 0.125132000 0.1250520
0.1250000
0.00 0.1250080
0.1249780 0.126976000 0.125002000 0.125035000 0.122583000 0.125150000 0.125302000 0.125378000 0.12545200 0.125588000 0.125043000 0.125686000 0.125736000 0.125800000 0.1258000
0.1259170
0.1270 0.127621000 0.130157000 0.131499000 0 0.125039000
0.125042000 0.125059000 0.125065000 0.125089000 0.125117000 0.125152000 0.125195000 0.125241000 0.125320000 $0.125362 n$ no 0.125407000 0.125455000 0.125544000 0.125572000 $0.125 a 15000$ 0.127345000 0.128604000 0.129898000 0.131229000 0.124643000 0.124672000 0.124697000 0.126777000 0.124827000 0.124883000 0.126983000 0.125029000 0.1250700 0.125160000 0.125167000 0.125195000 0.125226000 0.125308000 0.125353000 $0.1014790 \%$ $0.1001120-01$ $0.9590420-01$ $0.9584760-01$ $0.9581450-01$ $0.9579110-01$ $0.9578850-01$ $0.9581510-02$ $0.9586020-01$ $0.9592550-01$ $0.9599660-01$ $0.9606690-01$ $0.9013550-01$ $0.9628000-01$ $0.9634370-01$ $0.9660510-01$ $0.9651200=01$ $0.9656220-01$ $0.9661180-01$ $0.9770480-01$ $0.9971340-01$ $0.9969860-01$
0.100716000 $0.9428730-01$ $0.9420030-01$ $0.9626860-01$ $0.9426210-01$ a. $9426270-01$ $0.9427100-01$ $0.9628650-01$
$0.9432070-01$
0.604998002 0.664997002 0.6649003002 0.66503002 0.664995002 0.665001002 0.655000002 0.655004002 .65503002 0.655003002 0.655002002 0.655001002 $\begin{array}{lll}0.6550000 & 02 \\ 0.6550000 & 02 \\ 0.65\end{array}$ 0.654997002 0.654999002
0.654997002
0.654990 0.654998002 0.6549980
0.6549970
0.62 0.654997002 0.654995002 0.654995002 0.654994002 0.6549960
0.65500002
0.65502 0.655001002 $\begin{array}{lll}0.655001002 & 02 \\ 0.654995002 & 02 & 0\end{array}$ 0.654997002 0.645003002 0.645003002 0.645000002 0.645000002 0.645001002 0.645001002 0.645001002 0.645001002 0.645001002 0.645001002
0.645002002
0.6450020 0.645022002 0.645002002 0.645002002 0.6450020
0.645022
0.642 0.645003002 0.645003002 0.645003002 0.644997002 0.645005002 0.646998002

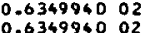
0.634996002 $\begin{array}{llll}0.6349940 & 02 \\ 0.634990 & 02 & \\ 0.634940 & 02\end{array}$ $\begin{array}{lll}0.0349940 & 02 \\ 0.634940 & 02 & \end{array}$ .636995002 $\begin{array}{llll}0.6349950 & 02 \\ 0.6346950 & 02 \\ 0.634950 & 0.634958 & 02\end{array}$ 0.634995002 0.634995002 0.634945002 0.634995002 0.636996002 0.636996002 0.634996002 0.034996002
0.03499000
0.02 $\begin{array}{lll}0.6349960 & 02 \\ 0.6349960 & 02 \\ 0.63402 & 0.02 & 0\end{array}$ $\begin{array}{llll}0.6349960 & 02 \\ 0.4249900 & 02 & \end{array}$ 0.425001002 0.414995002 0.414995002 $\begin{array}{llll}0.4149960 & 02 \\ 0.4149960 & 02\end{array}$ 0.4149970 02 $\begin{array}{llll}0.41499710 & 02 \\ 0.414970 & 02 & \end{array}$ 0.4149910
0.4149980
0.42 0.414999002 0.416997002 0.415000002 0.4150030
0.4150010
0.452 0.415001002 0.415002002 0.415002002 0.415003002 0.615003002 0.415004002 0.4150040
0.4150010
0.42 0.414995002 $\begin{array}{lll}0.4149970 & 02 \\ 0.415040 & 02 \\ 0.404990 & 02\end{array}$ 0.406997002 0.404997002 0.404998002 0.404999002
0.4049980
0.42 0.404993002 0.404999002 0.140559000 0.141081000 0.142623000 0.144203000 0.145833000 0.139608000 . . 0.139921000 0.140120000 0.140227000 0.110337000 0.140450000 0.140564000 0.140680000 0.140916000 0.141034000 0.141151000 0.141380000 0.141494000 0.14173000 0.142140000 0.143675000 0.145251000 0.1408780000 0.140957000 0.141032000 0.141176000 0.141249000 0.141324000 0.141403000 0.141485000 0.141573000 0.161759000 0.14195700 0.142060000 0.142165000 0.162375000

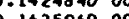
0.142596000 0.143120000 0.144672000 0.146266000 0.167901000 0.161818000 0.141895000 0.141974000 0.142138000 0.142222000 0.142308000 0.142395000 $0.14<480400$ 0.142674000 0.142472000 0.142974000 0.143077000 0.143183000 0.163291000 0.143401000 0.143512000 0.143622000 0.1566710 o0 0.149774000 $0.149843 n$ n 0.149917000 0.150080000 0.150168000 0.150261000 . 0.150501000 0.150666000 0.150773000 0.150882000 0.151103000 0.151214000 0.151326000 0.151551000 0.151665000 0.151781000 0.152201000 0.153762000 0.1570330 0.150344000 0.150420000 0.15049500 0.150569000 0.150643000 0.150719000 0.15087700

$0.7004790-02$ $0.7187110-02$ $03440-02$
$4340-02$ $0.4776920-02$ $0.55118990-02$ . $4598580-02$ $0.4936010-02$ 0.5459790-02 $0.5664210-02$ $0.5810310-02$ $0.5952420-02$ $0.6152290-02$ $0.6216560-02$ 0.628503002 $0.6434770-02$ $0.0523010-02$ $0.6626770-02$ $0.6767800-02$ $0.6903650-02$ $0.7118160-02$ 


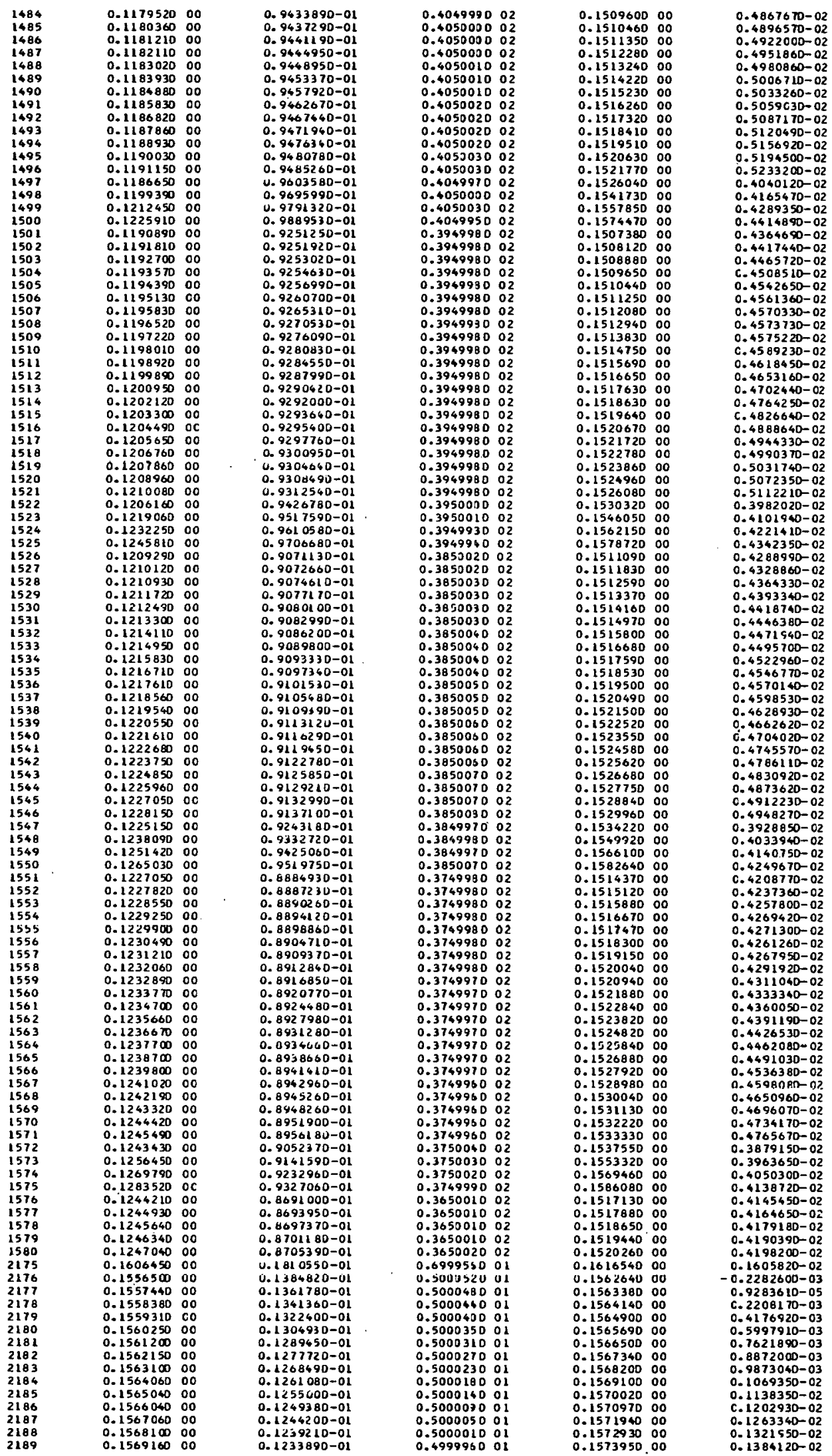




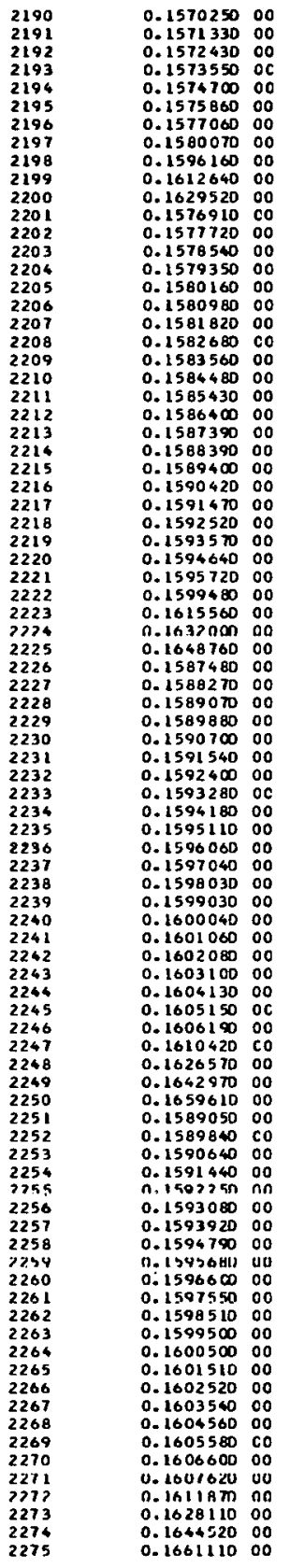
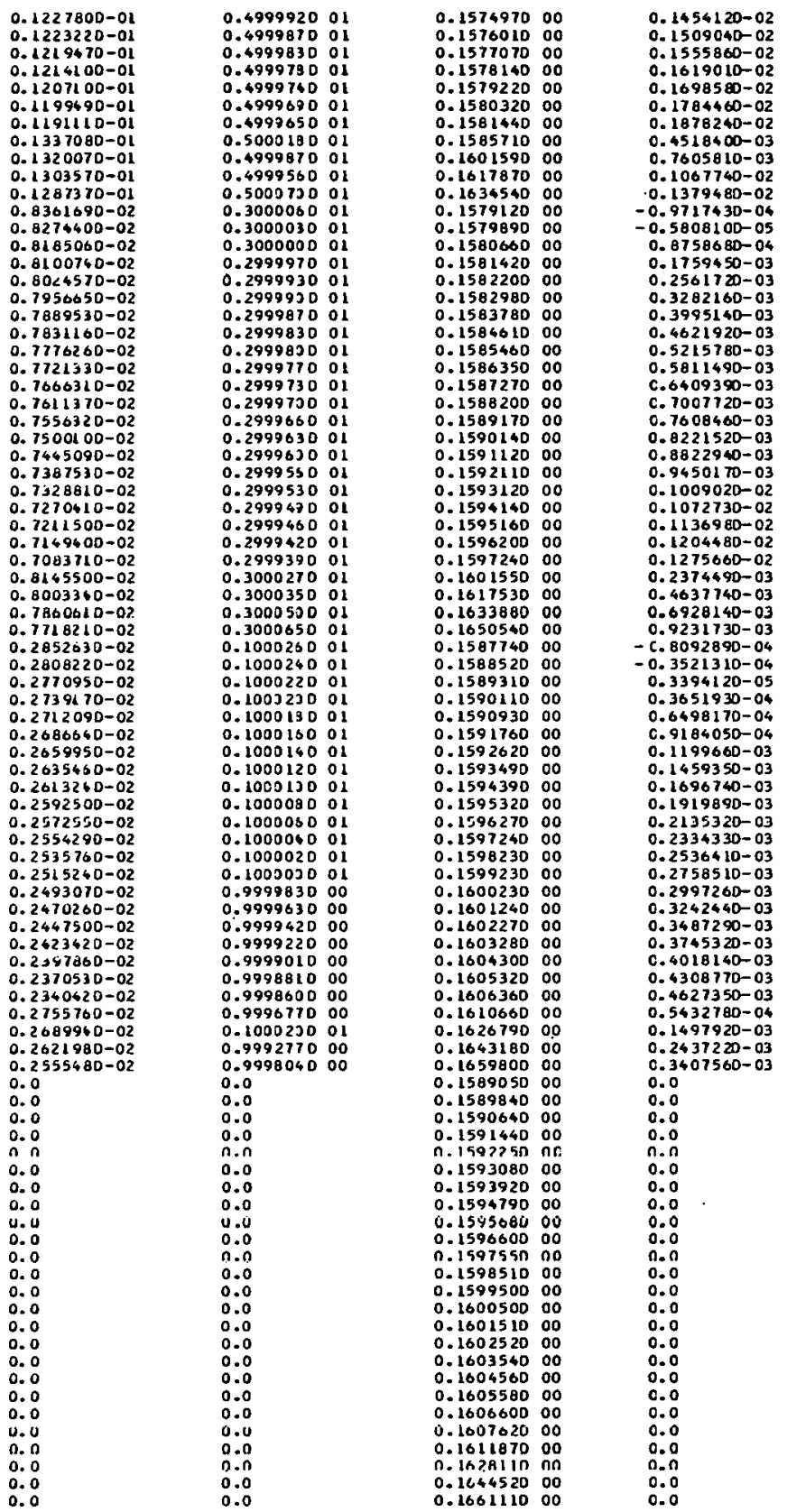

\section{$\square 320 \mathrm{ksi}$ Fiber Stress}

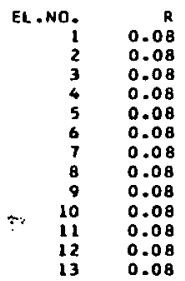

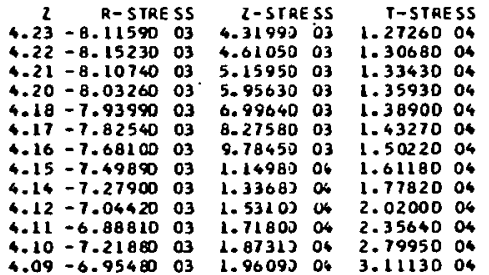

STRESS Rz-STRESS N-STRESS S-STRESS N5-STRESS F-STRESS E-STRESS SHEAR $3.6043002 \quad 4.33003-8.12003-2.52002-1.17004 \quad 1.380-01 \quad 4.57002$

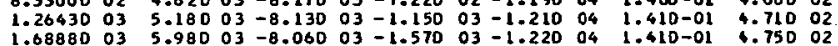

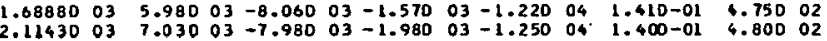

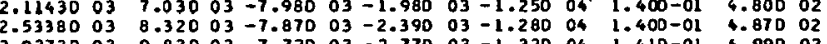

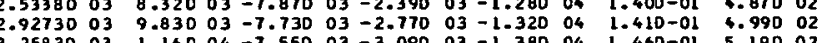

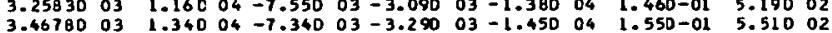
$3.4622003 \quad 1.54004-7.10003-3.27003-1.550041 .720-01 \quad 5.99002$ $3.0876003 \quad 1.72004-6.94003-2.88003-1.67004 \quad 1.990-010.690002$

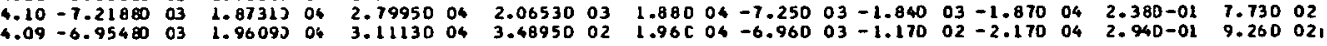




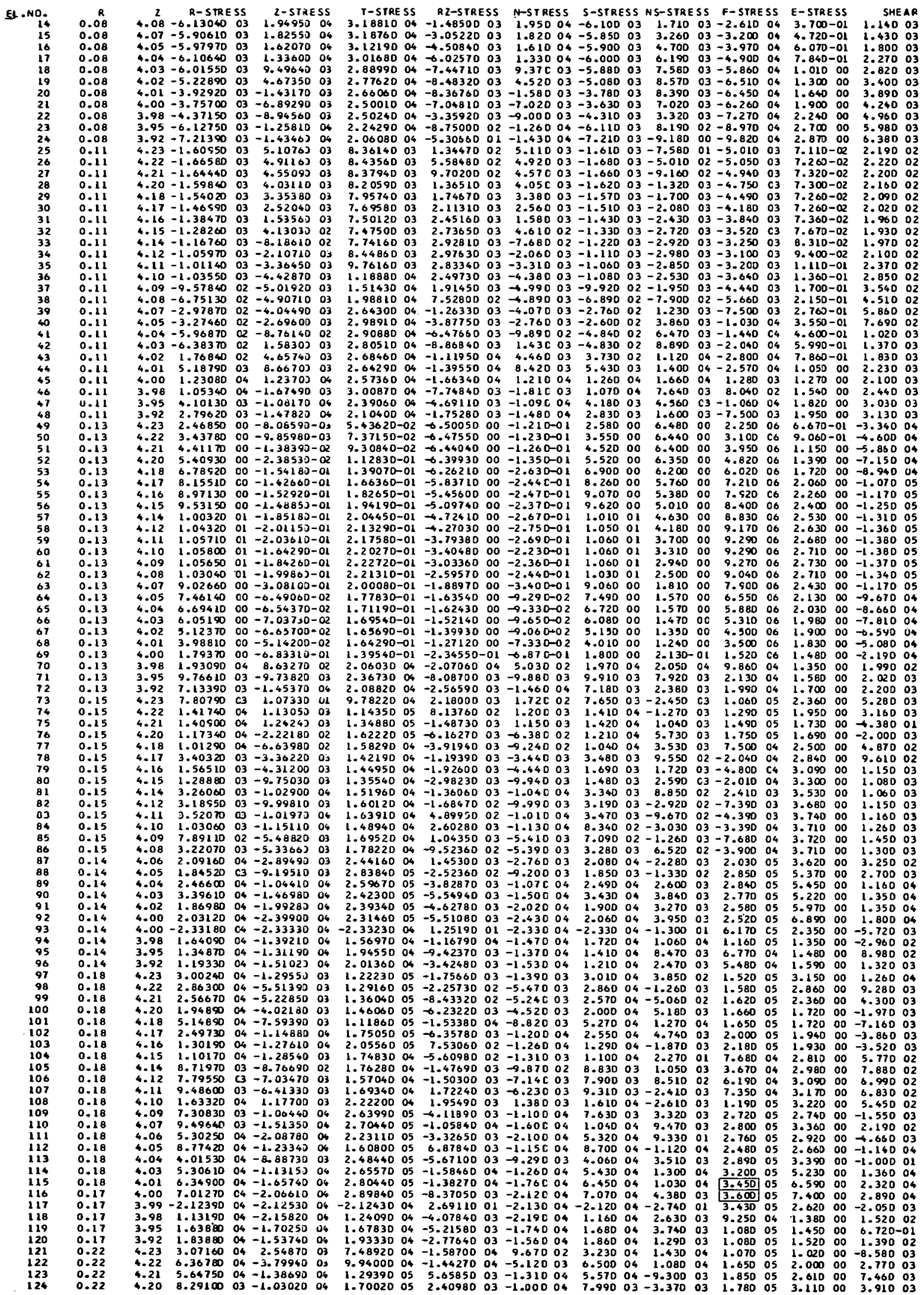




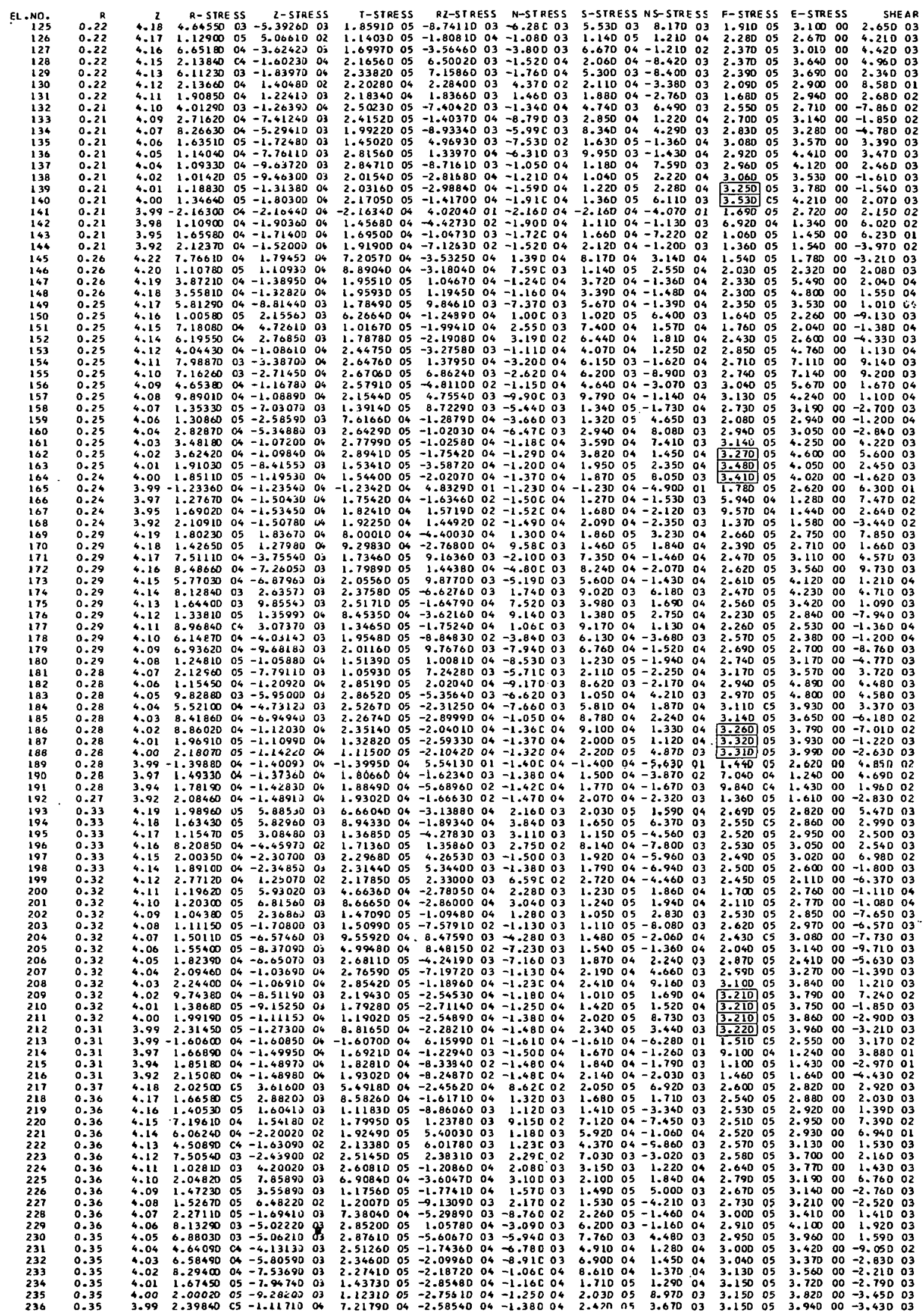




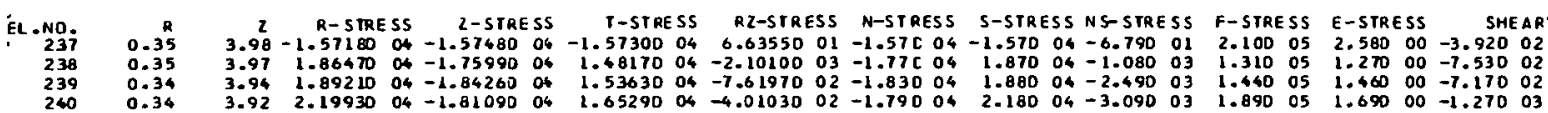

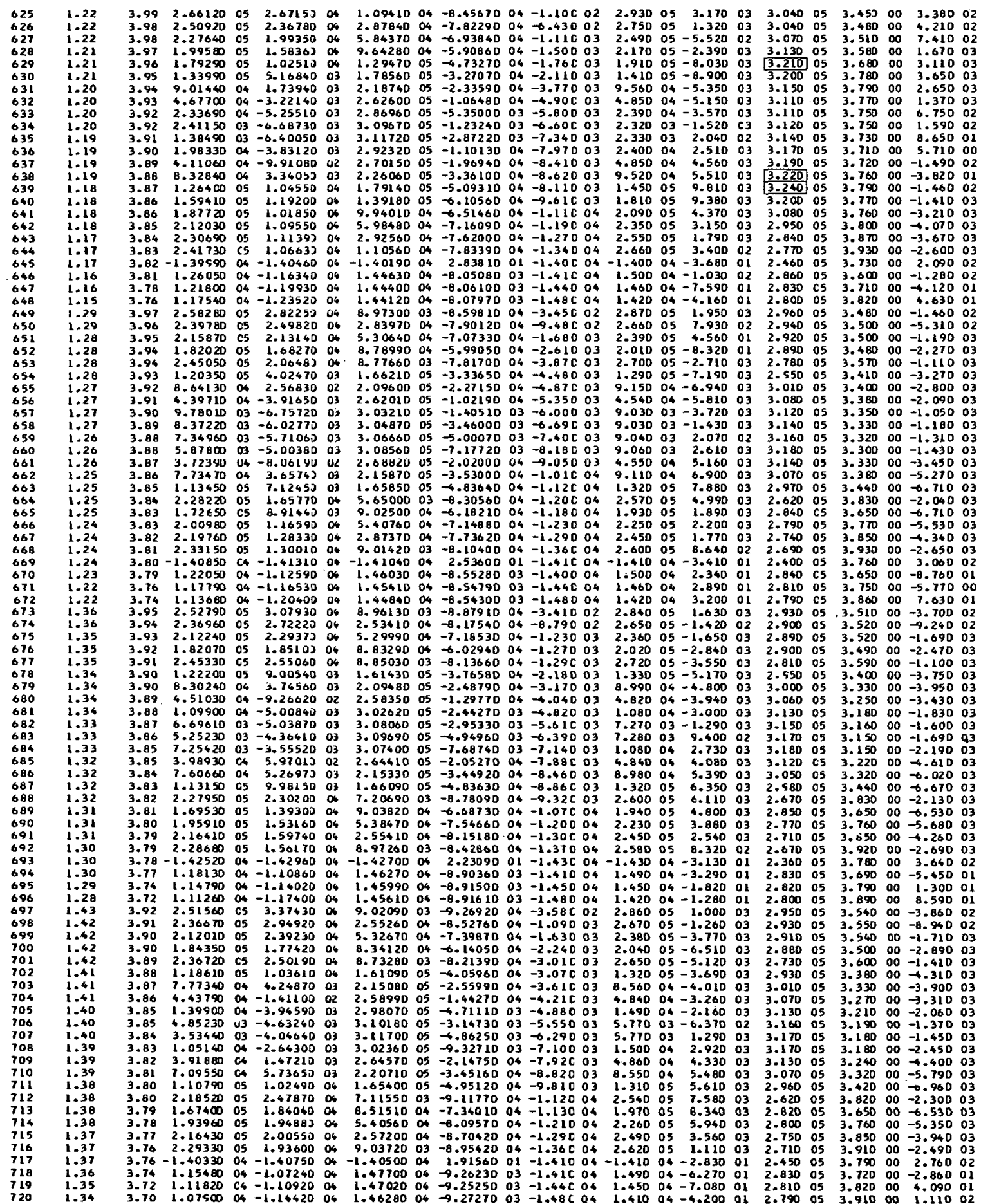

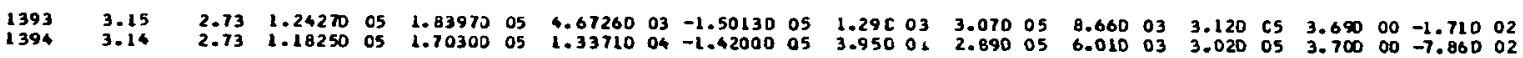




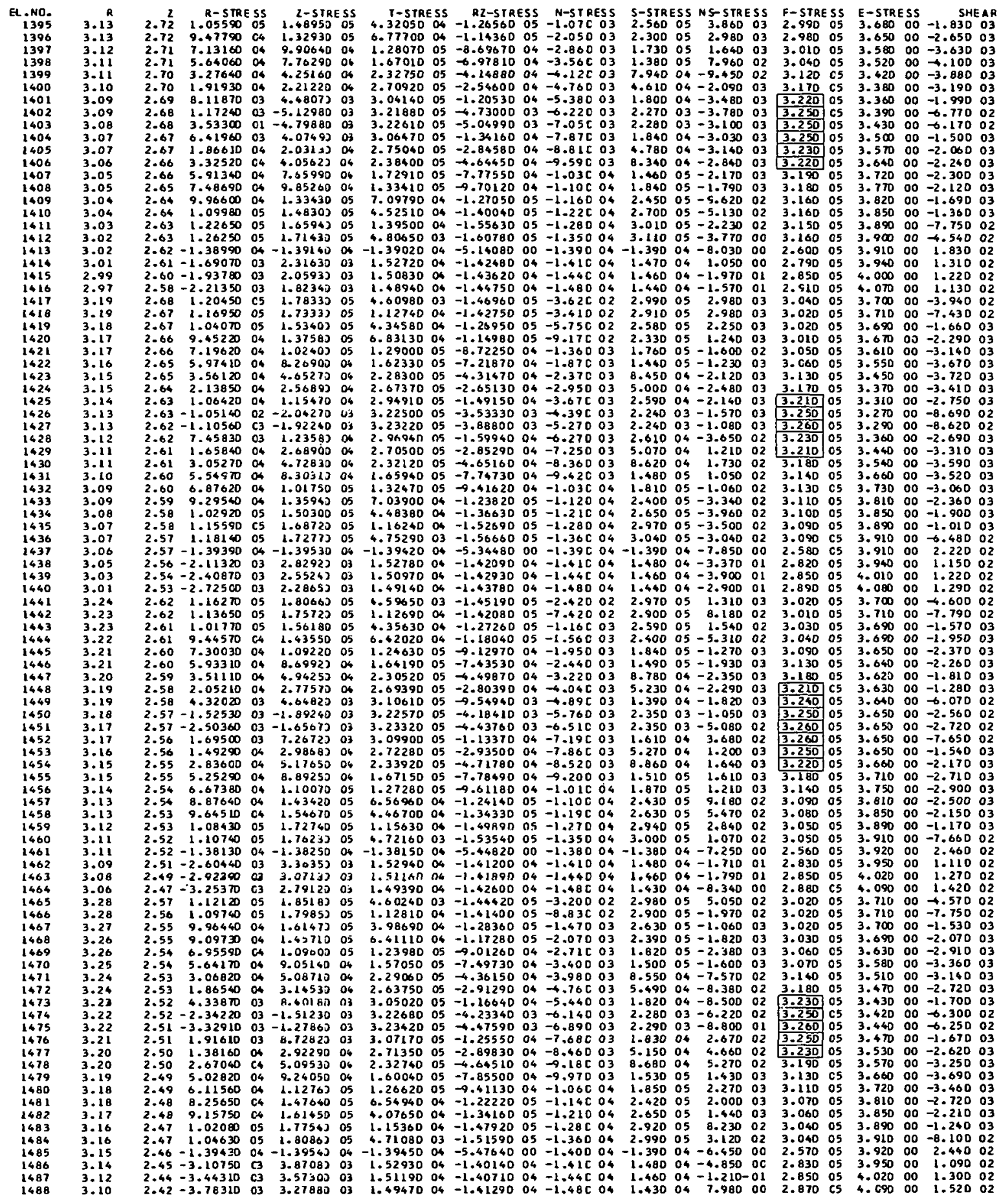

$\begin{array}{ll}1969 & 6.06 \\ 1970 & 4.04 \\ 1971 & 4.03 \\ 1972 & 4.02 \\ 1973 & 4.01 \\ 1974 & 4.01 \\ 1975 & 3.99 \\ 1976 & 3.99 \\ 1977 & 3.99 \\ 1978 & 3.97 \\ 1979 & 3.97 \\ 1980 & 3.96 \\ 1980 & 3.95 \\ 1902 & 3.94 \\ 1982 & 3.94\end{array}$

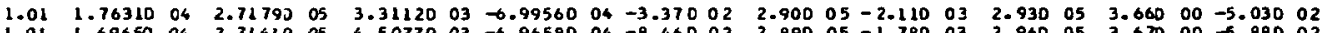

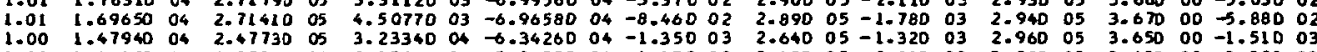

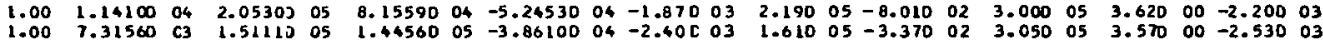

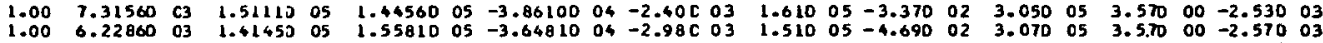

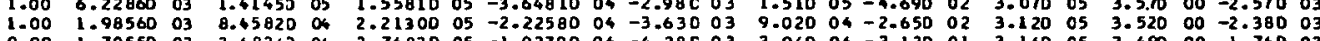

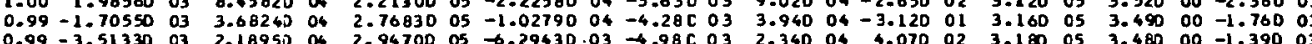

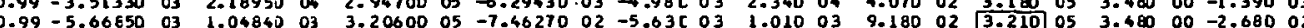

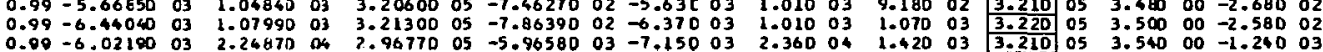

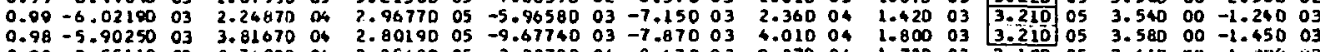

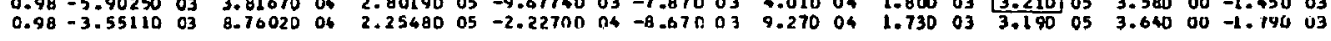




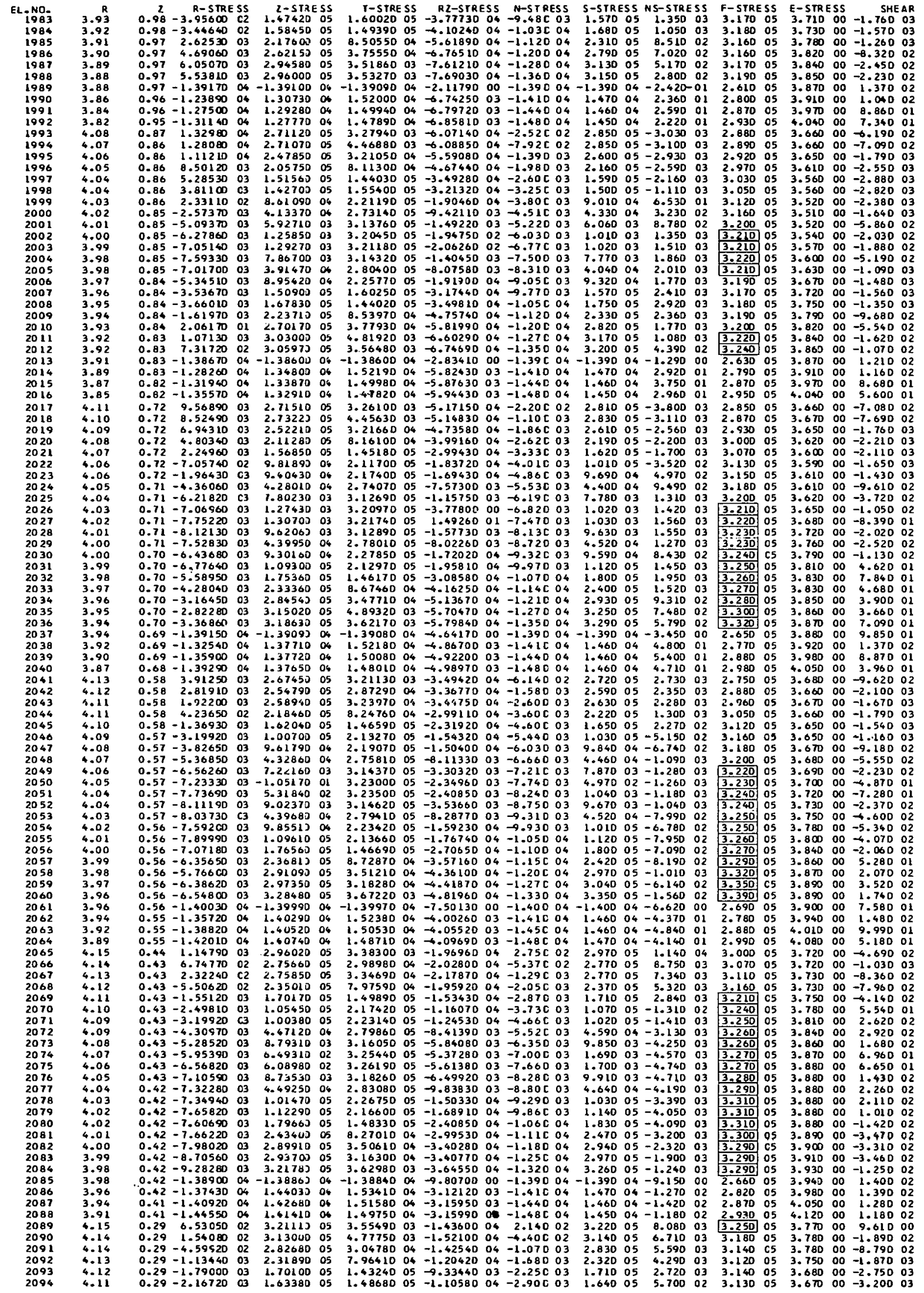




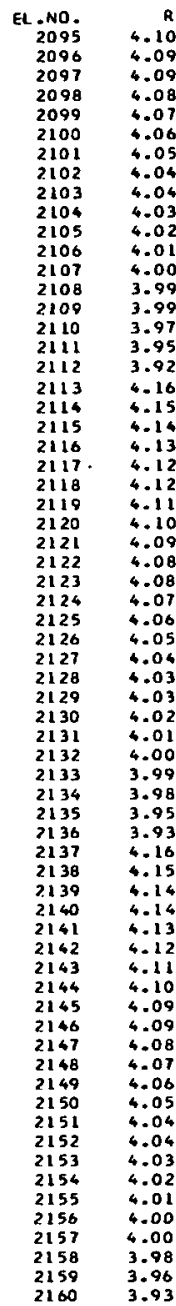

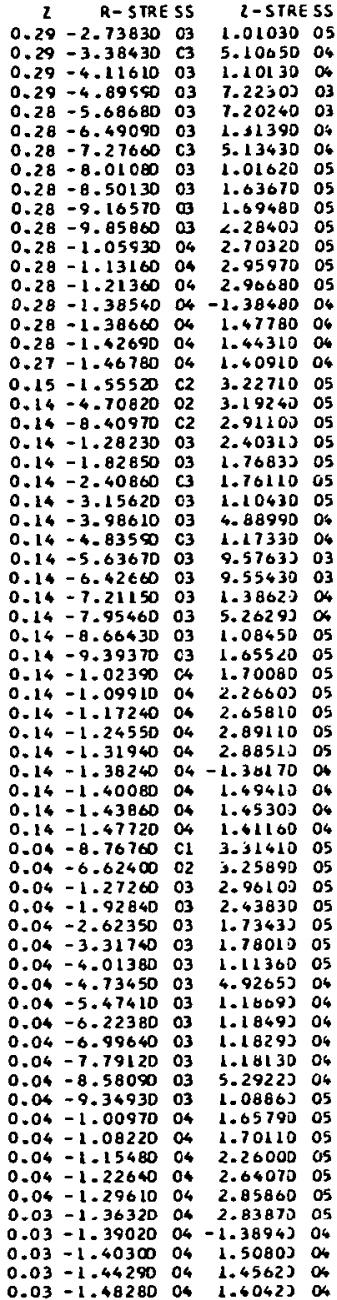

T-STRESS RZ-STRESS N-STRESS S-STRESS NS-STRESS F-STRESS E-STRESS SHEAR 2.16810 of $-8.6217003-3.43003 \quad 1.020$ 05 -1.32003 3.180 $05 \quad 3.590000-3.27003$

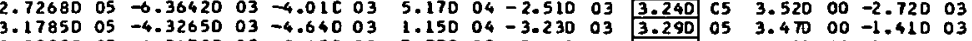

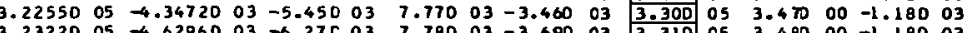

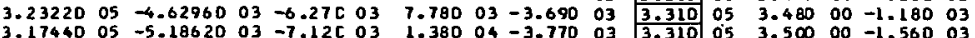

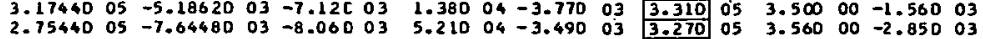

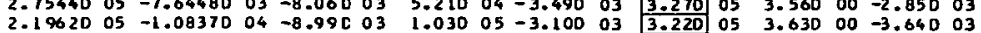

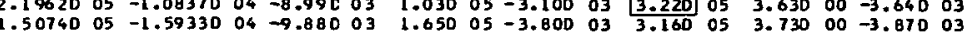

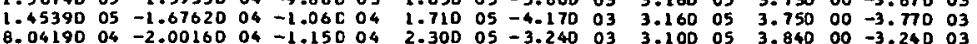

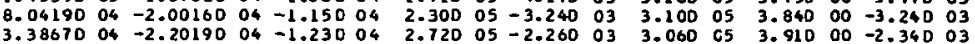

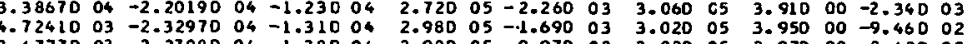

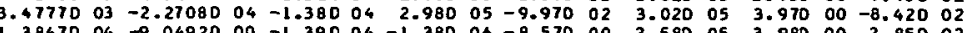

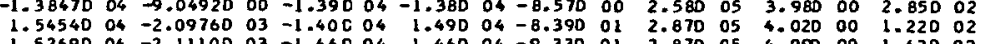

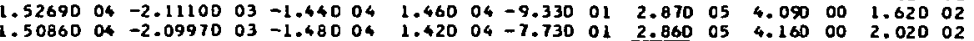
$3.5761003-8.99700 \quad 03-3.90 \mathrm{C} 02 \quad 3.230$ 05 $2.29003 \quad 3.270$ 05 $3.81000-1.74001$

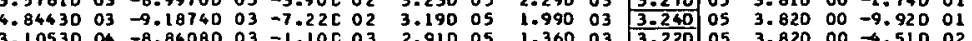

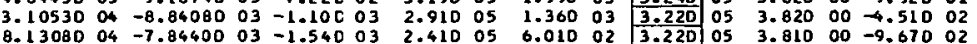

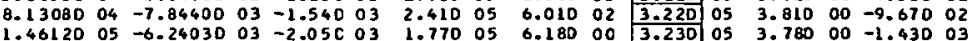

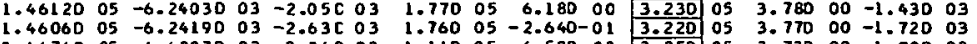

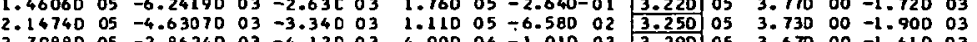

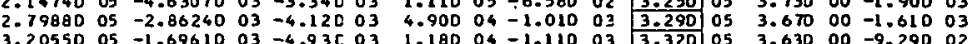

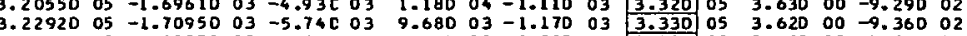

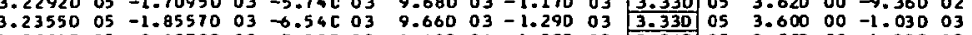

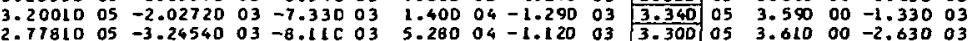

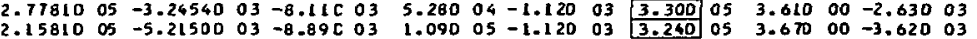

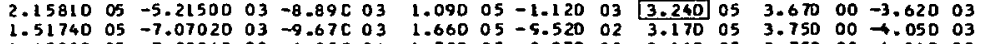

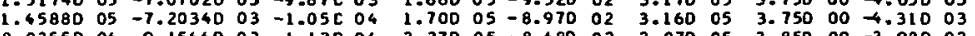
8.02550 o6 $-9.1566003-1.13004 \quad 2.27005-8.48002 \quad 3.07005 \quad 3.85000 \quad-3.98003$

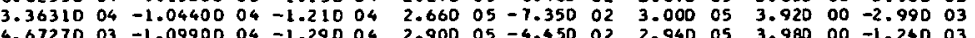

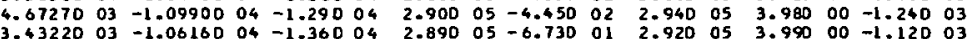

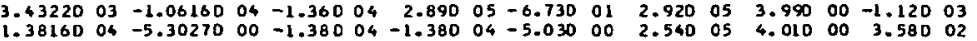

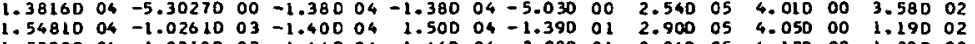

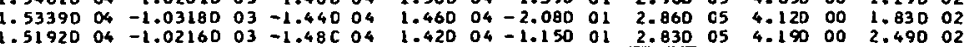

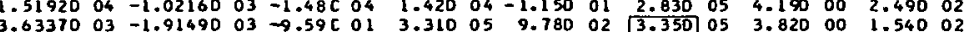

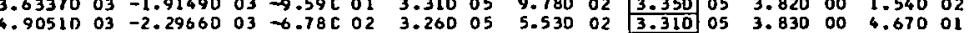

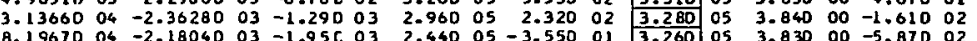

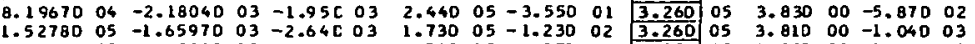
1.46860 05 $-1.6253003-3.33 C_{03} \quad 03 \quad 1.780$ o5 $-4.27001 \quad 3.250$ 05 $3.80000-1.40003$

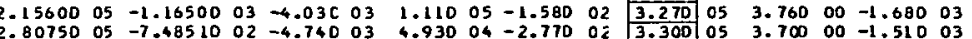

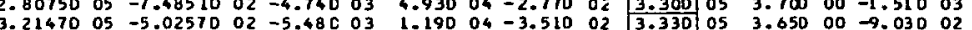

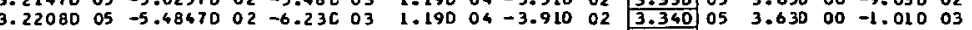

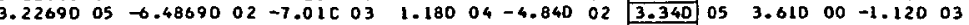

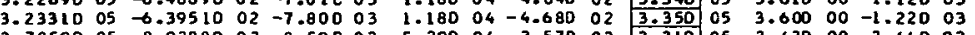

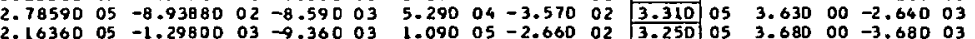

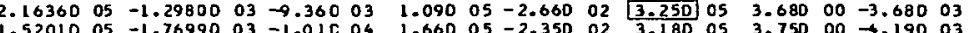

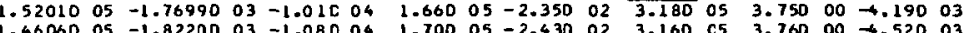

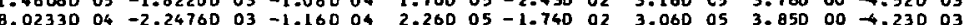
3.35490 04 $-2.50690 \quad 03-1.23004 \quad 2.64005-9.500$ o1 2.980 05 $3.93000-3.24003$

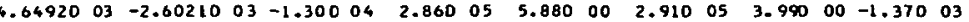

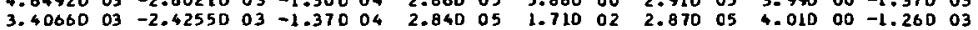
$-1.3894004-1.4894000-1.39 c 04-1.39004-1.42000 \quad 2.540$ c5 $4.02000 \quad 3.67002$

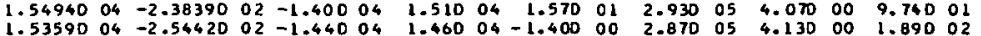

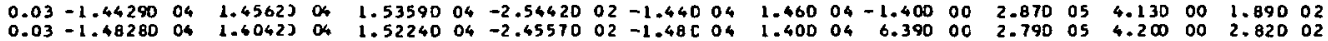




\section{Distribution}

Energy Research and Development Administration - Oak Ridge

Hickman, H. D.

Leed, R. E.

Zachry, D. S., Jr

Lawrence Livermore Laboratory

Chiao, T. T.

Stock, R. P.

Werne, R. G.

Los Alamos Scientific Laboratory

Hockelt, J. E.

Oak Ridge Gaseous Diffusion Plant

Stief, S. S.

Wilcox, W. J., Jr

Oak Ridge Y-12 Plant

Alvey, H. E.

Burditt, R. B.

Burkhart, L. E.

Butturini, W. G.

Dritt, W.S.

Foulk, D. L.

Fraser, R. J.

Gritzner, V. B.

Hensley, C. E.

Huddleston, R. L.

Jones, F. W.

Kahl, K. G.

Keith, A.

Kite, H. T. (7)

Knight, C. E., Jr (20)

Kovach, L.

Lundin, M. I.

Mills, J. M., Jr

Phillips, L. R.

Post, D. W.

Oliphant, G. W.

Perry, A. E.
Smith, H. F., Jr

Smith, R. D.

Stoner, H. H.

Tewes, W. E.

Thompson, W. F.

Tilson, F. V.

Weathersby, W. E.

Whitson, W. K.

Yaggi, W. J./Googin, J. M.

$Y-12$ Central Files (5)

$Y-12$ Central Files (master copy)

$Y-12$ Central Files (route copy)

Y-12 C.entral Files (Y-12RC.)

Zerby, C. D.

Paducah Gaseous Diffusion Plant

Millican, $R$.

Sandia - Albuquerque

Gerstle, F. P.

Schuster, D. M.

In addition, this report is distributed in accordance with the category UC-32, Mathematics and Computers, as given in the USERDA Standard Distribution Lists for Unclassified Scientific and Technical Reports, TID-4500. 